Ann. Biol. anim. Bioch. Biophys., Ig62, 2 (I), 5I-Io8.

\title{
RECHERCHES EXPÉRIMENTALES SUR LA DURÉE DE PASSAGE DES SPERMATOZOÏDES DANS L'ÉPIDIDYME DU TAUREAU
}

\author{
Marie-Claire ORGEBIN-CRIST ( ${ }^{1}$ ) \\ avec la collaboration technique de Liliane Boivineau et Y. de Fontaubert \\ Station de Recherches de Physiologie animale, \\ Centre national de Recherches zootechniques, Jouy-en-Josas (Seine-et-Oise).
}

SOMMAIRE

INTRODUC'TION

CHAPITRE I

REVUE BIBLIOGRAPHIQUE

A. - Morphologie de L'ÉPIDIDyMe.

I. Caractères anatomiques.

2. Caractères histologiques.

3. Caractères histochimiques.

B. - Physiologie de l'épididyme.

I. Action sur les spermatozoïdes :

a) Maturation des spermatozoides;

b) Résorption des spermatozoïdes.

2. Transport des spermatozoïdes dans l'épididyme :

a) Détermination de la vitesse de transit des spermatozoìdes dans l'épididyme par des méthodes indirectes;

b) Détermination de la vitesse de transit des spermatozoïdes dans l'épididyme au moyen du marquage par les radioéléments ;

c) Mécanisme du transport des spermatozolides dans l'épididyme;

d) Variations du temps de transit des spermatozoïdes en fonction de la fréquence des collectes.

CHAPITRE II

MATÉRIEL ET MÉTHODES

A. - Animaux utilisés.

B. - TECHNiQues D'INJECTION.

$-{ }^{32} \mathrm{P}$;

- ${ }^{198} \mathrm{Au}$.

(1) Adresse actuelle : The Population Council, Inc., The Rockefeller Institute, New York 2 r, N. Y. 
C. - Prélèvements des Échantillons a analyser.

I. Appareil génital.

2. Spermatozoïdes :

a) Collecte de sperme ;

b) Spermatozoïdes épididymaires.

1). - Techniques phiysico-chimiques.

I. Lxxtraction des différentes fractions phosphorées des spermatozoïdes :

a) Revue bibliographique;

b) Technique utilisée ;

c) Discussion :

a) Les pertes d'ADN au cours des extractions :

- variations dans la teneur en ADN en fonction du nombre des lavages avec la solution de Krebs-IIENSELEIT-Ringer,

- variations dans la teneur en ADN des spermatozoïdes avec la température ;

ß) La contamination des composés phosphorés radiocatifs les uns par les autres: - contamination par le plasma séminal des phospholipides,

2. Dosage du phosphore.

- contamination de l'ADN.

3. Mesure de la radioactivité.

E. - Techniques histologiques

I. Techniques histologiques classiques.

2. Techniques autoradiographiques.

\section{CHAPITRE III}

\section{DURÉE DU TRANSIT ÉPIDIDYMAIRE}

A. -- INCORPORATION DU ${ }^{32}$ P DANS LES DIFFÉRENTS CONSTITUANTS DU SPERME.

I. Variation de la radioactivité dans le sang.

2. Variation de la radioactivité du sperme :

a) Variation de la radioactivité du plasma séminal ;

b) Variation de la radioactivité des spermatozoïdes:

a) Phospholipides,

ß) Phosphoprotéines,

$\gamma$ ) Acide désoxyribonucléique.

c) Discussion sur l'utilisation du :

๔) Plasma séminal.

ß) Phospholipide,

$\gamma)$ L'acide désoxiribonucléique.

B. - I)ÉtERMINATION EXPÉRIMENTALE DE LA JURÉE DU TRANSIT ÉPIDIDYMaIRE.

CHAPITRE IV

\section{VARIATIONS DANS LA DURÉE, DU TRANSIT ÉPIDIDYMAIRE}

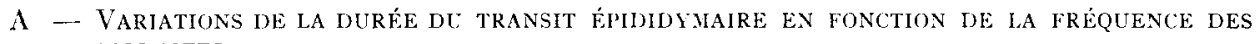
COLLECTES.

I. Recherche des variations dans l'arrivée des spermatozoïdes dans la tête de l'épididyme en fonction de la fréquence des collectes.

2. Recherches des variations dans l'arrivée des spermatozoïdes dans l'éjaculat en fonction de la fréquence des collectes.

3. Recherches sur la variation de la durée de transit des particules radioactives dans un éjaculat.

B. - Variations de l'age moyen des spermatozoïjes dans un éjaculat. 
Discussion.
A. Variations de la durée du transit épididymaire sclon les espèces.
B. Fréquence des collectes et hétérogénéité de l'éjaculat.
C. Résorption des spermatozoïdes.

RÉSLMÉ ET CONCLUSION.

\section{INTHODECTION}

Les spermatozoïdes subissent au cours de la spermatogenèse des modifications morphologiques et physiologiques qui se poursuivent durant leur séjour dans l'épididyme. Ce fait a été bien mis en évidence par BIANDAU et RUMERn (I96r). Ces auteurs inséminent des Rattes adultes avec du sperme provenant soit de la queue soit de la tête de l'épididyme et ils trouvent 97 p. Ioo des œufs fécondés par les spermatozoïdes de la queue de l'épididyme 24 heures après l'insémination, et seulement 7 p. Ioo dans le cas des spermatozoïdes de la tête de l'épididyme. Ceci montre que les spermatozoïdes de la tête de l'épididyme ne sont pas encore mûrs.

L'importance du rôle de l'épididyme sur la maturation des spermatozoïdes a d'ailleurs été soulignée depuis fort longtemps. VAN I)ER STRICHT (I893) se représentait l'épididyme comme un réservoir protégeant les spermatozoïdes jusqu'au moment de leur décharge. La plupart des auteurs, Tournade (IgI3), STIGrer (I9I8), REDENz (I924), VON LANZ (I924), BENOIT (I925), attribuent à la sécrétion épididymaire un rôle actif dans le processus de maturation. Young (I927-I933) pense, au contraire, que la maturation n'est pas liée à une influence extérieure exercée par l'épididyme, mais qu'elle dépend uniquement de l'âge des spermatozoïdes.

De toute façon, quelle que soit l'hypothèse envisagée, le degré de maturité des spermatozoides dépend du temps pendant lequel ils subissent l'action des facteurs intrinsèques ou extrinsèques qui leur permettent de devenir fécondants.

On sait qu'un éjaculat constitue une population hérétogène : on y trouve des spermatozoïdes morts et d'autres qui présentent tous les degrés de motilité. On peut se demander si ces différences ne tiennent pas au fait que certains spermatozoïdes ont séjourné plus ou moins longtemps dans l'épididyme. ORTAVANT (I956) et CLERMONT, LEBLOND, MEISSIER (I959) ont montré que tous les spermatozoïdes primaires, formés en même temps, évoluent de façon synchrone et donnent naissance à des spermatozoïdes qui arrivent, dans le même temps, dans la tête de l'épididyme en ayant pratiquement le même âge. Si l'on admet que les différences entre les propriétés des spermatozoïdes recueillis dans un même éjaculat proviennent d'une différence de maturité, il faut supposer que dans l'épididyme, tous les spermatozoïdes ne progressent pas à la même vitesse.

En profitant des possibilités offertes par le marquage des cellules au moyen des radioéléments, nous nous sommes attachés dans ce travail :

I $^{\circ}$ A déterminer le temps de passage des spermatozoïdes dans l'épididyme.

$2^{\circ} \mathrm{A}$ étudier les variations de ce temps de transit en fonction de la fréquence des collectes. 
CHAPI'TRE: I

\section{REVUE BIBLIOGRAPHIQUE}

\section{A. - Morphologie de lépididỵme \\ I. - CARACTL̀RIS ANATOMIQUES}

L'étude anatomique et histologique de l'épididyme a été effectuées par BExorT (I925) chez de nombreuses espèces. C'est à son travail que nous nous référons pour décrire les principales caractéristiques morphologiques des voies excrétrices. L'épididyme, organe vecteur des spermatozoïdes, est relié au testicule et plus particulièrement aux canaux séminifères, lieu de la formation des spermatozoïdes, par le rete testis. Le rete testis, que l'on nomme également réseau de Haller, est un système de cavités irrégulières largement anastomosées entre elles. Il occupe, chez 1'Homme, la Souris et le Rat, une position superficielle, mais chez le Cobaye, le Chien, le Chat et le 'Taureau, le système lacunaire du réseau de Haller plonge dans le testicule en suivant son grand axe jusqu'au $2 / 3$ et même aux $3 / 4$ de l'organe (che $\%$ le 'Taureau) (fig. I).

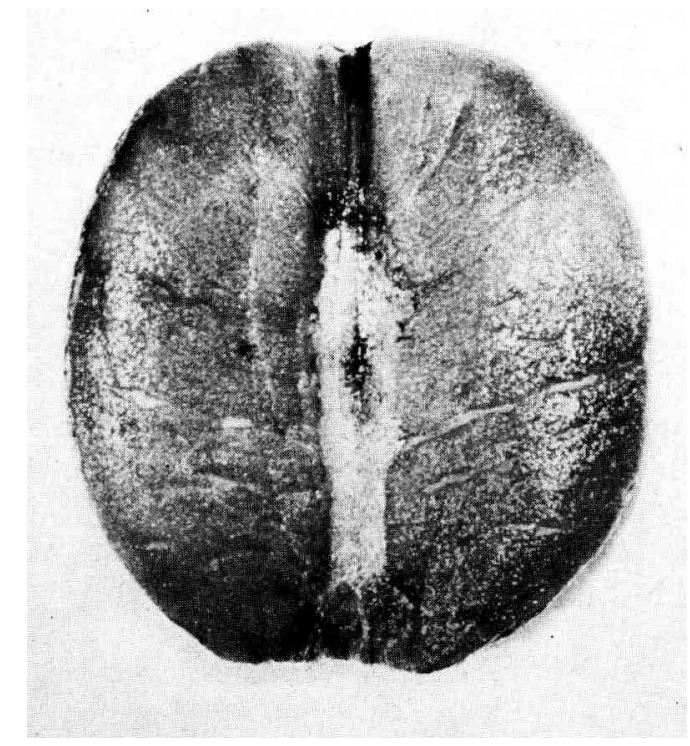

Hig. 1. --. Coupe transzersale din lesticule de Tiarean montrant le rete testis 
La jonction entre le rete testis et les tubes séminifères s'effectue par l'intermédiaire des canaux droits et la jonction avec le canal épididymaire proprement dit se fait par les canaux efférents. Chez la Souris et le Rat, les canaux efférents constituent un tractus allongé qui s'étend du rete testis à la tête de l'épididyme. Ils se réunissent en un canal efférent unique qui se prolonge dans le canal épididymaire. Chez le Chien, le Chat et le Taureau, les canaux efférents forment la majeure partie de la fraction proximale de l'épididyme. Ils se jettent successivement dans le canal épididymaire.

L'épididyme peut être globalement divisé en trois parties : la tête, qui adhère intimement au testicule à son pôle supérieur, la queue, fixée au pôle inférieur et, joignant les deux parties précédentes, le corps.

L'épididyme est constitué entièrement par les circonvolutions d'un canal unique extrêmement long. Chez le Taureau il atteint 33 à 35 mètres selon MarTin et SHAUDER (I938) et 40 à 50 mètres selon HARCENCO (I939). Des cloisons conjonctives séparent ces circonvolutions en une série de lobules.

Le canal déférent se termine par une dilatation, l'ampoule déférentielle avant de se jeter dans le conduit urogénital, 1'urètre.

\section{II. - CARACTìRES hISTOIOGIQULS}

De nombreux auteurs ont étudié la structure histologique de l'épididyme, Hentry (IgOO) et Aigrer (I900) sut le Rat, Bexoit (I925), chez différents animaux de laboratoire et aussi chez le Chat, le Chien, le Cheval et le Taureau, Rrid et ChiLAND (I957), REID (I959) chez le Rat, NICANDER (I957-r95') chez le Lapin, l'Étalon, le Bélier et le Taureau.

1)'après ces auteurs la paroi du canal épididymaire est constituée de 3 couches cellulaires. Én allant de la périphérie vers la lumière dı canal on rencontre successivement :

- une couche de fibres musculaires lisses circulaires;

- une couche discontinue de cellules basales;

- et enfin une couche continue de hautes cellules cylindriques.

Cette structure de base se retrouve tout au long de l'épididyme mais la couche musculaire très mince dans la tête de l'épididyme, s'épaissit considérablement au niveau de la queue. Eille se double, au niveau du canal déférent, d'une couche externe beaucoup plus mince de fibres musculaires longitudinales (BENOIT I925). Les cellules cylindriques limitant la lumière du canal présentent de grandes variations histologiques selon le niveau du canal oì elles se trouvent. Dans les canaux efférents l'épithélium comprend deux types cellulaires : des cellules ciliées et des cellules glandulaires. Dans le canal épididymaire toutes les cellules épithéliales ont une fonction glandulaire et elles sont toutes munies de poils immobiles, les stéréocils. REID et Cleband (I957) chez le Rat, Nicander (I958) chez l'Étalon, le Bélier et le T'aureau ont pu définir des zones histologiques distinctes dans l'épididyme en se basant sur la hauteur des cellules épithéliales, leur coloration, le nombre, la taille et la distribution des vacuoles intracellulaires, la densité et la nature des inclusions cytoplasmiques, la forme des noyaux. 


\section{III. -- CARACTÈRES HISTOCHIMIQUES}

Les études histochimiques montrent également la grande diversité des segments de l'épididyme. Depuis que LEBLOND (1950) a étudié la distribution du matériel PAS positif dans l'épididyme du Rat, de nombreux auteurs ont repris ce problème chez différentes espèces. MANEELY en a fait la revue en I959.

Les cellules épithéliales de la partie proximale de la tête de l'épididyme ne montrent qu'une activité PAS très faible dans le cytoplasme; seuls les stéréocils sont fortement positifs. Dans la partie moyenne de la tête et surtout dans la partie distale, on observe une augmentation des granules intracytoplasmiques PAS positifs. Dans la queue de l'épididyme seule la partie distale présente une forte réaction au PAS.

Les enzymes présents dans l'épithélium épididymaire ont également une répartition extrêmement définie chez la Souris, selon ALLEN et SLATER (I957-I96I). Dans les cellules épithéliales de la tête de l'épididyme sont localisées les phosphatases acides et alcalines. D'autres enzymes présentent un gradient d'activité croissant de la tête à la queue de l'épididyme (les aliestérases, la diphosphoripydine-nucléotide-diaphorase). FindLAy et LEVVY ( 1960 ) ont également montré que la $\mathrm{N}$-acétylglucosaminidase est présente principalement dans la tête de l'épididyme chez le Porc.

$\mathrm{I}_{1}$ a localisation des enzymes ne se fait pas simplement selon l'emplacement le long du canal épididymaire mais aussi selon le type cellulaire : ainsi la phosphatase acide est présente surtout au niveau de l'appareil de Golgi dans les cellules ciliées de l'épithélium de la tête de l'épididyme. Cet enzyme, nous l'avons vu, est totalement absent dans le corps et la queue de l'épididyme; par contre, la thiamine pyrophosphatase, qui est également un constituant du matériel de Golgi, se trouve dans tout le canal épididymaire.

Cette diversité histologique et cytochimique des différentes parties du canal épididymaire laisse supposer qu'à chaque niveau de l'épididyme doit correspondre un rôle physiologique bien déterminé.

\section{H. - Physiologie de l'épididỵme}

\section{I. - ACtTION SUR LES SPERMA'TOzoİDES}

a) Maturation et survie des spermatozoïdes.

Comme nous l'avons vu dans l'introduction, il est classique d'admettre 1'importance du rôle joué par les voies excrétrices du testicule sur la maturation des spermatozoïdes; VON EBNER (I888) et SCHAFFER (I892) en avaient émis 1'hypothèse. Mais VAN I)ER STRICH'T (I893) fut le premier à mettre en évidence cytologiquement des phénomènes de sécrétion dans l'épithélium épididymaire chez le Lézard. MYERsWARD (I897) pense que cette sécrétion sert à la nutrition des spermatozoïdes. De nombreuses études effectuées depuis (HAMmar, I897 HENRY, I900 ; REGAUD, I90I ; REDENZ, I924 ; BENOIT, I925 ; NEMILOFF, I926 ; WAGENSEIL, I928) attribuent toutes aux sécrétions épididymaires un rôle nutritif pour les spermatozoïdes durant leur passage dans l'épididyme. 
TOURNADE (I9I3) met en évidence l'existence d'un gradient croissant de motilité des spermatozoïdes tout au long de l'épididyme et conclut que l'épithélium épididymaire agit directement sur les spermatozoïdes.

STIGLER (IgI8) montre que, chez le Cobaye, le Rat et la Souris, les spermatozoïdes acquièrent au cours de leur passage dans l'épididyme, une certaine résistance aux agents nocifs. En effet les spermatozoïdes de la partie distale de l'épididyme conservent mieux leur motilité aux hautes températures que ceux de la partie proximale ou testiculaire.

Courrier (I920), étudiant le cycle sexuel des Chauves-Souris, observe que pendant le repos hibernal, les spermatozoïdes stockés dans la queue de l'épididyme peuvent $\mathrm{y}$ rester vivants plusieurs mois, nourris par la sécrétion épididymaire.

BENOIT (I925) démontre expérimentalement l'importance du rôle nourricier de l'épididyme vis-à-vis des spermatozoïdes. Dans les épididymes de Souris laissés en place après castration bilatérale, les spermatozoïdes meurent très rapidement; mais, après castration unilatérale, leur motilité est normale, du côté opéré, 2 mois après l'intervention. Pour cet auteur, la fonction protectrice de l'épididyme est conditionnée et entretenue par l'hormone testiculaire. MoORE (I927) réussit à remplacer cette hormone testiculaire par une injection d'extrait lipoïdique de testicule de Taureau.

Par ailleurs, Hammond et Aspeil (I926) montrent que chez le Lapin, les spermatozoïdes peuvent garder leur pouvoir fécondant et leur motilité dans l'épididyme ligaturé durant 30 à 60 jours. Chez le Taureau, Kirillov et Morozov (I937) obtiennent après ligature des canaux efférents des spermatozoïdes motiles, 2 mois après l'opération. Il semble donc que les sécrétions du fluide épididymaire et des glandes annexes exercent une influence favorable sur le processus de maturation des spermatozoïdes.

Cependant Young (I930) arrive à des conclusions très différentes. Chez le Cobaye, par ligature, il sépare les extrémités proximales et distales de la queue de l'épididyme. Ayant abattı, après 25 jours, ces animaux, il insémine des femelles avec des spermatozoïdes provenant de ces deux parties de la queue de l'épididyme. Il obtient, avec les spermatozoïdes de la partie proximale, 49 p. Ioo de gestation, et avec les spermatozoïdes de la partie distale, 25 p. roo de gestation. Les inséminations effectuées avec les spermatozoïdes provenant des fractions comparables d'épididyme non ligaturé de mâles normaux donnent respectivement $33 \mathrm{p}$. Ioo et $68 \mathrm{p}$. Ioo de gestation ; il en déduit que la maturation commence naturellement dans le testicule et se poursuit dans l'épididyme, mais ne dépend pas de la qualité des sécrétions de l'un ou l'autre de ces organes. A l'appui de sa théorie, il observe que, dans les tubes séminifères de certains animaux, des spermatozoïdes deviennent mobiles 25 jours après la ligature de la tête de l'épididyme alors qu'ils sont normalement immobiles. Il en conclut que les facteurs de maturation sont intrinsèques aux spermatozoïdes eux-mêmes, et qu'ils dépendent simplement de la présence ou de l'absence d'un complexe hormonal testiculaire.

\section{b) Résorption des spermatozoïdes}

Simeone et Young (I93I) ont discuté les différentes possibilités d'élimination des spermatozoïdes du canal épididymaire, quand les animaux sont au repos sexuel. Ils envisagent l'élimination par l'urine, le passage à travers la paroi de l'épididyme, 
la liquéfaction et la résorption dans l'épididyme. Finalement, sur la base d'observations histologiques faites chez le Cobaye où ils trouvent dans le canal déférent des masses de spermatozoïdes en dégénérescence, ces auteurs pensent que l'élimination des spermatozoïdes non utilisés se fait par dégénérescence et liquéfaction dans le canal déférent. OrTavast a également observé chez des Béliers et des Taureaux normaux des figures de dégénérescence des spermatozoïdes principalement au niveau des ampoules déférentielles.

I'après CI.UBB (I95r), il est possible, si les animaux sont au repos sexuel, que les spermatozoïdes s'accumulent dans la partie distale du canal épididymaire, y créant une pression interne. Quand cette pression dépasse un certain niveau elle déclencherait des contractions péristaltiques évacuant les spermatozoïdes.

Il n'est cependant pas exclu qu'il se produise une résorption des spermatozoïdes dans l'épididyme lui-même.

Én effet KYRLE et SHOpper (I9I5) ont signalé les premiers, que l'épithélium des canaux efférents en plus de sa fonction sécrétoire pouvait contribuer à l'élimination de la lumière du canal des cellules provenant des tubes séminifères. I'autres auteurs ont montré d'ailleurs une résorption des spermatozoïdes par l'épithélium épididymaire. Chez la Taupe, Mrctkie:wski (I948) situe cette résorption dans les segments médians et terminaux du canal épididymaire. WEGELIN (I92I) et MorGENSTERN (I924) ont cru voir chez l'Homme une élimination des spermatozoïdes nécrosés par des spermiophages géants dont l'origine pour MORGENSTERN est située dans l'épithélium épididymaire, mais les observations de ces deux derniers auteurs portent sur des cas pathologiques.

Von Wagenen (I924), Young (I933) ont signalé que la ligature des canaux efférents chez lex petits Rongeurs détermine à l'intérieur du testicule dans les I2 à 24 heures suivant l'opération, une augmentation du volume du fluide sécrété. Il en résulte, d'après ces auteurs, un accroissement de la pression testiculaire entraînant une atrophie des cellules germinales; si la ligature est plus distale, l'atrophie est moins rapide. Ces expériences montrent que les sécrétions testiculaires sont normalement résorbées au cours de leur passage dans les canaux efférents et la partie proximale de la tête de l'épididyme.

La résorption des particules de colorant par cette région de l'épididyme a été bien montrée, que celles-ci soient administrées par voie sous-cutanée (Von MoldeNDORF, I920 ; VON LANZ, I926 ; NASSONOV, I927 ; WAGENSEIL, I928) ou qu'elles soient injectées directement dans le rete testis (Too'thill et Young, I93I ; Clubb, I95I ; Mason et Shaver, I952).

Cette revue bibliographique relative à l'action de l'épididyme sur les spermatozoïdes permet de penser que les spermatozoïdes quittent le testicule en étant morphologiquement immatures et avec un pouvoir fécondant nul ou très faible. Ils acquièrent ce pouvoir fécondant au cours de leur passage dans l'épididyme. Si les spermatozoïdes ne sont pas éjaculés, ils perdent progressivement leur pouvoir fécondant et disparaissent par liquéfaction, par résorption ou par éjaculation.

Quelle que soit la théorie admise sur les causes de la maturation et de la sénescence des spermatozoïdes, celles-ci ne se réalisent que progressivement. Il est donc essentiel de déterminer le temps exact pendant lequel les spermatozoïdes séjournent normalement dans l'épididyme. Nous allons passer en revue les différents résultats déjà obtenus sur ce sujet. 


\section{II. - TRANSPORT DES SPERMatozö̈des DANS L'ÉPIDIDYME}

a) Détermination de la vitesse de transit des spermatozoïdes dans l'épididyme par des méthodes indirectes.

Les premiers auteurs qui s'intéressèrent à ce sujet tels que LODE (I89I) et EXNER (I904) pensaient que le passage des spermatozoïdes dans l'épididyme est très rapide, n'excédant pas deux jours chez l'Homme et le Chien. Ils se basaient sur le fait qu'après le troisième ou le quatrième éjaculat, ils ne trouvaient plus de spermatozoïdes et que 3 jours plus tard ils en obtenaient de nouveau dans l'éjaculat.

La plupart des auteurs ont tenté de résoudre ce problème par injection de colorant dans la tête de 1'épididyme.

'ToOTHIL et Young (I93I) montrèrent que les particules d'encre de Chine injectées dans la tête de l'épididyme de Cobayes adultes n'atteignent la queue de 1'épididyme qu'après $\mathrm{I}_{4}$ à I9 jours.

ClubB (IO5I) reprit ce problème. En injectant de l'encre de Chine dans le rete testis chez plusieurs espèces, il trouve que la durée du transit épididymaire est égale à :

22 à 25 jours chez le Cobaye;

I9 à 22 jours chez le Rat;

9 à ro jours chez le Hamster.

GRANT (I958) remplaçant l'encre de Chine par du bleu trypan, injecté dans les canaux efférents du Rat, trouve une durée de transit épididymaire égale à 13 jours. C'est ce qu'observent aussi MACMILLAN et HARRISON (I955), après injection de sulfate de baryum dans les canaux efférents.

Chez le Bélier, Gunn (1936), trouve que les particules d'encre de Chine, injectées dans le rete testis, apparaissent dans l'éjaculat II jours plus tard.

Chez le même animal, PHILIIPs et Mc KENZIE (I934) tentèrent une approche directe du problème, en réalisant une isolation scrotale destinée à provoquer des anomalies morphologiques dans les spermatozoïdes testiculaires par suite de l'augmentation de température. Ils observent que le temps nécessaire pour que ces spermatozoïdes anormaux arrivent dans l'éjaculat est en moyenne de 8,8 jours après 1'isolation.

PoLovceva (1938) arrive à un résultat analogue par une autre méthode. Chez le Bélier, cet auteur ligature la tête de l'épididyme et recherche le temps que mettent les derniers spermatozoïdes pour arriver dans l'éjaculat. Il trouve ainsi un temps moyen de 7 jours.

Ainsi diverses études poursuivies sur une même espèce ne donnent pas toujours entre elles des résultats concordants. Ceci est lié à une impossibilité d'interprétation de ces expériences. Dans le cas des injections de colorant le temps mesuré correspond non pas au passage des spermatozoïdes eux-mêmes mais à celui du fluide épididymaire ; par ailleurs, les différences observées peuvent dépendre du volume de colorant injecté. Dans le cas d'une isolation scrotale, l'endroit du tractus où les spermatozoïdes sont altérés par la chaleur n'étant pas connu avec précision, il est difficile d'en déduire la durée de transit épididymaire (GLover, I960). Quant aux ligatures de la tête de l'épididyme elles suppriment l'apport des sécrétions testiculaires qui, pour certains auteurs, conditionnent la progression des spermatozoïdes dans 1'épididyme. 
Mais pour suivre dans le temps le déplacement des spermatozoïdes dans 1'épididyme, il semble que la technique du marquage par des éléments radioactifs permette une précision plus grande. Aussi cette méthode a-t-elle donné lieu à de nombreux travaux.

\section{b) Détermination de la vitesse de transit des spermatozoïdes dans l'épididyme au moyen du marquage par radioélément}

De nombreux isotopes ont été utilisés pour marquer les spermatozoïdes et suivre ensuite leur évolution : le ${ }^{32} \mathrm{P}$ a été le premier isotope choisi pour ce genre d'études.

Bishop et WEinstock (I948) ont en effet montré que, chez le Taureau, les spermatozoïdes éjaculés sont capables d'absorber in vitro du ${ }^{32} \mathrm{P}$ ajouté sous forme de $\mathrm{PO}_{4}$ $\mathrm{HNa}_{2}$. Par la suite Bishor (I952) a constaté que le ${ }^{32} \mathrm{P}$ s'incorpore principalement dans les composés phosphorés acidosolubles.

Di Stefano et Mazia (I953) ont observé qu'une forte proportion de ${ }^{32} \mathrm{P}$ s'incorpore dans les pièces intermédiaires des spermatozoïdes d'Oursins.

Puis de nombreux auteurs ont montré que le ${ }^{32} \mathrm{P}$ administré in vitro par voie intraveineuse s'incorpore également dans les spermatozoïdes. BENGSTON (I949) après avoir injecté $d u^{32} \mathrm{P}$ à des Lapins mâles, retrouve une forte radioactivité dans le sang et le foie des femelles une heure après l'accouplement avec ces mâles marqués; le ${ }^{32} \mathrm{P}$ s'était donc incorporé in vivo dans les spermatozoïdes ou le plasma séminal.

Lorentz, Cavoulas et Carson (I950) ont observé le même phénomène chez le Coq. Mais ils ont montré surtout que les maxima de radioactivité dans le plasma sanguin, le plasma séminal et les spermatozoïdes n'apparaissent pas simultanément et que les spermatozoïdes ne deviennent radioactifs qu'après plusieurs semaines. Novik (I956), Manzina (I958) ont confirmé ces observations.

$\mathrm{Si}$ ces travaux mettent en évidence l'existence d'une incorporation du ${ }^{32} \mathrm{P}$ dans les spermatozoïdes, ils ne montrent pas dans quelle fraction phosphorée elle se produit. Parallèlement à ces travaux de nombreux auteurs étudiaient l'incorporation du ${ }^{32} \mathrm{P}$ dans les cellules de divers organes. C'est ainsi que KLINE et CIIFTON (I952) en utilisant la technique d'extraction des composés phosphorés introduite par SchmidT et Thannhauser (I945) et Schneider (I946), ont pu déterminer la durée de vie des leucocytes au moyen du ${ }^{32} \mathrm{P}$ et sont arrivés ainsi à suivre la formation, la décharge, puis la destruction des leucocytes dans le sang.

De la même manière, OrTavant (I956) a marqué les spermatozoïdes de Bélier par du ${ }^{32} \mathrm{P}$ et suivi ensuite leur évolution. Il en a déduit, d'une part, la durée du cycle spermatogénétique qui est de 49 jours et, d'autre part, la durée du transit épididymaire qui, chez le Bélier, varie de I4 à 2 I jours.

DAwson ( $195^{8}$ a) a repris les mêmes expériences chez le Bélier et chez le Taureau (I95 b ). Chez le Bélier, il trouve une vitesse de passage des spermatozoïdes dans l'épididyme de ro à I 4 jours. Nous discuterons de ces travaux et des conclusions qui en en sont proposées au cours de ce travail.

De nombreux auteurs ont utilisé d'autres radioéléments pour marquer les spermatozoïdes : SIRLIN et EDWARDS en ont fait une revue en I958. Signalons simplement Heath et al. (I953), Glucksmann et al. (I955) qui ont utilisé le ${ }^{35}$ S, Sirlin et EDWARds (I955) l'adénine $8-{ }^{14} \mathrm{C}$, Siri In (I958) CIERMONT et al. (I959) Foote et 
Koffed-Johnsen (I959), Johnson et Cronkite (I959) et Kaplan (I960), la thymidine tritiée. Mais ces auteurs n'ont pas utilisé leurs résultats en vue de déterminer la durée du transit épididymaire.

\section{c) Mécanisme du transport des spermatozoïdes dans l'épididyme}

Les facteurs qui conditionnent le déplacement des spermatozoïdes sont mal connus. D'après ToOTHILL et YOUNG (I93I) au moins quatre facteurs peuvent intervenir :

- 1'action des cils vibratils bordant la lumière des canaux éfférent;

- les contractions péristaltiques du canal épididymaire;

- la production constante du fluide testiculaire et des spermatozoïdes par les tubes séminifères;

— et enfin l'élimination des spermatozoïdes déjà formés selon le rythme des éjaculations.

Des études plus récentes (Risley, I958 ; Macmillan, I958; Cross, I959; MaCMILLAN et AUKLAND (I960) montrent le rôle prédominant que doivent avoir les contractions péristaltiques sur la progression des spermatozoïdes dans l'épididyme.

\section{d) Variation du temps de transit des spermatozoüdes dans l'épididyme en fonction de la fréquence des collectes}

On observe couramment que le premier éjaculat obtenu d'un 'Taureau après un long repos sexuel contient une plus forte proportion de spermatozoides immobiles que les éjaculats suivants.

De plus, WILLET et OHms (I958) ont montré en collectant deux éjaculats en l'espace de quelques minutes chez un Taureau que la résistance à la congélation des spermatozoïdes du premier éjaculat est plus faible que celle des spermatozoïdes de l'éjaculat suivant. Pour ces auteurs, cette différence de résistance est due aux spermatozoïdes eux-mêmes et non au plasma séminal. WALEs et WHITE (I959), dans une expérience similaire, rapportent également que la résistance au choc thermique est plus grande pour les spermatozoïdes du deuxième éjaculat que pour ceux du premier, ceci chez 7 'Taureaux sut 9 .

DE GRoo'T (I96I) montre par une étude statistique que les spermatozoïdes du premier éjaculat sont moins mobiles et ont une plus grande sensibilité au froid que les spermatozoïdes du deuxième éjaculat obtenu au cours d'une même collecte.

Ces résultats semblent donc indiquer que les spermatozoïdes stockés dans l'épididyme commencent à y subir un processus de vieillissement, dî̀ à une influence nocive trop prolongée des sécrétions du canal épididymaire ou simplement à une sénescence.

On peut prévoir qu'inversement en effectuant des collectes successives séparées par un court intervalle de temps on doit pouvoir obtenir des spermatozoïdes d'âge moyen décroissant qui finalement seront immatures.

Contrairement à ce que nous venons de voir, STIGLER (I9I8) avait observé chez l'Homme que les spermatozoïdes du deuxième éjaculat sont moins résistants vis-àvis de la chaleur que ceux du premier éjaculat obtenus au cours de la même journée. LLOYD-JONES et HAYEs (I9I8) remarquèrent, chez le Lapin, que la vitalité des sper- 
matozoïdes décroît quant le nombre des éjaculations augmente au cours d'un test d'épuisement.

Des résultats semblables sont rapportés chez 1'Homme par ManTEGazza (I866), chez le Cheval par LEwis (I9II), chez le Chien par Amantea et Kryszkowski (I92I), chez le Taureau par LagerLof (I936).

Tous ces résultats tendent donc à montrer qu'à la suite d'éjaculations répétées, des spermatozoïles immatures apparaissent dans la queue de l'épididyme ; ceci peut s'expliquer par des variations de la durée du séjour des spermatozoïdes dans l'épididyme en fonction de la fréquence des copulations. C'est ce que montrent certaines observations directes. Ainsi GunN (I936) en étudiant le passage du sperme dans l'épididyme chez le Bélier au moyen d'injection d'encre de Chine trouve un temps de transit plus court de 6 jours chez des animaux fréquemment collectés. OrTavant (1956) montre également que chez des Béliers au repos sexuel les spermatozoïdes mettent au moins 2I jours à traverser l'épididyme, et que ce temps est réduit à I4 jours lorsqu'on effectue des récoltes fréquentes.

Cependant, KOEFED-JOHNSEN (I 959), recherchant chez le Taureaul'influence que peut avoir la fréquence des collectes sur l'apparition des spermatozoïdes à ADN marqué dans l'éjaculat, arrive à une conclusion différente. Ėn effet, ces spermatozoïdes apparaissent toujours entre le $47^{\mathrm{e}}$ et le $5 \mathrm{I}^{\mathrm{e}}$ jour après l'injection, que les animaux soient collectés 2 à 3 fois par jour ou $\mathrm{I}$ fois par semaine. Il en conclut que le temps de formation des spermatozoïdes et leur temps de transit dans l'épididyme sont remarquablement constants et ne sont pas influencés par la quantité de spermatozoïdes éjaculés. Mais, l'examen attentif des résultats de KOEFED-JoHNSEN montre qu'il existe peut-être une légère influence de la fréquence des collectes sur la date d'apparition des spermatozoïdes marqués. Par ailleurs, il n'est pas exclu que la fréquence des collectes modifie l'arrivée de ces spermatozoïdes dans la tête de l'épididyme.

Il était donc nécessaire avant d'étudier les mécanismes de la résorption des spermatozoïdes de connaître avec précision la durée du transit épididymaire. 


\section{MATÉRIEL ET MÉTHODES}

\section{A. - Animaux utilisés}

Les aninaux utilisés sont des Taureaux adultes de race Française. Frisonne Pie-noire, Normande et Ilamande. Leur âge varie de 2 ans à 6 ans et leur poids de 500 à $\mathrm{I} 000 \mathrm{~kg}$.

Nous avons utilisé :

26 Irançais Frisons Pie-noire

5 Normands

I Flamand

soit 32 'laureaux en tout - 46 expériences ont été réalisées, certains animaux étant utilisés plusieurs fois.

\section{B. - Choix des isotopes et technique d'injection}

Pour notre travail nous avons éliminé d'emblée les marqueurs tels que la thymidine - ${ }^{\mathbf{3}} \mathrm{H}$, l'adénine $8{ }^{-14} \mathrm{C}$; d'une part à cause de leur prix et des doses nécessaires, d'autre part, en raison de leur longue période qui rend leur utilisation impossible sur une large échelle chez les animaux domestiques.

Nous avons utilisé comme marqueur le ${ }^{32} \mathrm{P}$; la teneur élevée des spermatozoïdes en phosphore (MANN, I954) laissait présumer une radioactivité détectable malgré des doses injectées relativement faibles.

TABLEAU I

Distribution des composés phosphorés dans le sperme de Bélier (ManN, 1954) résultals exprimés en $m \mathrm{~g} \mathrm{P}$. pour $\mathrm{r}$ oo $\mathrm{ml}$ sperme.

\begin{tabular}{|c|c|c|c|}
\hline & Sperme & Spermatozoïdes & Plasma séminal \\
\hline$\ldots \ldots \ldots \ldots \ldots \ldots \ldots \ldots$ & 328.5 & 196,7 & $1 / 1,8$ \\
\hline $\mathrm{P}$ acidosoluble ... & 159,4 & 27,4 & 132,0 \\
\hline $\mathrm{P}$ phospholipidique & 30,8 & 27,9 & 2,9 \\
\hline$P A D N \ldots \ldots \ldots \ldots \ldots \ldots \ldots$ & 111,0 & 111,0 & 0 \\
\hline $\mathrm{P}$ résiduel $\ldots \ldots \ldots \ldots \ldots \ldots \ldots \ldots$ & 27,3 & 20,4 & 6,9 \\
\hline
\end{tabular}

Le ${ }^{32} \mathrm{P}$ de période $\mathrm{I}_{4,7}$ jours, émetteur de rayonnements $\beta$, d'énergie $\mathrm{I}, 7 \mathrm{Mev}$, était fourni par le Commissariat à l'Énergie Atomique sous forme de $\mathrm{PO}_{4} \mathrm{HNa}_{2}$ en solution stérile ayant une activité de $2 \mathrm{mC} / \mathrm{ml}$. Cet isotope fut administré dans la jugulaire de l'animal à la dose de 0,05 à $0, \mathrm{I} \mathrm{mC} / \mathrm{kg}$ de poids vif.

Nous avons par ailleurs utilisé des particules de charbon de sucre sur lestjuelles de l'198 Au de période $i 2,69$ jours est adsorbé. Ces dernières furent spécialement préparées par le C. I. A. à une dimension voísine de celle des spermatozoïdes (5à $10 \mu) .99 \mathrm{p}$. 100 des rayonnements émis par le ${ }^{198} \mathrm{Au}$ sont d'origine $\beta$ ayant une énergie de $0,96 \mathrm{Mev}$. Les particules sont mises en suspension dans du 
dextran, fortement agitées pour rompre les liaisons électrostatiques qui les retiennent en amas, et i ijectées directement dans le rete testis. Approximativement $100 \times 10^{6}$ particules ayant une activité totale de $32 \mathrm{mC}$ sont ainsi injectées dans le testicule.

\title{
C. - Prélèvements des échantillons à analyser
}

\author{
I. - L'APPAREIL GÉNITAL
}

Dans la majorité des cas l'appareil génital est prélevé par castration. Celle-ci est effectuée :

- soit sous anesthésie générale par injection intraveineuse de chloral $(0,5 \mathrm{mg} / \mathrm{kg}$ de poids vif) après une préparation au largactil $(0,5 \mathrm{mg} / \mathrm{kg}$ de poids vif) I heure avant l'opération.

- soit sous anesthésie locale à l'aminocaïne et au chlorure d'éthyle.

\section{2. - LES SPERMATOZOÏDES}

\section{a) Collecte du sperme}

Nous avons récolté le sperme au moyen d'un vagin artificiel selon la technique décrite par ANDERSON (I945), BONADONNA (I948) et TERRIL (I949). Le vagin artificiel, après avoir été aseptisé avec de l'alcool à 95 p. 100, est lubrifié à l'aide d'une pâte soluble à l'eau froide (DAuzier et al., r952). La température du vagin doit varier selon les animaux de $4 \mathrm{I}^{\circ} \mathrm{C}$ à $45^{\circ} \mathrm{C}$ et l'éjaculat est recueilli dans un tube gradué au $\mathrm{I} / \mathrm{I} O \mathrm{de} \mathrm{cm}^{3}$. Après avoir noté le volume de l'éjaculat, la motilité du sperme est évaluée selon une notation allant de o lorsque tous les spermatozoïdes sont immobiles à 5 lorsque les spermatozoïdes présentent une motilité d'ensemble en " tourbillons".

La concentration du sperme est déterminée au photocolorimètre selon une technique dérivée de celle de Rothschild (i950), Willet et Buckner (i95I), Cox et Melrose (i953).

Pour séparer les spermatozoïdes du plasma séminal, le sperme est traité $20 \mathrm{mn}$ à 5000 tours $/ \mathrm{mn}$ dans une centrifugeuse maintenue à $0^{\circ} \mathrm{C}$. Après élimination du surnageant, le culot de spermatozoïdes est remis en suspension dans une solution de Krebs-Henseleit-Ringer préconisée par MANN (I954) pour la dilution du sperme, dont la composition est la suivante :

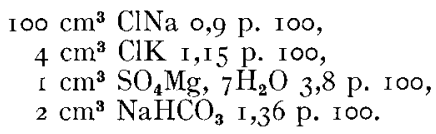

La suspension est centrifugée Io $\mathrm{mn}$ à $0^{\circ} \mathrm{C}$ et le culot de spermatozoïdes obtenu est lavé 2 fois de la même manière. On obtient ainsi les spermatozoïdes séparés du plasma séminal.

\section{b) Obtention des spermatozoides de l"épididyme}

Nous avons suivi la technique de Dallam et Thomas (1953) en la modifiant légèrement au cours des expériences.

I'épididyme est séparé du testicule et débarrassé du tissu conjonctif qui l'entoure en prenant garde de ne pas couper le canal épididymaire lui-même. En effet les fibrilles musculaires de la paroi de l'épididyme maintiennent à l'intérieur de celui-ci une pression telle qu'à la moindre lésion du canal le sperme se répand à l'extérieur.

L'épididyme est ensuite fractionné en 6 parties, la tête, le corps et la queue étant séparés en fraction proximale et distale (fig. 2).

Chaque partie de l'épididyme est finement découpée dans une solution de Krebs-IIenseleit, rendue hypotonique en ajoutant aux volumes indiqués précédemment de l'eau distillée jusqu'à $500 \mathrm{ml}$. Cette solution est sans action sur les spermatozoîdes mais cause l'hémolyse des hématies. On laisse macérer l'ensemble $30 \mathrm{mn}$ à $0^{\circ} \mathrm{C}$ puis on filtre sur 6 couches de gaze. Ce filtrat est centrifugé pendant $10 \mathrm{mn}$ à $5000 \mathrm{t} / \mathrm{mn}$. Le surnageant coloré en rose par l'hémoglobine est écarté.

Le culot est homogénéisé très brièvement à très faible vitesse dans un Potter-Elvehjem, puis centrigufé à $0^{\circ} \mathrm{C}$ pendant $10 \mathrm{mn}$. De nouvelles homogénéisations suivies de centrifugations permettent d'obtenir une préparation de spermatozoïdes débarrassés des hématies et du tissu conjonctif. 


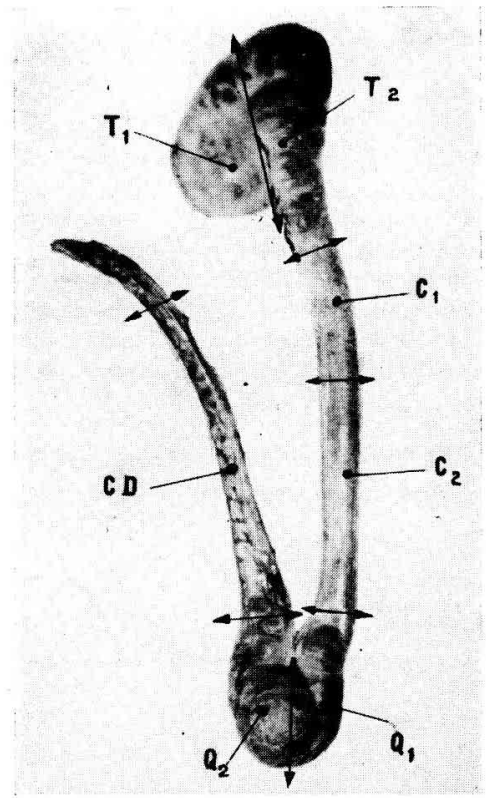

FIc. 2. - Schéma de dissection de lépididyme : $\mathrm{T}_{\mathbf{1}}$ Partie proximale de la tête -

$\mathrm{T}_{2}$, Partie distale de la tête $-\mathrm{C}_{1}$, Partie proximale du corps $--\mathrm{C}_{2}$, Partie distale du corps -

$\mathrm{Q}_{1}$, Partie proximale de la queue - $\mathrm{Q}_{2}$, Partie distale de la quene - $\mathrm{CD}$, Canal déférent.

\section{1). - Techniques physico-chimiques \\ I. - EXTTRACTION DES DIFFÉRENTES FRACTIONS PHOSPHORÉES DES SPERMATOZOÏDES}

Le ${ }^{32} \mathrm{P}$, principal marqueur utilisé, s'incorpore dans les composés phosphorés du plasma séminal dont le principal est constitué par la glycéryl-phosphoryl-choline (DIAMENT et al., 1952). On le retrouve également dans certains constituants des spermatozoides tels que phospholipides, phosphoprotéines, nucléotides et acides nucléiques. Pour déterminer la radioactiviété spécifique de chacun de ces composés, il est nécessaire d'obtenir les différentes fractions qui les renferment. Pour ce faire, nous nous trouvons en présence de nombreuses méthodes.

\section{a) Données bibliographiques}

Nous avons éliminé un certain nombre de techniques malgré leur simplicité parce qu'elles ne réalisaient l'extraction que des acides nucléiques seuls.

Citons la méthode de Pollister et Mirsky (1946). Ces auteurs réussissent l'extraction des acides nucléiques des spermatozoïdes de Truite, Salmo fario, par du CINa N. Malheureusement, cette méthode ne convient pas à l'extraction des nucléoprotéines des spermatozoïdes de toutes les espèces. Déjà pour l'Oursin, l'extraction n'est possible qu'avec du CINa $2 \mathrm{M}$. Quant aux Mammifères, le problème est plus difficile : aucune nucléoprotéine de spermatozoïdes de Taureau ou de Bélier ne peut être extraite par une solution saline à quelque concentration que ce soit (DALLAM et THOMAs, I953; MANN, 1954). L'extraction n'est pas réalisée non plus avec NaOH o, I N (BERRY et MAYER, 1959). Chez l'Homme, Zamenhoff, Shettles et ChargafF (1950) ont montré qu'il est nécessaire de traiter le sperme par de la trypsine cristallisée pour que l'extraction des acides nucléiques puisse se faire. BorenfREUND, FITT et BENDICH (I96I) sur des spermatozoïdes bovins et humains ont refait la même observation. Cette grande résistance des spermatozoïdes aux solutions salines concentrées peut être due à la présence d'une membrane protéique protectrice entourant la tête des spermatozoïdes (GREEN, 1940; ZITTLE et O'DELL, I94I). Elle peut dépendre aussi du degré de polymérisation des différents acides nucléiques pour différentes espèces (WILKINS et RANDALL, 1953).

Annales de Biologie animale. -- r 962 . 
Ogur et Rosen (i949) préconisent la séparation des acides nucléiques par extraction à l'acide perchlorique. Cette technique donne d'excellents résultats sur les tissus végétaux, mais elle est plus difficilement applicable aux tissus animaux, car l'acide perchlorique froid extrait l'ADN en même temps que l'ARN (Habers et NeumanN, I954).

Schmidt et Thannhauser (1945) et Schneiner (I945) ont été les premiers à proposer une méthode de fractionnement des différents composés phosphorés des tissus en vue d'obtenir les acides nucléiques. Cette méthode permet en outre d'opérer sur de petites quantités de tissus animaux.

SCHMidT et Tiannhauser (1945) traitent les tissus homogénéisés par de l'acide trichloracétique et par un solvant des lipides pour enlever toutes les substances acidosolubles et lipidiques. I.e résidu est incubé avec un alcali, la chaîne d'acide ribonucléique se trouve alors fractionnée en nucléotides fortement alcalisolubles par estérification du radical $\mathrm{OH}$ libre sur le carbone 2 ou 3 du ribose. Ie désoxyribose ne possède pas ces radicaux OH et ne peut, par conséquent, fournir de tels nucléotides : il reste inattaqué. Par acidification de l'hydrolysat l'ADN précipite avec les protéines, l'ARN restant en solution sous forme de nucléotides acidosolubles. La quantité de phosphore peut ensuite être estimée sur les 2 fractions.

Schneider (I945) extrait les acides nucléiques en traitant le résidu délipidé par de l'acide trichloracétique chaud. Les acides nucléiques passent alors en solution sous forme de produits acidosolubles. Les réactions colorées des sucres sont utilisées pour distinguer l'ARN de l'ADN : la réaction à l'orcinol étant plus communément utilisée pour l'ARN et la réaction à la diphénylamine ou l'indole pour l'ADN.

Cette méthode a pour elle l'avantage de la rapidité et de la simplicité, mais elle ne permet pas, comme celle de Schmidt et T'hannuauser, la séparation entre l'ARN et l'AIDN. Cependant cette dernière méthode a été vivement critiquée par DAvidson, FrAzER et HutciIISON (I95I), HokIN et HOKIN (I 953), DRASHER (I953).

DAvidson, Frazer et HUTCiIson montrent que la fraction ADN peut être contaminée par des traces persistantes de phosphate acidosoluble puisque l'adjonction de phosphate inorganique radioactif à un homogénat de foie d'animaux ayant reçu du ${ }^{\mathbf{3 2}} \mathrm{P}$ par injection 2 hcures avant, entraîne une contamination de la fraction $\mathrm{ADN}$, même après 20 rinçages à l'acide trichloracétique.

Ces auteurs ont également montré que la méthode de ScHmidT et Thanninauser donne pour de nombreux tissus un rapport $P$. ARN/P. ADN plus grand que les autres méthodes. Dans le foie par exemple la fraction ARN peut contenir en plus des ribonucléotides $25 \mathrm{p}$. 100 de composés phosphorés non nucléotidiques (DAVIISSON et SMEILIE, 1952) représentés principalement par des phosphopeptides et des phosphates d'inositol (Hutchinson et al., i 956). La contamination de l'ARN est donc plus importante que celle de l'ADN.

D'autre part, MAURITZEN, Roy et STEDMAN (I952) ont montré, en fractionnant du thymus, que l'ADN peut être dégradé au cours de l'hydrolyse alcaline et qu'une certaine partie doit passer dans le surnageant acide, c'est-à-dire dans la fraction $A R N$. De même Mc INDOE et Davidson (I952), en dissolvant et en reprécipitant à plusieurs reprises le précipité obtenu par la méthode de SchmiDT et Thannhauser, ont remarqué que l'ADN devient progressivement alcali-soluble.

MARKo et ButLer (I95I) pensent que l'acide trichloracétique n'est pas complètement éliminé et qu'il en reste une certaine quantité dans le résidu insoluble à l'acide, même après les rinçages, et que cette acidité résiduelle peut entraîner des modifications chimiques dans l'ADN qui le rend sensible à l'hydrolyse alcaline. Ils proposent, après les rinçages à l'acide et à l'eau, plusieurs extractions avec une solution d'éthanol saturé en acétate de Na pour neutraliser cette acidité.

En dépit de ces critiques la technique de Schmid et ThanNiauser reste très utilisée et nous semble convenir à l'étude du problème envisagé.

Toutes les études critiques dont nous avons parlé ont en effet été faites sur des homogénats de fo.e, pancréas ou de thymus, dont les noyaux sont très sensibles à toutes les variations dans le processus expérimental. Ainsi Lilienfeld (1894) a réalisé l'extraction par l'eau distillée, de l'acide nuzléique à partir d'homogénats de thymus. Mirsky et PoLLISTER (I942) réalisent l'extraction avec du ClNa, I M. Mais nous avons vu que l'extraction des acides nucléiques des spermatozoïdes de Mammifères n'est pas aussi aisée.

Aux expériences faites par DAvidson (I95I) pour montrer la contamination de la fraction ADN, LUNDIN (1958) donne une explication différente. Te phosphate radioactif livré par le Radiochemical Center d'Amersham ne contient que $40 \mathrm{p}$. 100 d'orthophosphate. Fn hydrolysant le ${ }^{32} \mathrm{P}$ avec $\mathrm{SO}_{4} \mathrm{H}_{2}$ concentré pendant 60 minutes à $150^{\circ} \mathrm{C}, 99 \mathrm{p}$. 100 du ${ }^{32} \mathrm{P}$ est converti en orthophosphate. En repre$\mathbf{n}$ ınt, à l'aide de cette préparation, les expériences de contamination de Davinson, il montre qu'en utilisant le ${ }^{\mathbf{3 2}} \mathrm{P}$ sous forme d'orthophosphate, pratiquement tout le $\mathbf{P}$ inorganique est enlevé par 3 rinçages à l'acide trichloracétique. Par conséquent cette critique par Davioson de la méthode de Schmidt et Thannhalser n'est pas fondée.

Les critiques insistent également beaucoup sur la contamination de la fraction ARN par des phosphoprotéines ou même par du phosphore inorganique. Les spermatozoides ne contenant pas ou peu de ribonucléotides, nous n'avons pas été amenés à étudier cette fraction.

De plus, lorsque les résultats sont exprimés en activité spécifique du phosphore, une légère peret 
d'ADN au cours de l'hydrolyse alcaline n'influence pas les résultats. Par contre la contamination par un autre composé tels que les phosphoprotéines pourrait être gênante, mais, comme nous le verrons plus tard, au moment où l'ADN des spermatozoïdes est marqué, les phospholipides et les phosphoprotéines ne le sont pratiquement plus (IABERs et NeuMANN, 1954).

Nous avons donc utilisé la méthode de Schmidt et THannhauser modifiée par Scinneider (1946) et Marko et Butler (195I).

\section{b) Technique utilisée}

I a suspension lavée de spermatozoïdes est homogénéisée au moyen d'un Potter-Elvehjem dans ro volumes d'acide trichloracétique ro p. 100 à $0^{\circ} \mathrm{C}$. I a suspension est laissée $3 \circ \mathrm{mn}$ à cette température, puis centrifugée à froid pendant io $\mathrm{mn}$ à 5000 tours/mn. Ie surnageant contient le phosphore inorganique et les composés phosphorés acidosolubles ; le résidu est extrait 2 fois avec de l'acide trichloracétique $10 \mathrm{p}$, Ioo et lavé avec de l'eau bidistillée à $0^{\circ} \mathrm{C}$. Puis le résidu est neutralisé par de l'éthanol-acétate froid, centrifugé et rincé une fois avec la même solution avant de commencer la délipidation.

Le résidu est ensuite mis en suspension dans ro volumes d'un mélange chloroforme-méthanol (2 - I) pendant i heure à I $8^{\circ} \mathrm{C}$. Après centrifugation, le surnageant contenant les phospholipides est prélevé. Le résidu est ainsi extrait 2 fois, lavé dans 5 volumes d'éther et séché sous ventilation à la température ambiante.

$100 \mathrm{mg}$ de résidu sec ainsi délipidé sont hydrolysés avec $10 \mathrm{~cm}^{3}$ d'une solution $\mathrm{NaOH}, \mathrm{N}$, à $37^{\circ} \mathrm{C}$, pendant 20 heures; une bonne dissolution du résidu est assurée au moyen d'une agitation discontinue. L'hydrolyse alcaline de l'ARN donne naissance à des nucléotides alcali-labiles, tandis que l'ADN ne subit pas une telle dégradation. Aussi après centrifugation à $0^{\circ} \mathrm{C}$, l'ADN est précipité à froid avec 0,2 volumes de $\mathrm{ClH}, 6 \mathrm{~N}$ et I volume d'acide trichloracétique $5 \mathrm{p}$. 1 oo.

Le précipité est lavé 3 fois avec $5 \mathrm{~cm}^{3}$ d'acide trichloracétique froid puis I'ADN est extrait par $6 \mathrm{~cm}^{3}$ d'acide trichloracétique $5 \mathrm{p}$. i oo durant i $5 \mathrm{mn}$ à $90^{\circ}-95^{\circ} \mathrm{C}$.

\section{c) Discussion}

Nous avons cherché à connaître, dans le cas particulier de nos expériences, les marges de sécurité de la méthode utilisée aussi bien pour l'isolement des spermatozoïdes que pour l'extraction des fractions phosphorées.

\%. - Les pertes d'ADN au cours des extractions.

Salisbliry et al. (I960) ont remarqué que la conservation des spermatozoïdes à $5^{\circ}$, dans des conditions permettant un métabolisme aérobie ralenti du sperme, pendant $2,3,5$ et ro jours, amène une diminution marquée de l'ADN-Feulgen positif des têtes de spermatozoïdes.

Aussi avons-nous voulu voir si, au cours du lavage des spermatozoïdes par la solution de KrebsHenseleit-Ringer et selon les conditions où sont faits ces lavages, il ne se produit pas de diminution dans la teneur en ADN des spermatozö̈des obtenus.

Variations dans la teneur en $\mathrm{ADN}$ des spermatozoides en fonction du nombre de lavages avec a solution de Krebs-Henseleit-Ringer.

Après une série de collectes nous avons mélangé tous lés éjaculats obtenus et nous les avons répartis en 8 lots : les 4 premiers lots étaient lavés une seule fois avec la solution de Krebs-HenseleitRinger, les 4 autres étaient lavés 6 fois avant de poursuivre l'extraction des composés phosphorés.

\section{TABIEAU 2}

Influence du nombre de lavages adec la solution de Krebs-Henseleit-Ringer sur la teneur en $A \mathrm{IN}$ des spermatosoildes (résultats exprimés en $\gamma$ de $\mathrm{P} / \mathrm{r}^{9}$ spermatozoïdes)

\begin{tabular}{|c|c|c|c|}
\hline $\begin{array}{l}\text { Nombre } \\
\text { de lavages }\end{array}$ & $\begin{array}{c}\text { Nombre } \\
\text { d'cehantillons }\end{array}$ & $M \pm S_{m}$ & Test " $l "$ \\
\hline 1 & it & $19 \times, 7 \pm 8,9$ & \\
\hline 6 & ! & $1 \times 7,5 \pm 3,3$ & \\
\hline
\end{tabular}

Les résultats résumés dans te tableau 2 indiquent que la différence entre les 2 séries n'est pas significative. 
Influence de la température au cours des manipulations du sperme sur la teneur en AI) des spermatozoiides

Après la collecte, l'éjaculat est placé dans un themos à $37^{\circ} \mathrm{C}$, puis la motilité des différents éjaculats est déterminée à l'intérieur d'une enceinte à $37^{\circ} \mathrm{C}$. Les éjaculats sont alors mis à $0^{\circ} \mathrm{C}$. Ces différentes opérations demandant une heure en movenne il était nécessaire de contrôler que ce séjour prolongé à $37^{\circ} \mathrm{C}$ du sperme n'altérait pas l'ADN des spermatozoïdes.

Aussi, immédiatement après l'éjaculation avons-nous fractionné le sperme en 2 parties égales dont l'une est mise dans un thermos rempli de glace tandis que l'autre est traitée comme à lordinaire.

TABLEAU 3

Influence de la température au cours des manipulations du sperme sur la teneur en phosphore de l'ADN des spermatozoides (résultats exprimés en $\gamma \mathrm{P} / \mathrm{I}^{9}$ spernatozoïdes)

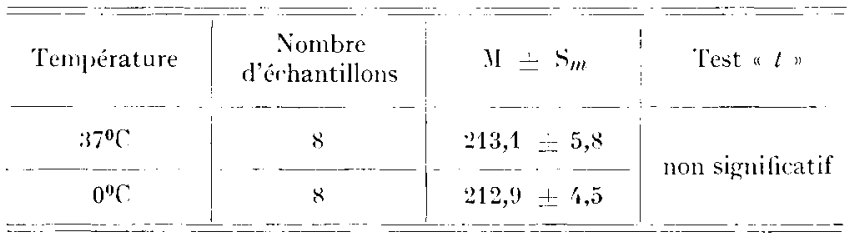

Les résultats indiqués dans le tableau 3 montrent que la différence entre les deux séries n’est pas significative. Nous pouvons en conclure que la (juantité d'ADN n'est pas influencée par la température au cours des manipulations du sperme. On notera que la teneur moyenne en phosphore de l'ADN par $10^{9}$ spermatozoïdes correspond aux chiffres donnés par SuMMFrillu et OLDS (I96I).

3. - La contamination des composés phosphorés radioactifs les uns par les aulres. Contamination des phospholipides par le plasma séminal.

Après une injection de ${ }^{32} \mathrm{P}$, le plasma séminal est le premier constituant marqué. Sa radioactivité augmente rapidement et commence seulement à décroître quand les phospholipides du sperme deviennent radioactifs. Aussi une contamination de ceux-ci par le plasma séminal est-elle toujours à craindre. Nous avons étudié cette possibilité en deux temps :

En recherchant tout d'abord le pourcentage de phosphore qui était enlevé à chaque lavage des spermatozoïdes par rapport à la quantité totale de phosphore du plasma séminal obtenu lors de la première centrifugation ; (tableau 4 ).

TABI,EAU 4

Quantité totale de phosphore enlevée à chaque lavage des spermatozoïdes par la solution de Krebs-Henseleit-Ringer exprimée en $\%$ de la quantité totale de $P$ du plasma séminal obtenue à la première centrifugation

\begin{tabular}{c|c|c}
\hline Nombre de lavages & Nombre d'échantillons: & UI \\
\hline 1 & 8 & $12,0 \pm 1,4$ \\
2 & 8 & $2,5 \pm 0,5$ \\
3 & 8 & $1,2 \pm 0,3$ \\
4 & 6 & $1,0 \pm 0,5$ \\
5 & 6 & $0,9 \pm 0,3$ \\
\hline
\end{tabular}

Puis en cherchant le pourcentage de radioactivité enlevé à chaque lavage, par la solution de Krebs-Henseleit-Ringer par rapport à la radioactivité totale du plasma séminal obtenu lors de la première centrifugation (tableau 5). 


\section{TABLEAU 5}

Radioactivité totale enlevie à chaque lavage des spermatozoïles par la solution de Krebs-Henseleit-Ringer exprimée en pourcentage de la radioactivité totale du plasma séminal obtenu à la première centrifugation

\begin{tabular}{c|c|c}
\hline Nombre de lavages & Nombre d'échantillons & $M \pm S_{m}$ \\
\hline 1 & $1^{\prime}$ & $7,7 \pm 1,1$ \\
2 & $1^{\prime}$ & $1,1^{\prime} \pm 0,2$ \\
3 & $11^{\prime}$ & $0,5 \pm 0,1$ \\
1 & $1^{\prime}$ & $0,2 \pm 0,1$ \\
5 & $1 t_{1}$ & $0,07 \pm 0,1$ \\
6 & 10 & 0 \\
\hline
\end{tabular}

Nos résultats indiquent qu'après le $3^{\mathrm{c}}$ lavage, le pourcentage de phosphore, aussi bien que le pourcentage de radioactivité qui est enlevé, est très faible. On doit cependant remarquer que si, au $4^{\mathrm{e}}$ lavage, la radioactivité est faible, une certaine quantité de phosphore est cependant enlevée. Flle doit correspondre à du phosphore acidosoluble qui est définitivement enlevé par la suite par l'acide trichloracétique. Nous en avons conclu que 3 lavages au moins sont nécessaires pour éliminer le phosphore en provenance du plasma séminal.

Contamination de l'ADN.

Nous avons vu dans la discussion générale de la méthode de Schuidt et linannuaser que la plupart des critiques qui s'y adressent avaient peu d'importance lorsque cette technique est appliquée à des spermatozoïdes.

Cependant, pour vérifier qu'il ne se produit pas de contamination de la fraction ADN par les phospholipides nous avons recherché l'efficacité des lavages du résidu au cours de l'extraction de ceux-ci.

On voit que 3 lavages suffisent à éliminer les composés phospholipidiques. İn effet, alors yue le premier lavage permet de récupérer 6,0 p. 100 du phosphore des phospholipides obtenu à la première extraction et le deuxièm: lavage $1,3 \mathrm{p}$. 10o, on ne retrouve jamais de phosphore au troisième lavage. La quantité de phosphore correspondant aux phosphoprotéines extraites après l'hydrolyse avec NaOH par l'acide trichloracétique froid est trop peu importante comparativement a la quantité de phosphore de la fraction $A D N$, pour pouvoir contaminer celle-ci et elle est éliminée facilement par plusieurs lavages.

D'ailleurs toutes ces fractions : plasma séminal, phospholipides, phosphoprotéines, ont leur maximum de radioactivité bien avant l'ADN et quand celui-ci commence à êt re marqué, la radioactivité spécifique de tous ces composés est devenue très faible.

Dans la discussion générale, nous avons vu également que Makko et BUTLER prétendent que l'acidité résultant du traitement à l'acide trichloracétique dénature l'ADN au cours de l'hydrolyse.

Ces auteurs proposent un traitement par l'éthanol-acétate $\left(1,3,5 \mathrm{~g} / \mathrm{I}\right.$ ooo $\left.\mathrm{cm}^{3}\right)$ pour neutraliser cette acidité. Nous avons comparé, sur des fractions de mêmes éjaculats la méthode originale de Schmidt et Thanniauser et celle modifiée par Marko et Brtuer.

\section{TABLEAU 6}

Influence du pII du résidu dílipide' sur la teneur en phosphore do l'ADN des spermatozoiles

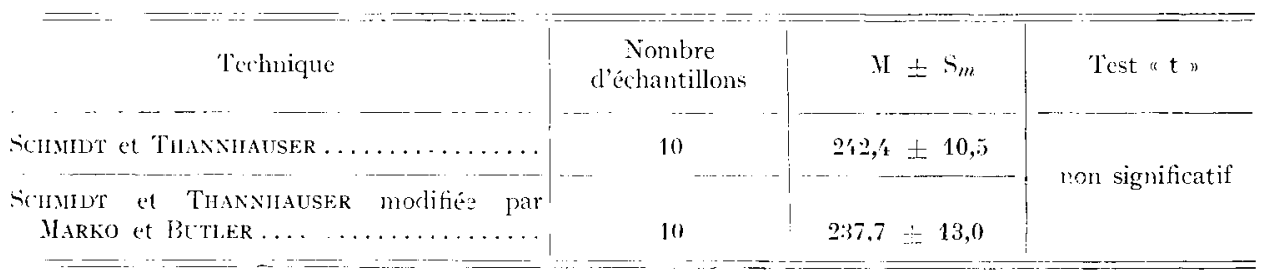


Dans le cas de la méthode originale de Scrmidot et Tianniauser le pII du culot des spermatozoïdes avant l'hydrolyse alcaline était en moyenne de 2,6 ; dans le cas de la méthode de SCHMIDT et Thannirauser modifiée par Marko et Butler il était de 8,5. Malgré cette différence de pH, on n'observe pas de différence significative entre les 2 groupes de résultats.

L'AIDN extrêmement polymérisé des spermatozoïdes se montre donc stable et résiste certainement mieux à la dénaturation que l' $\mathrm{ADN}$ des cellules de foie ou de thymus sur lescuelles ont été essayées les différentes méthodes d'extraction des composés phosphorés.

\section{2. - DOSAGE DU PHOSPhORE}

La détermination de la (quantité de phosphore dans chacune des fractions extraites est effectuée selon la technique d'ALLEN (1940) pour les fractions désoxyribonucléiques, selon la technique d'ERNSTER (1950) pour les fractions phospholipidiques. Ia technique d'ALLEN permet de doser des quantités de $\mathrm{I}^{\prime}$ de 20 à $200 \gamma$ tandis que celle d'ERnster permet de doser des quantités plus faibles de l'ordre de 2 à $20 \%$.

\section{3. - Mesure de la Radioactivité}

Une partie aliquote (I ou $2 \mathrm{ml}$ ) de chaque fraction extraite, est mise dans une coupelle et séchée sous une lampe à rayonnement infra rouge. La radioactivité de la coupelle séchée est mesurée sous un compteur cloche à atmosphère organique. Les résultats sont toujours ramenés au jour de l'injection et exprimés en activité spécifique. Seules sont considérées comme significatives les mesures qui après calcul du test " $t$ " sont différentes du mouvement propre du compteur avec une probabilité de 95 p. ıoo. L'activité spécifique est par définition la radioactivité par unité de poids ou de volume : les activités sont donc exprimées en coups/mn et les quantités de $\mathrm{P}$ en $\mu \mathrm{g}$ ou en $\mathrm{mg}$.

$$
\text { activité spécifique }=\frac{n b}{\mu \mathrm{cp} / \text { minute. }}
$$

\section{E. - Technique autoradiographique}

Nous avons choisi cette méthode pour mettre en évidence des particules d'or radioactif progressant dans l'épididyme.

Fin effet, cette technique permet de localiser les corps radioactifs présents sur une coupe histoIogique, par les particules ionisantes (rayons $\alpha, \beta$ ou $\gamma$ ) qu'ils émettent et qui impressionnent les émulsions photographiques.

L'état actuel des techniques photographiques permet d'obtenir des autoradiographies de 2 types assez différents qui sont l'autoradiographie par noircissement global et l'autoradiographie par trajectoires individuelles.

Dans l'autoradiographie par noircissement, on observe, soit à l'wil soit au microscope, une tache noire plus ou moins dense située en regard du centre radioactif. I.e pouvoir séparateur de cette méthode est assez faible, de l'ordre de io à $20 \mu$.

L'autoradiographie par trajectoires individuelles ne s'applique pas aux rayons $\gamma$ mais seulement aux particules lourdement chargées : elles sont capables d'effectuer dans la couche d'émulsion sensible un parcours déterminé en impressionnant les molécules de BrAg rencontrées le long de ce parcours.

On reconnaît, sur coupes histologiques, les particules de charbon, soit par le noircissement de l'émulsion, soit par les trajectoires individuelles résultant du rayonnement du ${ }^{198} \mathrm{Au}$.

Nous avons utilisé l'émulsion pelliculable KODAK AR ro ainsi que l'émulsion liquide ILFORD $\mathrm{K}_{5}$ qui présente une sensibilité moindre que l'émulsion ILFORD $G_{5}$ mais cependant supérieure à celle de l'émulsion KODAK AR Io. Pour assurer l'adhérence de l'émulsion au verre, les lames doivent être revêtues d'un film de gélatine. Nous avons utilisé les lames spécialement préparées par Ilford à cet effet.

Pour ces études l'épididyme est prélevé sitôt la castration et fixé en entier dans du Bouin-Hollande pour éviter les déplacements des spermatozoïdes à l'intérieur du canal épididymaire.

Après fixation, l'épididyme est découpé en 6 fractions (tête proximale et distale, corps proximal et distal, queue proximale et distale) et chaque partie est déshydratée à l'alcool et au benzoate de méthyle avant inclusion dans de la paraffine $45^{-6} 5^{\circ} \mathrm{C}$. Les coupes sont faites à $5 \mu$, elles sont étalées à l'aide d'eau distillée et collées sur les lames substratées puis déparaffinées au toluène. 
L'émulsion pelliculable KODAK AR io est appliquée sur la lame selon la technique de DONIACH et PELC (1950) et de ZajDeLA (I952). L'émulsion ILFORD K5 est rendue liquide par chauffage au bain-marie à $48^{\circ} \mathrm{C}$. Une grosse goutte d'émulsion est déposée près d'une extrémité de la lame. Une raclette prenant appui par sa collerette sur le bord de la lame chasse l'émulsion devant elle dans un mouvement de translation lent et régulier. Elle assure la répartition de l'émulsion en couche uniforme d'épaisseur constante. Nous avons utilisé principalement une raclette portant un épaulement de $500 \mu$. L'épaisseur de la couche sensible, une fois sèche, est alors de $50 \mu$.

Les lames sont ensuites séchées sous ventilation toute une nuit puis conservées en boîte à l'abri de la lumière dans un château de plomb en sous-sol, $\grave{a} \pm 1^{\circ} \mathrm{C}$. Du chlorure de calcium maintient un taux d'humidité constant à l'intérieur des boîtes.

Après 8 à 15 jours d'exposition, les lames sont révélées à l'aide d'un révélateur à l'amidol pendant io à 30 minutes, selon l'épaisseur de l'émulsion, à 19-20 $0^{\circ} \mathrm{C}$ (FARAGGI, I952).

La composition de ce révélateur est la suivante:

sulfite de sodium anhydre $\ldots \ldots \ldots \ldots \ldots \ldots \ldots \ldots \ldots \ldots$

bromure de potassium à $10 \% \ldots \ldots \ldots \ldots \ldots \ldots \ldots \ldots$

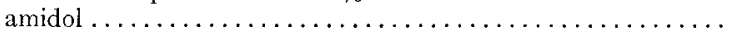

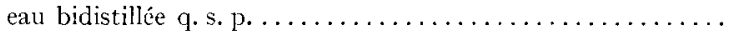

$18 \mathrm{~g}$

$8 \mathrm{~cm}^{3}$

$4,5 \mathrm{~g}$

$1000 \mathrm{~cm}^{3}$

Ce révélateur est préparé dans le noir et utilisé immédiatement.

Les préparations rincées sont passées pendant 5 à 8 minutes dans un bain d'arrêt d'acide acétique à $2 \mathrm{p}$. 100 et enfin fixées après un nouveau rinçage pendant $3^{\circ}$ minutes à 3 heures, selon l'épaisseur de l'émulsion, dans une solution d'hyposulfite de sodium à zoo g, par litre. Après lavage pendant 2 à 3 heures à l'eau du robinet, les coupes sont colorées à l'hémalum de Mayer pendant $15 \mathrm{mn}$, puis après un nouveau lavage, séchées et examinées. 


\section{DURÉE DU TRANSIT ÉPIDIDYMAIRE CHEZ LE TAUREAU}

Par définition, la durée de passage des spermatozoïdes dans l'épididyme est déterminée par la différence entre l'arrivée des spermatozoïdes dans la tête de l'épididyme et 1'arrivée de ces mêmes spermatozoïdes dans le canal déférent, donc pratiquement dans l'éjaculat.

Nous avons vu précédemment que parmi les nombreuses méthodes utilisables pour déterminer ce temps de passage, celle basée sur le marquage des spermatozoïdes par le ${ }^{32} \mathrm{P}$ nous semblait la meilleure. Nous allons voir tout d'abord dans quels constituants des spermatozoïdes le ${ }^{32} \mathrm{P}$ s'incorpore et quels sont ceux qui conviennent le mieux pour l'étude de ce passage.

\section{1. - Incorporation du ${ }^{32} \mathrm{P}$ dans les différents constituants du sperme}

\section{I. - VARIATIONS DE LA RADIOACTIVITÉ DANS LE SANG}

Nous avons vu ainsi qu'immédiatement après l'injection $d u^{32} \mathrm{P}$ une radioactivité très forte apparaît dans le sang. Elle correspond au marquage des composés phosphorés acidosolubles du sérum. Mais très rapidement le phosphore du sérum s'échange avec le phosphore des différents tissus, et moins d'une heure après l'injection, la radioactivité spécifique du phosphore acidosoluble dans le sérum est très faible (fig. 3).

DAwson (I958) a d'ailleurs montré, chez le Bélier, une élimination aussi rapide du ${ }^{32} \mathrm{P}$ dans le sang. C'est une donnée tout à fait classique, mais il était important de la vérifier dans nos conditions expérimentales afin de s'assurer que la plus grande partie du ${ }^{32} \mathrm{P}$ est utilisée dans un laps de temps très court. On peut donc penser que dans les cellules germinales fortement marquées l'incorporation du ${ }^{32} \mathrm{P}$ a été bien localisée dans le temps.

\section{2. - VARIations DE RADIOACTIVIT丢 DANS LE SPERME}

Quand des échantillons de semence sont recueillis régulièrement après l'injection de l'isotope, on constate que le sperme devient immédiatement radioactif. Cette

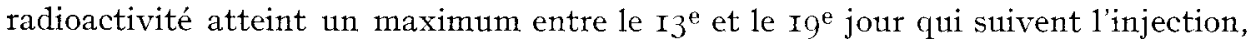
puis décroît jusqu'au $43^{\mathrm{e}}$ jour, pour enfin remonter vers le $52^{\mathrm{e}}$ jour, avant de décroître définitivement vers le $80^{\mathrm{e}}$ jour (tableau 7 , fig. 4). 


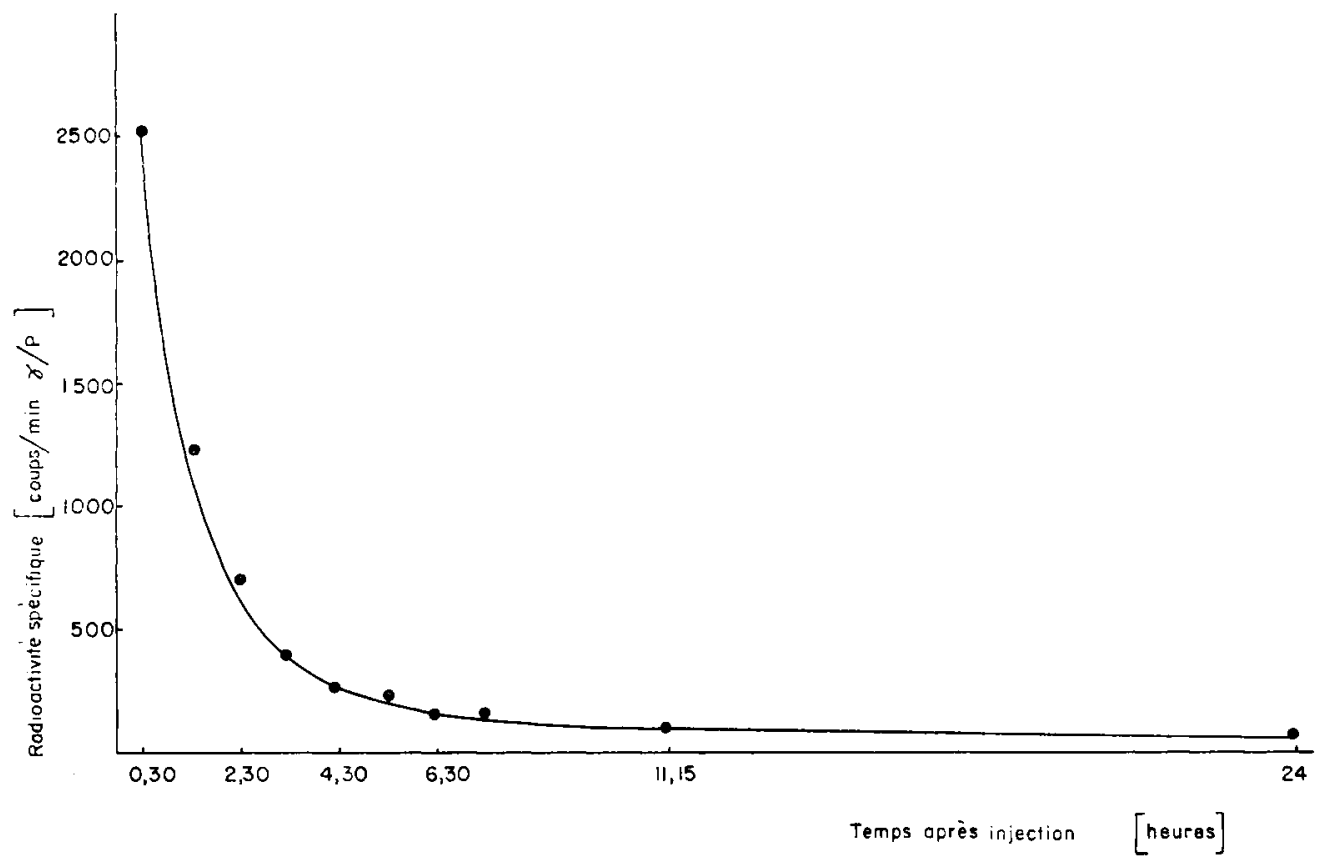

FIG. 3. - Radioactivité spécitique du phosphore acidosoluble du plasma sanguin apres une injection de $50 \mathrm{mC}$ de ${ }^{32} \mathrm{IO}_{4} \mathrm{IIXa}$ par woie intrateineuse

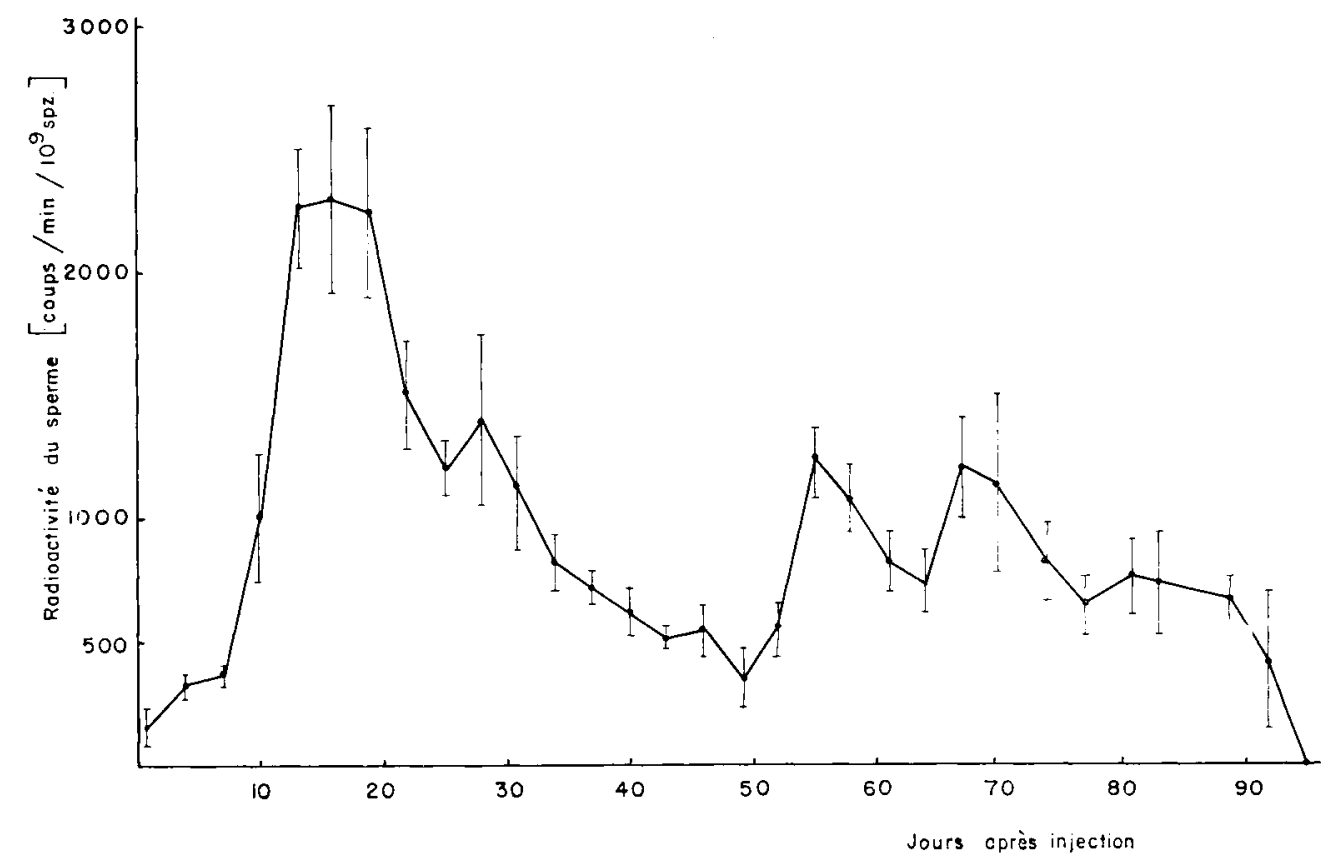

FIG. 4. - Variations de la radioativile dans le sperme de Taureau apres injection

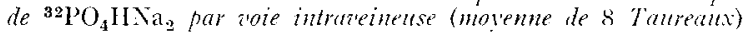




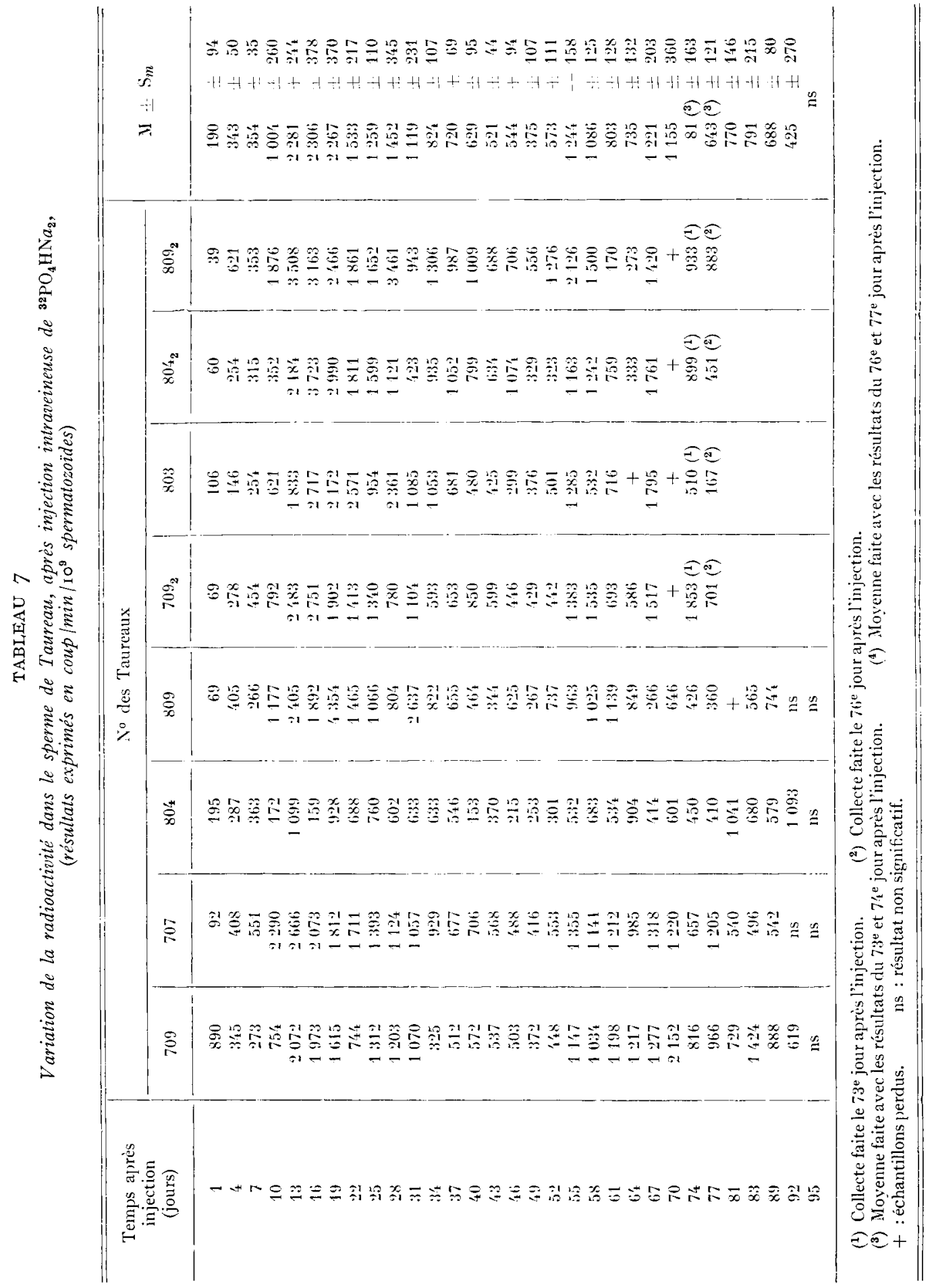




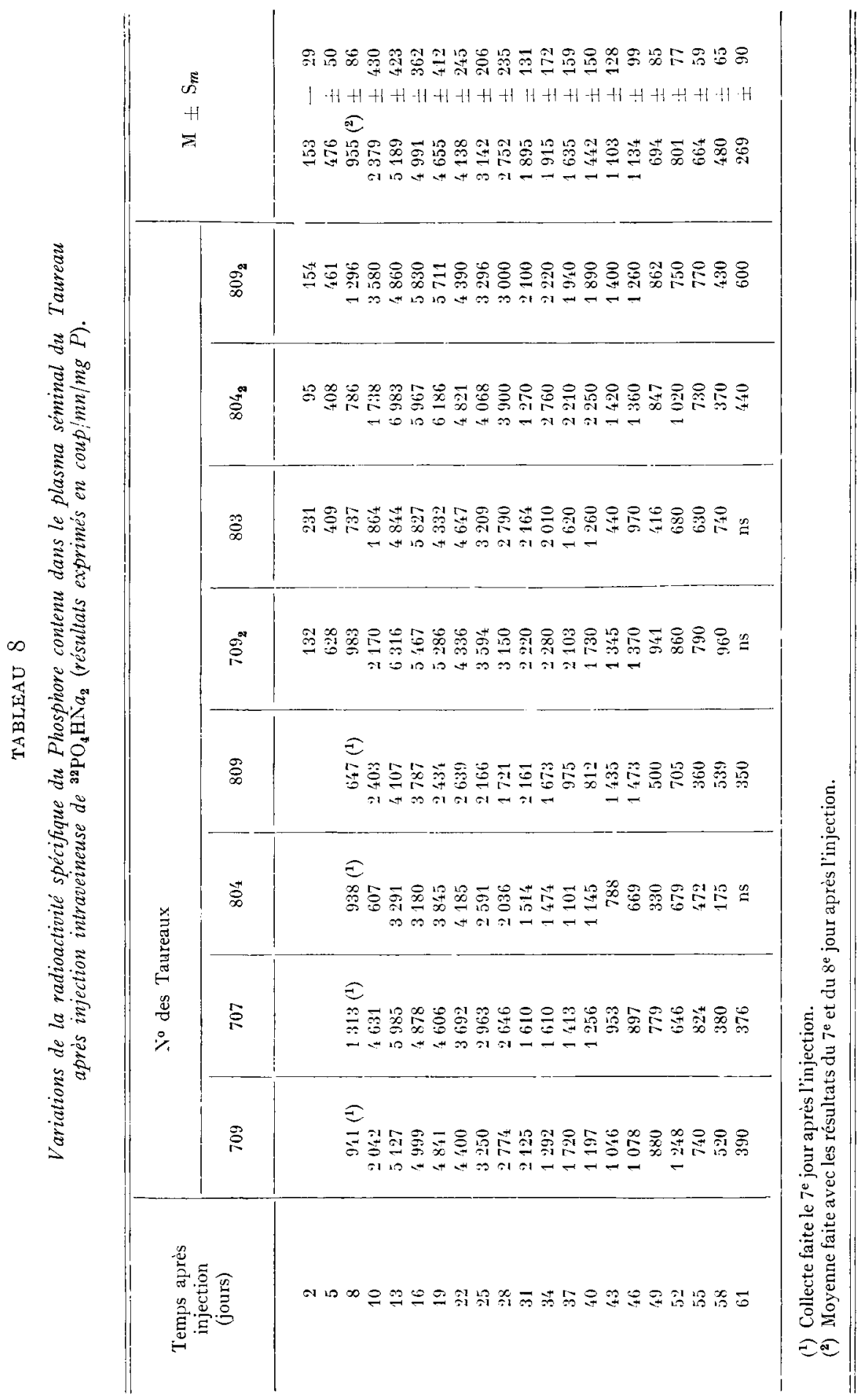




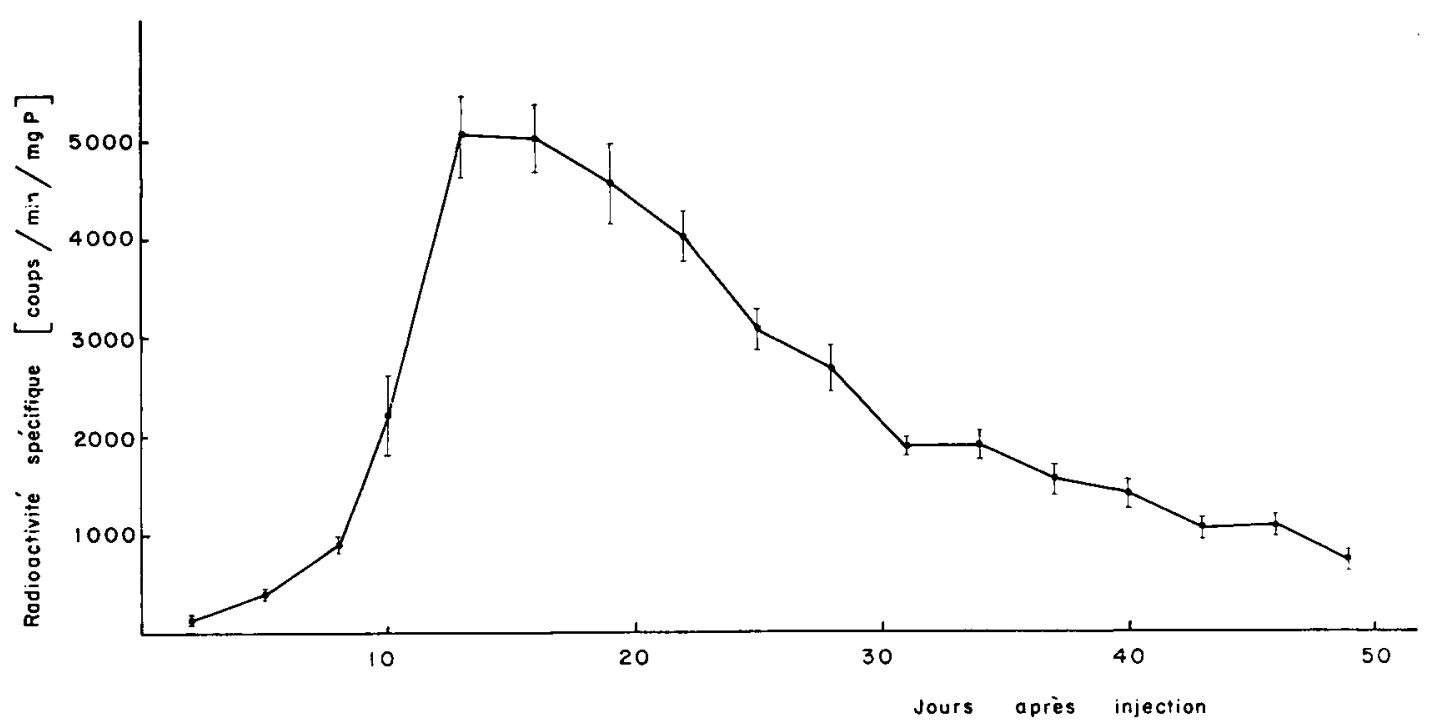

FIG. 5. - Variations de la radioactivité spécifique du phosphore du plasma séminal de Taureau après injection de ${ }^{32} \mathrm{PO}_{4} \mathrm{HNa}_{2}$ par voie intraveineuse (noyenne de 8 Taureaux)

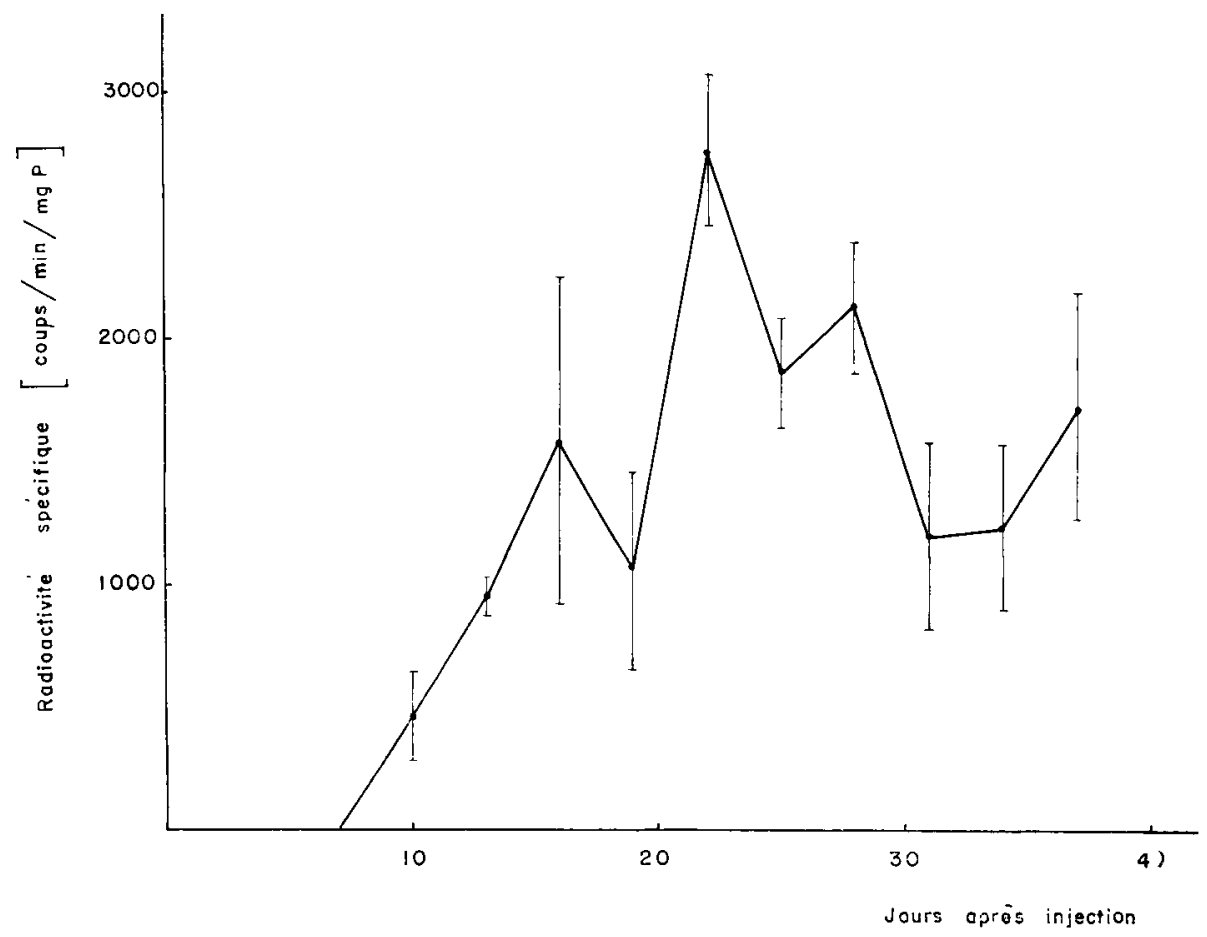

FIG. 6. - Variations de la radioactivité spécifique du phosphore des phospholipides dans les spermatozoüles de Taureau après iniection de ${ }^{32} \mathrm{PO}_{4} \mathrm{IINa}_{2}$ par voit intrateineuse (movenne de 8 Turreatix) 
TRANSIT ÉPIDIDYMAIRE DES SPERMATOZOIDES

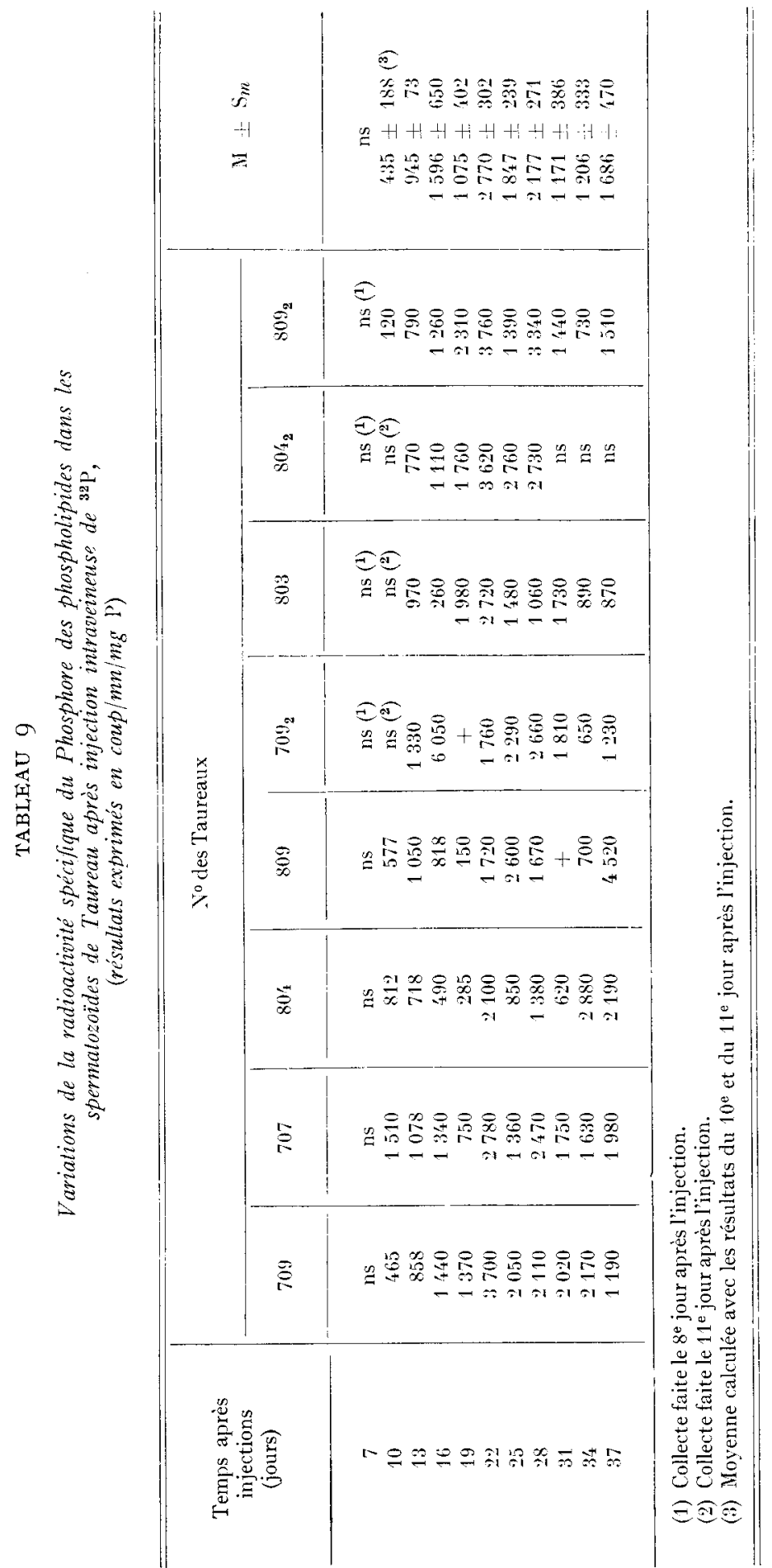




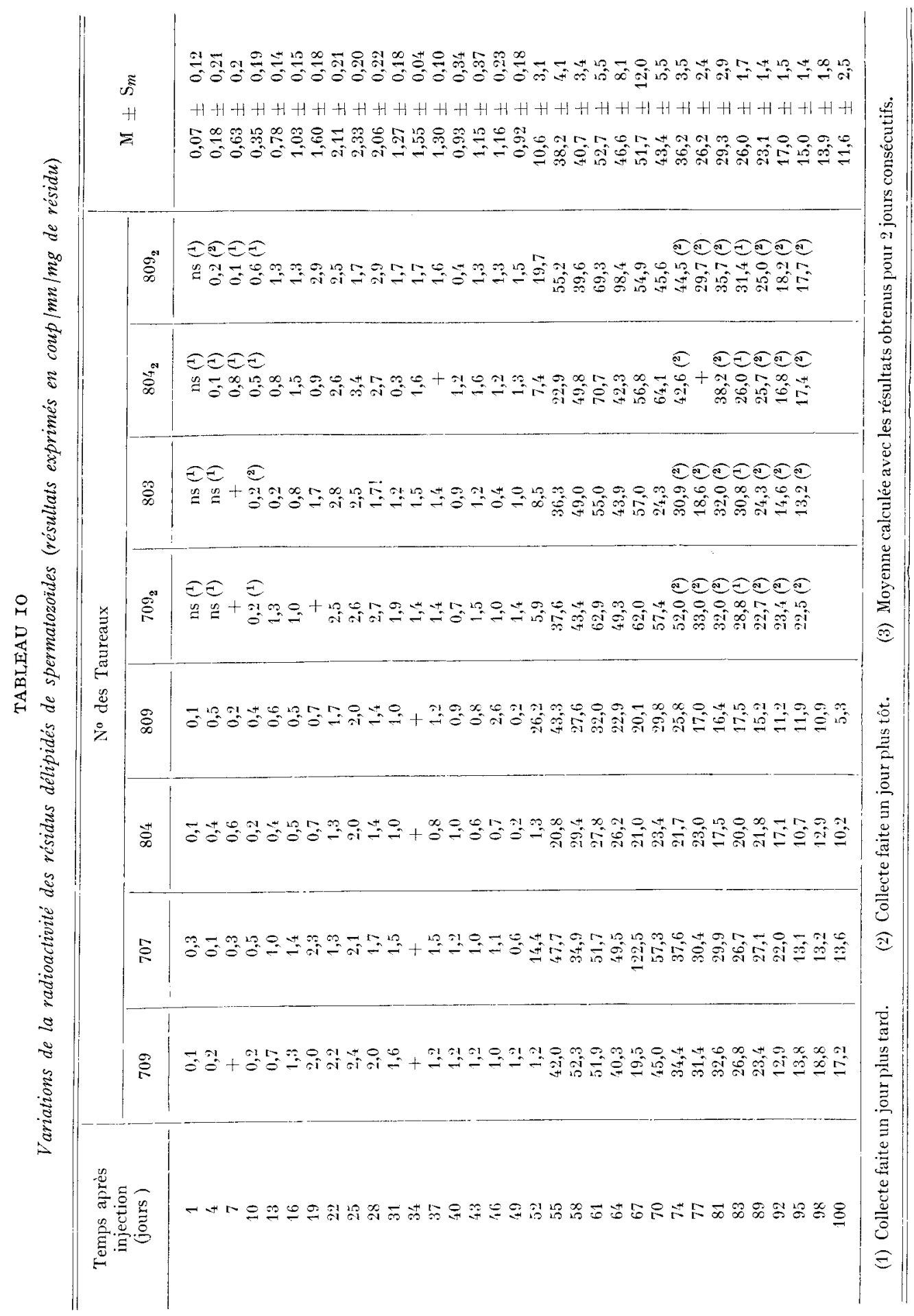


Nous retrouvons donc les 2 ondes de radioactivité depuis longtemps décrites par Lorentz, Cavoulas et Carson (I950) sur le Coq, Ortavant (I954) sur le Bélier, DAwson (I958) sur le Taureau. Ces 2 ondes correspondent, pour la première au marquage dut plasma séminal, et pour le deuxième à celui des spermatozoïdes eux-mêmes.

\section{a) Variations de la radioactivité du plasma séminal}

La courbe donnant la radioactivité spécifique du plasma séminal en fonction du temps atteint un maximum entre 13 et I6 jours (tableau 8, fig 5).

Le plasma séminal chez le Taureau provient du mélange complexe des liquides sécrétés par les épididymes, les canaux déférents, les ampoules déférentielles, les vésicules séminales, la prostate et les glandes de Cowper. Les substances sécrétées sont de nature chimique très différente : fructuose, acide citrique, etc. ; le principa1 composé phosphoré est la glycéryl-phosphoryl-choline. DAwson (I958), en séparant la glycéryl-phosphoryl-choline du plasma séminal par chromatographie, a montré que les courbes donnant les variations de la radioactivité spécifique du plasma total et de la glycéryl-phosphoryl-choline, se superposent exactement. La variation de radioactivité du plasma séminal observée correspond donc à celle de la glycéryl-phosphoryl-choline.

\section{b) Variations de la radioactivité des spermatozoïdes}

\section{x-Phospholipides.}

Les lipides sont principalement localisés dans la gaine mitochondriale de la pièce intermédiaire et dans la capsule lipoïdique des spermatozoïdes (CAvazos, I954). Extraits par le mélange chloroforme-méthanol, ils commencent à être radioactifs vers le $\mathrm{I}^{\mathrm{e}}$ jour après $\mathrm{l}^{\prime}$ injection et atteignent une radioactivité maximum aux environs du $22^{\mathrm{e}}$ jour, soit 6 à 9 jours plus tard que le plasma séminal (tableau 9, fig. 6) .

\section{$\beta$ - Phosphoprotéines et phosphore résiduel.}

Le résidu délipidé présente deux pointes de radioactivité, l'une assez faible entre le $8^{\mathrm{e}}$ et le $25^{\mathrm{e}}$ jour après $1^{\prime}$ injection et 1'autre très marquée, le $49^{\mathrm{e}}$ jour. Il est vraisemblable que cette première onde de radioactivité correspond au marquage des phosphoprotéines nucléaires. Ce maximum de radioactivité apparaît en même temps que celui des phospholipides de la pièce intermédiaire mais ne peut être attribué à une contamination du résidu par ces derniers car les liquides de lavage après l'extraction lipidique ne contiennent pas de phosphore (tableau Io, fig. 7).

Cependant comme nous n'avons pas étudié cette fraction après l'hydrolyse et précipitation de la fraction désoxyribonucléique par de l'acide trichloracétique, les quantités de phosphore étant trop faibles pour obtenir une précision suffisante, nous ne pouvons pas conclure d'une façon certaine sur l'évolution de la radioactivité de cette fraction.

\section{Y - Acide désoxyribonucléique.}

La deuxième onde radioactive observée sur le résidu délipidé correspond au marquage de l'acide désoxyribonucléique des spermatozoïdes. En effet, par extraction à partir de ce résidu, nous avons isolé la fraction désoxyribonucléique et nous avons pu voir que la radioactivité spécifique est nulle jusqu'au $5^{2}$ jour, date à laquelle elle s'élève brusquement pour atteindre un maximum vers 1 e $60^{\circ}$ jour puis décroître 


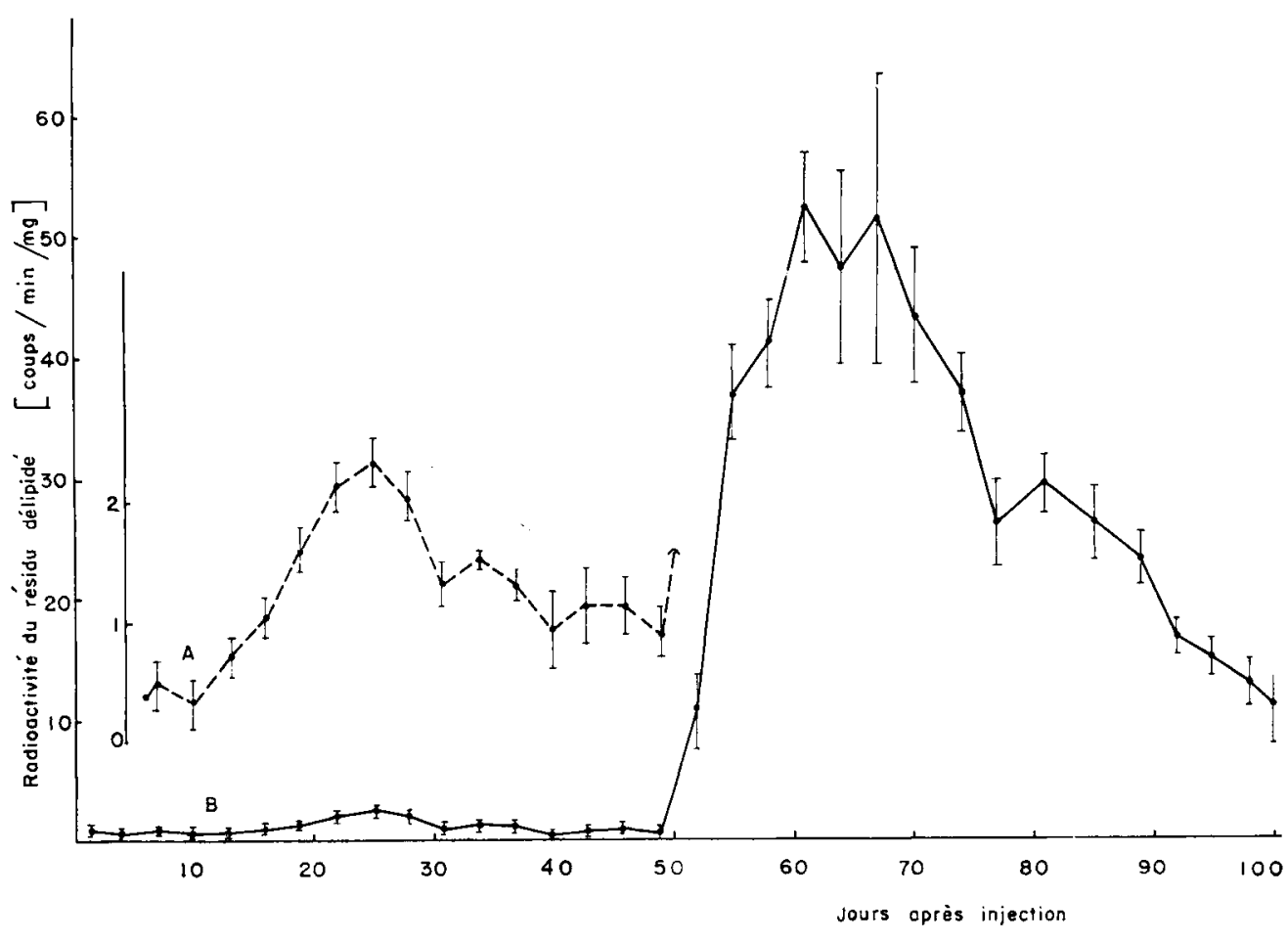

F1G. 7. - Variations de la radioactivité des résidus délipidés dans les spernatozoìdes de Taureau après injection de ${ }^{32} \mathrm{PO}_{4} \mathrm{HNa}_{2}$ par voie intraveineuse (noyenne de 8 Taureaux) - Courbe $\mathrm{A}$ correspond à la contrbe $\mathrm{B}$ d une échelle 10 jois plus grande.

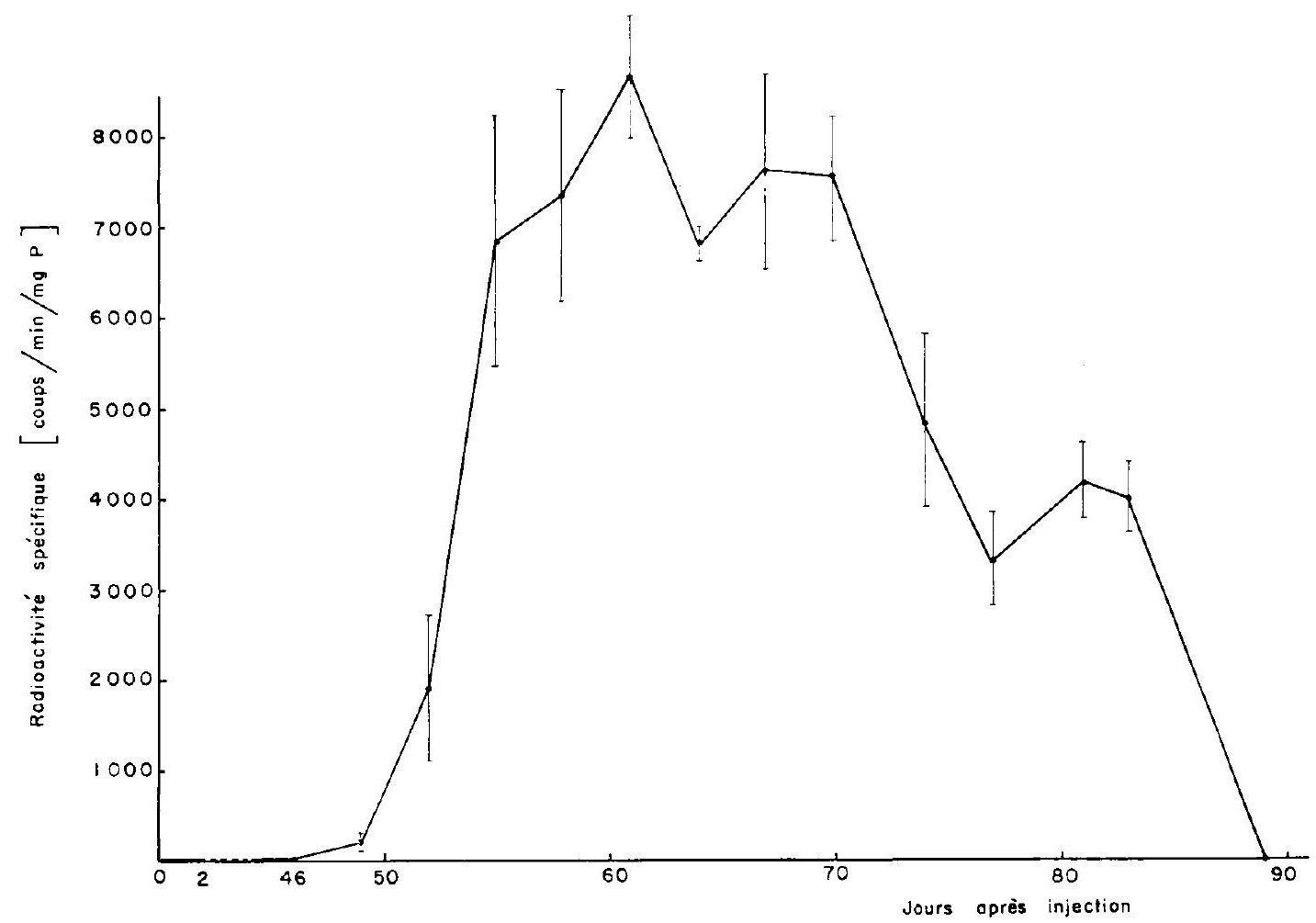

FIG. 8. - Variations de la radioactivité spécifique du phosphore de l'ADN dans les spermatozoïdes de Taureat apres injection de ${ }^{32} \mathrm{PO}_{4} \mathrm{HNa}_{2} \mathrm{par}$ voie intraveineuse (noyenne de 4 animaux) 
jusqu'au $90^{\mathrm{e}}$ jour. Les comptages effectués alors ne sont pas significativement différents du mouvement propre du compteur lui-même (tableau II fig. 8).

\section{TABLEAU II}

Variations de la radioactivité spécifique du $\mathrm{P}$ de l'ADN dans les spermatozoĩdes de Taureau après injection intraveineuse de ${ }^{32} \mathrm{PO}_{4} \mathrm{HNa}_{2}$ (résultats exprimés en coup/mn/mg P)

\begin{tabular}{|c|c|c|c|c|c|c|c|}
\hline \multirow{2}{*}{$\begin{array}{c}\text { Temps après injection } \\
\text { (jours) }\end{array}$} & \multicolumn{4}{|c|}{ Taureaux en expérience } & \multirow{2}{*}{$\mathrm{M}$} & \multirow{2}{*}{\multicolumn{2}{|c|}{$\pm \mathrm{S}_{m}$}} \\
\hline & 709 & 707 & 804 & 809 & & & \\
\hline $46 \ldots \ldots \ldots \ldots \ldots$ & $\mathrm{ns}$ & ns & ns & ns & & ns & \\
\hline $49 \ldots \ldots \ldots \ldots \ldots$ & $3 / 1\left(^{1}\right)$ & $344(2)$ & ns & ns & 171 & \pm & 99 \\
\hline $52 \ldots \ldots \ldots \ldots \ldots$ & $1321(\mathbf{2})$ & 2373 & ns & $3969\left({ }^{2}\right)$ & 1915 & \pm & 839 \\
\hline $55 \ldots \ldots \ldots \ldots \ldots$ & 7553 & 8586 & $2682\left({ }^{2}\right)$ & 8773 & 6898 & \pm 1 & 431 \\
\hline $58 \ldots \ldots \ldots \ldots \ldots$ & 8914 & 9739 & 4361 & 6386 & 7350 & \pm 1 & 225 \\
\hline $61 \ldots \ldots \ldots \ldots \ldots$ & 9635 & $96 / 40$ & 8961 & 6703 & 8734 & \pm & 696 \\
\hline $64 \ldots \ldots \ldots \ldots \ldots$ & + & + & 6916 & 6578 & $67 / 47$ & \pm & 169 \\
\hline $67 \ldots \ldots \ldots \ldots$ & 8175 & 9960 & 4763 & 7740 & 7659 & \pm 1 & 1079 \\
\hline $70 \ldots \ldots \ldots \ldots$ & 8229 & 8952 & 5797 & 7295 & 7568 & \pm & 681 \\
\hline $74 \ldots \ldots \ldots \ldots \ldots$ & 3251 & 7614 & $t_{4} 419$ & 4059 & 4835 & \pm & 959 \\
\hline $77 \ldots \ldots \ldots \ldots \ldots$ & 3736 & 3594 & 4266 & 1798 & 3348 & $\frac{1}{ \pm}$ & 537 \\
\hline $81 \ldots \ldots \ldots \ldots \ldots$ & 5259 & 4165 & 4549 & 3175 & 4287 & \pm & 434 \\
\hline $83 \ldots \ldots \ldots \ldots \ldots$ & 5100 & 3312 & 3452 & 4193 & $l_{1} 014$ & \pm & 411 \\
\hline $89 \ldots \ldots \ldots \ldots \ldots$ & ns & ns & ns & ns & & ns & \\
\hline $92 \ldots \ldots \ldots \ldots \ldots$ & ns & ns & ns & ns & & $\mathrm{ns}$ & \\
\hline
\end{tabular}

(1) $\mathrm{P}=0,08$.

(2) $\mathrm{P}<0,05$.

\section{c) Discussion}

Le ${ }^{32} \mathrm{P}$ s'incorpore donc dans tous les composés phosphorés du sperme, en particulier dans la glycéryl-phosphoryl-choline du plasma séminal, les phospholipides et l'acide désoxyribonucléique des spermatozoïdes. Nous allons voir les raisons qui nous ont amenés à choisir l'acide désoxyribonucléique comme composé de référence pour déterminer la durée du transit épididymaire.

\section{$\alpha$ - Plasma séminal.}

Bien que la glycéryl-phosphoryl-choline du plasma séminal apparaisse marquée dès les premiers éjaculats, le maximum de radioactivité ne se trouve qu'entre le ${ }^{2} 3^{\mathrm{e}}$ et le $\mathbf{I} 6^{\mathbf{e}}$ jour après l'injection. Comme la synthèse s'effectue en grande partie dans la tête de l'épididyme (Dawson I957), le délai entre l'injection de ${ }^{32} \mathrm{P}$ et le moment où la radioactivité de la glycéryl-phosphoryl-choline est maximum dans l'éjaculat doit correspondre au temps de passage du sperme à travers le canal épididymaire. Mais pour pouvoir déterminer celui-ci avec précision il faudrait savoir :

- à quel moment après l'injection la radioactivité de la glycéryl-phosphorylcholine est maximum dans la tête de l'épididyme.

- il faudrait également connaître l'importance de la vitesse de renouvellement du phosphore de la glycéryl-phosphoryl-choline. 
Enfin le temps de transit trouvé correspond au temps de passage du fluide épididymaire et pas nécessairement à celui des spermatozoïdes.

Aussi par suite de ces imprévisions nous ne nous sommes pas basés sur les variations de radioactivité du plasma séminal pour étudier le transit des spermatozoïdes dans l'épididyme.

$\beta$ - Phospholipides.

Les phospholipides peuvent nous apporter des renseignements plus précis et Dawson (1958) les a choisis comme référence pour calculer la vitesse de passage des spermatozoïdes dans l'épididyme. Le ${ }^{32} \mathrm{P}$ s'y incorpore vraisemblablement au cours de la spermiogenèse lors de la formation de la pièce intermédiaire (REDENZ, I924; Cavazos, I924). Nous avons vu qu'ils ont une radioactivité décelable Io à I3 jours après l'injection, le maximum se situant, vers 22 jours.

Ces résultats concordent avec ceux obtenus par DAwson (I958). Cet auteur pense qu'il n'y a pas d'échange appréciable di1 ${ }^{32} \mathrm{P}$ dans des phospholipides une fois que les spermatozoïdes ont quitté le testicule. Il suppose alors que le délai de Io-I4 jours trouvé chez le Bélier pour que les phospholipides marqués apparaissent dans l'éjaculat représente le temps nécessaire pour que les spermatozoïdes parcourent le canal épididymaire.

Mais, comme dans le cas de la glycéryl-phosphoryl-choline, ne connaissant ni le moment précis où le ${ }^{32} \mathrm{P}$ s'incorpore dans les phospholipides, ni la vitesse de renouvellement du phosphore dans ce constituant il est difficile d'en tirer des conclusions précises sur la durée de transit des spermatozoïdes dans l'épididyme.

\section{$\gamma$ - Acide désoxyribonucléique.}

ORTAVANT (I954) choisit l'ADN marqué comme composé de référence, pour suivre la progression des spermatozoïdes, dans l'épidydime du Bélier, car le moment de 1'incorporation du ${ }^{32} \mathrm{P}$ dans 1'ADN des spermatozoïdes est bien connu. TAYLOR (I953) et PLAU' (1954) en étudiant la formation des grains de pollen ont mis en évidence cette incorporation dans l'AIN des noyaux des microsporocytes au stade leptotène. How ARD et PELC (I950) ont montré que, 2 jours après une injection intrapéritonéale de ${ }^{32} \mathrm{P}$ à des Souris, l'isotope était incorporé dans les spermatogonies. ORTAVANT ( I956) a étudié l'incorporation du ${ }^{32} \mathrm{P}$ dans la fraction désoxyribonucléique des cellules germinales de Bélier et a montré que celle-ci s'effectue bien dans les spermatogonies mais aussi dans les jeunes spermatocytes primaires jusqu'au stade préleptotène. Ceci constitue le stade ultime d'incorporation au cours de la spermatogenèse. Cet auteur avait pris la précaution d'éliminer de ses préparations, phospholipides, phosphoprotéines et ARN, par un procédé dérivé de celui de Sulkin (I95I). En présence de désoxyribonucléase il observe d'ailleurs la disparition de toute radioactivité. Dans le cas d'utilisation d'autres isotopes, principalement des précurseurs directs de 1'ADN marqués soit au ${ }^{14} \mathrm{C}$ soit au tritium (SIrLIn et EdDWARds, I955; PELC et Howard, I956 ; Clenmont et $a l$, I959), les conclusions ont été les mêmes.

Ceci confirme les travaux de Caspersson (I940) qui par spectrophotométrie, a montré que la teneur en ADN des noyaux des spermatocytes de Criquet augmente au stade leptotène puis reste constante par la suite. Les spermatocytes contiennent alors la quantité d'ADN exactement nécessaire à la formation des 4 spermatozoïdes qui sont finalement produits (Lison et PAsTeELs, I949; SWIF'T : I950 ; SChrader et 
LEUCHTENBERGER, I950). On connaît done le moment précis où le ${ }^{32} \mathrm{P}$ s'incorpore dans l'ADN au cours de la spermatogenèse.

De plus Ortavant (I956) et Clemmont, LEBlond, Meissier (I959) ont montré que les cellules ayant ainsi incorporé le ${ }^{32} \mathrm{P}$ évoluent de façon strictement synchrone et aboutissent à la libération, dans la lumière des tubes séminifères, de spermatozoïdes ayant le même âge.

Le ${ }^{32} \mathrm{P}$ incorporé dans 1 'ADN du noyau reste ensuite métaboliquement stable. Certains auteurs ont même été jusqu'à penser que dans les cellules dites au repos (foie, rein) l'activité métabolique de l'ADN était nulle (DAVIDSON et LESLIE I950). Le renouvellement de l'ADN dans ces cellules est cependant certain bien que très

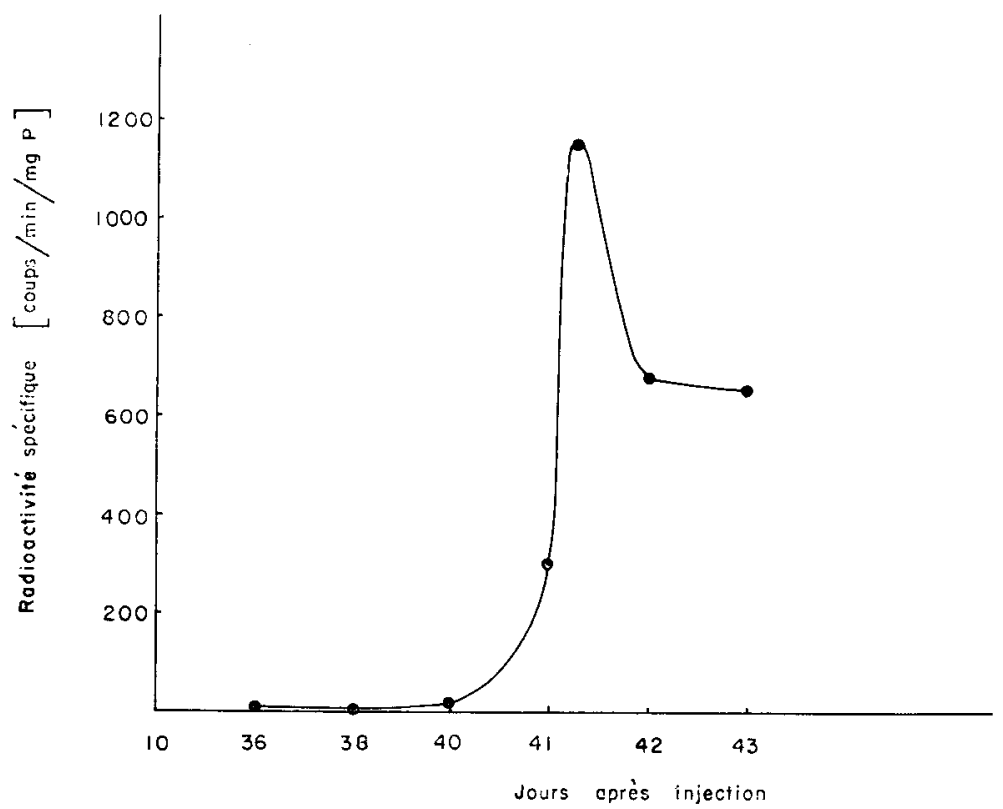

FIG. 9. - Variations de la radioactivité spécifique du phosphore de l'ADN des spermatozoides dans la tête de l'épididyme ches le Taureau après injection de ${ }^{32} \mathrm{PO}_{4} \mathrm{HNa}_{2}$ par voie intraveineuse

lent. BruEs, Tracy et CoHn (I944) ont montré, en utilisant du phosphore marqué, qu'après 3 jours, pas plus de II p. Ioo, et après 8 jours seulement 20 p. Ioo du phosphore de 1'ADN d'un foie non en croissance, s'était renouvelé. La durée de vie de l'ADN serait ainsi très longue, SwICK, Koch et HANDA (I956) l'ont estimée à I5o jour dans le foie de Rat adulte; BENDICH, RUSSEL et BROwN (I953), en comparant les vitesses d'incorporation $\mathrm{du}{ }^{14} \mathrm{C}$ dans $\mathrm{l}$ 'ADN de différents tissus, ont montré que si l'incorporation du marqueur était beaucoup plus faible dans le testicule que dans l'intestin grêle par exemple, le ${ }^{14} \mathrm{C}$ une fois intégré à l'ADN y reste stable, plus stable même que dans le foie. Le ${ }^{32} \mathrm{P}$ incorporé ainsi dans 1 'ADN reste donc stable dans le noyau durant tout le cycle spermatogénétique et peut être transmis aux cellules filles: Howard et Pelc (I950), Pelc et Howard (I956), Or'tavan't (I956). Clemmont, LEBLOND et MEISSIER (I959) en utilisant du tritium ont confirmé ces données. 
En résumé, à cause de ces trois principaux avantages : moment d'incorporation très localisé, évolution synchrone des cellules marquées et enfin renouvellement très lent de l'ADN dans la cellule nous avons choisi de suivre l'ADN marqué des spermatozoïdes.

\section{B. - Détermination expérimentale de la durée du passage des spermatozoïdes dans l'épididyme}

En castrant ro Taureaux à des temps différents après l'injection de ${ }^{32} \mathrm{P}(36,38$, $40,4 \mathrm{I}, 42,43$ jours), nous avons observé que jusqu'au $4 \mathrm{O}^{\mathrm{e}}$ jour après l'injection on ne trouve aucun spermatozoïdes à acide désoxyribonucléique radioactif dans la tête de l'épididyme. Ceux-ci apparaissent 4 I jours après l'injection dans la partie proximale de la tête de l'épididyme (fig. 9).

Pour détecter leur arrivée dans la partie distale de la queue de l'épididyme, nous avons simplement suivi les variations de la radioactivité des spermatozoïdes de l'éjaculat, puisque ceux-ci proviennent des ampoules du canal déférent et de la partie distale de la queue de l'épididyme. Nous avons donné les résultats précédemment (tableau II ; fig. 8) en étudiant 1'incorporation du ${ }^{32} \mathrm{P}$ dans les différents composés phosphorés du sperme et nous avons observé que les spermatozoïdes à acide désoxyribonucléique marqué apparaissent entre le $49^{\mathrm{e}}$ et le $55^{\mathrm{e}}$ jours après l'injection mais dans la majorité des cas ceci se produit le $52^{\mathrm{e}}$ jour. Nous en avons déduit que les spermatozoïdes mettent en moyenne II jours pour traverser l'épididyme.

Ce résultat ne peut cependant être acceptó sans critique car $1 e^{32} \mathrm{P}$ n'est-il pas capable d'altérer les cellules et de perturber le phénomène biologique observé ?

Plusieurs auteurs ont en effet signalé que le ${ }^{32} \mathrm{P}$ injecté à des animaux provoque des dommages importants aux testicules: WARREN, MacmILlan et Dixon (I950) sur la Souris, Russ (I950) sur le Hamster. Avec I $\mu \mathrm{C}$ par gramme de poids vif, Russ a trouvé que la plupart des tubes séminifères sont endommagés et ne renferment plus, 30 jours après l'injection, que des cellules de Sertoli. Chez le Bélier, Ortavant (I958) a constaté qu'avec des doses de I mC par kilogramme de poids vif, il se produit un arrêt des multiplications spermatogoniales, mais que les spermatocytes primaires déjà formés dans les 48 heures qui suivent l'injection continuent à se développer normalement. I1 rejoint en cela l'observation faite par SHAVER (I953) qui, après avoir stérilisé des Rats par les rayons $\mathrm{X}$, montre que la maturation des cellules germinales autres que les spermatogonies se poursuit à la vitesse normale.

En utilisant un autre isotope, le tritium, Johnson et CronkITE (I959) ont montré que l'effet biologique sur les spermatogonies des Souris recevant I $\mu \mathrm{C}$ par gramme de poids vif, correspondait à une irradiation de $5 \mathrm{r}$ par une source de ${ }^{60} \mathrm{Co}$. OAKBERG (I957) estime que cette dose ne ralentit pas le processus spermatogénétique et la maturation des spermatides en spermatozoïdes.

Nous avons administré le ${ }^{32} \mathrm{P}$ à la dose de 0,05 à $\mathrm{o}, \mathrm{I} \mathrm{mC}$ par kilogramme de poids vif, ces doses étant ro fois plus faibles que celles rapportées dans les travaux précédents nous pensons donc ne pas avoir provoqué de perturbations dans la vitesse de 1a spermatogenèse et que le temps de transit des spermatozoïdes dans l'épididyme que nous avons déterminé, correspond à la réalité. 
Il est d'ailleurs intéressant de noter qu'on peut retrouver cette valeur de façon indirecte, par le calcul, d'après les résultats trouvés dans la littérature. OrTavant (I956) et Almouist (I958) ont en effet étudié la distribution des spermatozoïdes dans les différentes parties de l'épididyme du Taureau (tableau I2).

TABLEAU I2

Nombre $\left(\mathrm{x}_{10}{ }^{9}\right)$ et pourcentage des spermatozoïdes dans chaque partie de l'épididyme du Taureau.

\begin{tabular}{|c|c|c|c|c|}
\hline \multirow{2}{*}{ Référence } & \multicolumn{4}{|c|}{ Épididyme } \\
\hline & Queue & Corps & Tête & 'l'otal \\
\hline Crtavant 1956 & $\begin{array}{c}31,8 \pm 2,4 \\
61,9 \%\end{array}$ & $\begin{array}{c}5,2 \pm 0,9 \\
10,1 \%\end{array}$ & $\begin{array}{c}14,3 \pm 1,7 \\
27,8 \%\end{array}$ & 51,3 \\
\hline ALMQUIST 1956. & $\begin{array}{c}37,3 \pm 3,2 \\
59,7 \%\end{array}$ & $\begin{array}{c}4,8 \neq 0,9 \\
7,7 \%\end{array}$ & $\begin{array}{c}20,3 \pm 2,57 \\
32,5 \%\end{array}$ & 62,4 \\
\hline
\end{tabular}

En tenant compte de l'importance relative des réserves spermatiques dans chacune des parties de l'épididyme et en supposant la vitesse des spermatozoïdes uniforme dans le canal épididymaire, il est possible de calctler le temps passé par les spermatozoïdes dans la tête, le corps et la queue de l'épididyme, soit :

$$
\begin{aligned}
& \text { tête }: 2,4 \text { à } 3,3 \text { jours ; } \\
& \text { corps }: 0,7 \text { à } I, 0 \text { jour ; } \\
& \text { queue }: 4,9 \text { à } 6,7 \text { jours. }
\end{aligned}
$$

D'après le tableau II, nous voyons en outre que l'épididyme entier contient en moyenne $56,8 \times \mathrm{IO}^{9}$ spermatozoïdes, connaissant d'une part, la quantité totale de spermatozoïdes contenus dans l'épididyme et d'autre part, la quantité de spermatozoïdes produits quotidiennement par le testicule (5 à $7 \times$ Io ${ }^{9}$ Al,MQUIS', I956) il est facile de calculer le temps nécessaire pour que tous les spermatozoïdes de l'épididyme soient renouvelés. On trouve 8 à II jours, résultats qui se trouve en parfait accord avec la valeur que nous avons déterminée expérimentalement. 


\section{VARIATIONS DANS LA DURÉE DU TRANSIT ÉPIDIDYMAIRE}

Ayant défini le temps que les spermatozoïdes passent dans l'épididyme, dans les conditions de la pratique courante, c'est-à-dire chez des animaux collectés tous les 3 jours, il restait à déterminer les variations possibles de la durée du transit épididymaire dans différentes conditions expérimentales et, en particulier, en fonction de la fréquence des collectes.

\section{A. - Variations dans la durée du transit épididymaire en fonction de la fréquence des collectes}

I. - RECHERCHE DES VARIATIONS DANS LA DATE D'ARRIVÉE DES SPERMATOZÖ̈DES MARQUÉS DANS LA TÊTE DE L'ÉPIDIDYME

OrTavant (I956) et CleRmont, LEBlond et Meissier (I959) ont fait remarquer la stabilité du cycle spermatogénétique chez le Bélier et le Rat. Tous les spermatocytes primaires, formés en même temps, évoluent de façon synchrone et donnent naissance à des spermatozoïdes qui arrivent dans la tête de l'épididyme en ayant le même âge. Nous avons cependant voulu vérifier que la fréquence des collectes n'influe pas sur l'arrivée des spermatozoïdes dans la tête de l'épididyme. Les résultats sont donnés dans le tableau $\mathbf{I}$.

\section{TABLEAU $\mathrm{I}_{3}$}

Influence du nombre de spermatozoüdes collectés sur la date d'apparition dans la tête de l'épididyme de spermatozoides à AI) marqué

\begin{tabular}{|c|c|c|c|c|c|c|c|c|c|c|c|c|}
\hline 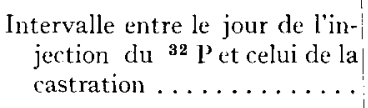 & 36 & 38 & & 40 & & & & 41 & & & 42 & 43 \\
\hline Taureaux $\ldots \ldots \ldots \ldots$ & 702 & 703 & 709 & 701 & 393 & 500 & 705 & 706 & 806 & $70^{\prime}$ & 394 & 556 \\
\hline $\begin{array}{l}\text { Radioactivité spécifique de } \\
\text { l'ADN } \mathrm{cp} / \mathrm{mn} / \mathrm{mg} \mathrm{P}^{\mathrm{P}} \ldots \ldots \ldots\end{array}$ & 0 & 0 & 0 & 0 & 0 & 301 & 420 & 1290 & 1960 & 964 & 685 & 666 \\
\hline $\begin{array}{l}\text { Nombre moyen }\left(\times 10^{9}\right) \text { de sper- } \\
\text { matozoüdes collectés par } \\
\text { jour } \ldots \ldots \ldots \ldots \ldots \ldots \ldots\end{array}$ & 3,0 & 2,8 & 0 & 2,4 & 2,9 & 0 & 0 & 0 & 3,3 & 5,8 & 2,3 & 2,0 \\
\hline
\end{tabular}


On constate que le $40^{\mathrm{e}}$ jour après l'injection il n'existe aucun spermatozoïde à $\mathrm{ADN}$ marqué dans la tête de l'épididyme, que les animaux soient collectés ou non. $\mathrm{Au}$ contraire, $4^{\mathrm{I}}$ jours après cette injection, on trouve toujours des spermatozoïdes marqués.

Ainsi, la fréquence des collectes n'influence pas la date d'apparition des spermatozoïdes radioactifs dans la tête de l'épididyme. Par conséquent, toute modification dans la date d'apparition de ces spermatozoïdes dans l'éjaculat proviendra d'une variation dans la durée du transit épididymaire.

\section{II. - RECHERCHE DES VARIATIONS DANS LA DATE D'ARRIVÉE DES SPERMATOZOIDES MARQUÉS DANS L'ÉJACULAT}

Nous avons recherché le moment où les premiers spermatozoïdes à ADN marqué apparaissent dans l'éjaculat selon que les animaux sont au repos sexuel, collectés 2 à 3 fois par semaine ou soumis à des "tests d'épuisement". Nous appellerons " test d'épuisement" une série de collectes successives effectuées pendant un temps très court, en général 2 à 3 heures, et arrêtées lorsque la concentration des éjaculats est inférieure à Ioo ooo spermatozoïdes par $\mathrm{mm}^{3}$. Cette étude porte sur 28 Taureaux et les résultats sont rassemblés dans le tableau i4 et la figure ro.

Nous avons ainsi trouvé que chez 2 animaux au repos sexuel depuis le jour de l'injection et soumis à un " test d'épuisement " 1'un au $49^{\mathrm{e}}$ jour et l'autre au $5^{2^{\mathrm{e}}}$

\section{TABLEAU I4}

Influence de la quantité de spermatozoüdes collectés sur la date d'apparition des spermatozoïdes à ADN marqué dans l'éjaculat chez le Taureau

\begin{tabular}{|c|c|c|c|}
\hline Taureau & $\begin{array}{c}\text { Nombre moyen }\left(\times 10^{9}\right) \\
\text { de spermatozoïdes col- } \\
\text { lectés par jour entre le } \\
\text { ate jour et le jour } \\
\text { d'apploarition des sper- } \\
\text { matozoïdes a ADX } \\
\text { marqué }\end{array}$ & $\begin{array}{l}\text { Date d'apprarition des } \\
\text { spermatozöles à ADN } \\
\text { marqué dans l'éjaculat }\end{array}$ & Iréquence des collectes \\
\hline $499 \ldots \ldots \ldots \ldots$ & 0 & 49 & épuisement à î j. \\
\hline $801 \ldots \ldots \ldots \ldots$ & 0 & $5 \geq$ & épuisement à $5:$ j. \\
\hline $809 \ldots \ldots \ldots \ldots$ & 1,3 & $\therefore 2$ & \\
\hline $80, \ldots \ldots \ldots \ldots$ & 1,5 & 55 & collecte tous les :3 jours depuis le \\
\hline $709 \ldots \ldots \ldots \ldots$ & 1,7 & 52 & jour de l'injection. \\
\hline $707 \ldots \ldots \ldots \ldots$ & 2,0 & 19 & \\
\hline $804_{2} \ldots \ldots \ldots \ldots$ & 3,1 & 52 & \\
\hline $809_{2}^{4} \ldots \ldots \ldots \ldots$ & 3,3 & 52 & \\
\hline $35773 \quad \ldots \ldots \ldots \ldots$ & 3,7 & 52 & collecte tous les $\because$ jours depuis $\mathbf{6} 6 \mathrm{j}$. \\
\hline $44828 \quad \ldots \ldots \ldots \ldots$ & 3,7 & 50 & \\
\hline $709_{2} \ldots \ldots \ldots \ldots$ & 4,1 & 55 & collecte tous les :3 jours depruis le \\
\hline $803 \ldots \ldots \ldots \ldots$ & 4,3 & 52 & jour de l'injection. \\
\hline $801_{2} \ldots \ldots \ldots \ldots$ & 7,6 & 49 & épuisement à $41 \mathrm{j}$. Collecte quoti- \\
\hline $805 \ldots \ldots \ldots \ldots$ & 9,3 & 49 & dienne à partir de $45 \mathrm{j}$. \\
\hline $499_{2} \ldots \ldots \ldots \ldots$ & $10, x$ & $4 !$ & \\
\hline $706_{2} \ldots \ldots \ldots \ldots$ & 12,6 & 49 & épuisement tous les 2 jours à partir \\
\hline $706 \ldots \ldots \ldots \ldots$ & 13,9 & 47 & de $4 \mathbf{1} \mathrm{j}$ \\
\hline $801_{3} \ldots \ldots \ldots \ldots$ & 14,4 & 49 & \\
\hline
\end{tabular}


jour la radioactivité spécifique de l'ADN, faible dans les premiers éjaculats allait en croissant jusqu'aux derniers éjaculats indiquant ainsi que les spermatozoïdes à ADN marqué étaient déjà arrivés dans la queue de l'épididyme à ces deux dates.

Chez 8 autres Taureaux collectés à raison de 2 éjaculats en moyenne, tous les 3 jours depuis le jour de l'injection, les spermatozoïdes à ADN marqué arrivent le $49^{\mathrm{e}}$ jour après l'injection chez un Taureau, le $52^{\mathrm{e}}$ jour chez 5 autres et le $55^{\mathrm{e}}$ jour chez les 2 derniers. Mais les animaux n'étant collectés que tous les 3 jours la date d'apparition n'est connue qu'avec une précision de 2 jours.

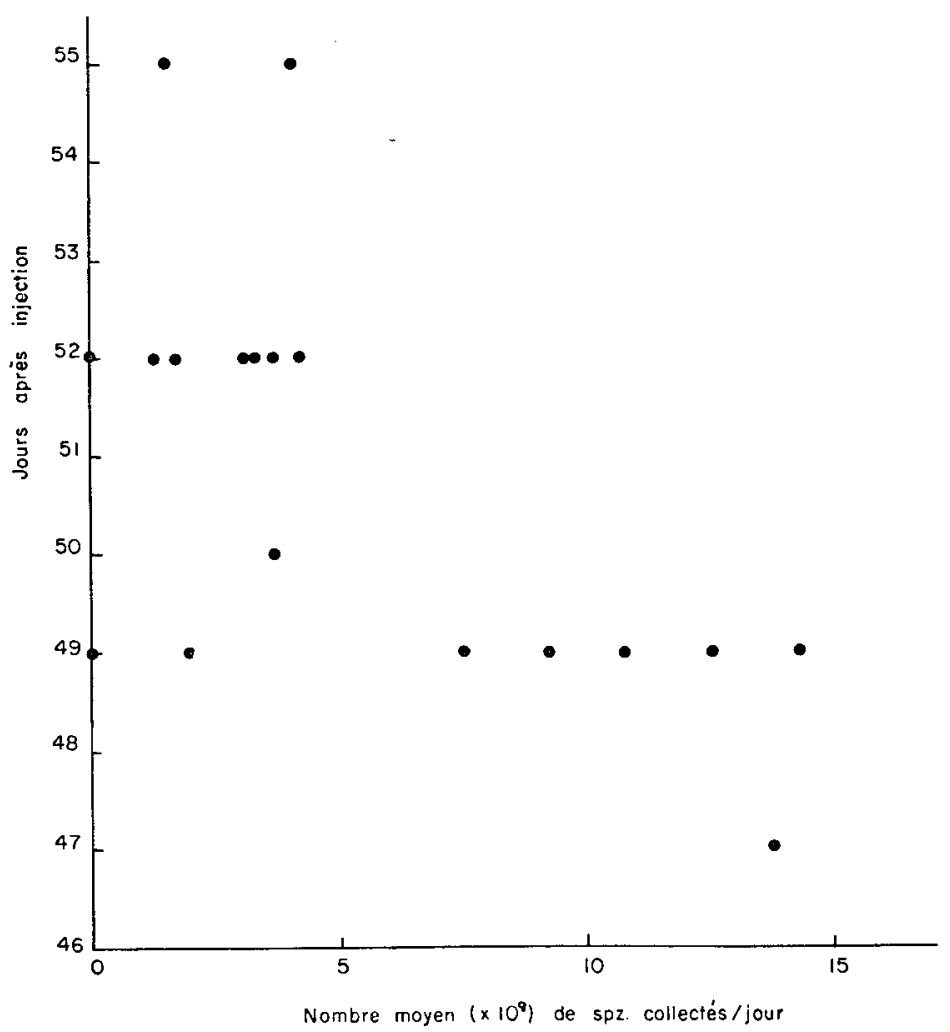

FIG. Io. - Variation du jour de l'apparition des premiers spermalogoïdes à ADN marqué dans l'éjaculat en fonction de la préquence des collectes

Enfin chez 2 animaux laissés au repos sexuel jusqu'au $46^{\mathrm{e}}$ jour après 1'injection puis collectés tous les 2 jours les spermatozoïdes à ADN marqué arrivent dans l'éjaculat le $5^{\mathrm{e}}$ jour après l'injection chez l'un et le $5^{2}$ jour chez l'autre.

En résumé, on voit que les spermatozoïdes à ADN marqué arrivent dans l'éjactulat le $52^{\mathrm{e}}$ jour après l'injection chez 8 Taureaux sur I 2 et ceci que les animaux soient au repos sexuel ou collectés régulièrement. On aurait donc pu conclure que la fréquence des collectes n'a pas d'influence sur la durée de passage des spermatozoïdes dans l'épididyme.

Cependant il faut remarquer que chez tous ces Taureaux le nombre moyen " journalier " de spermatozoïdes collectés entre le $4^{\mathrm{e}}$ et le jour d'apparition des spermatozoïdes marqués est inférieur à $7 \times 10^{9}$, valeur correspondant à la production sper- 
matogénétique quotidienne, estimée par ALMQUisT (I956). Il était donc nécessaire de poursuivre cette étude en augmentant la quantité de spermatozoïdes collectés.

Armquist (I958) étudiant la distribution des spermatozoïdes dans le tractus génital mâle d'un Taureau (Tableau I2 )a montré qu'il est possible, par un test d'épuisement, de vider presque complètement la queue de l'épididyme des réserves spermatiques qui s'y trouvent. Les spermatozoïdes arrivant toujours $1 \mathrm{e} 4 \mathrm{I}^{\mathrm{e}}$ jour après l'injection dans la tête de l'épididyme il doit donc être possible, en procédant à un test d'épuisement à ce moment, d'accélérer le passage des spermatozoïdes dans l'épididyme Les taureaux $n^{\circ} 80 \mathrm{I}$ et 805 ont donc été soumis à un épuisement le $4^{\mathrm{I}} \mathrm{e}$ jour après l'injection de ${ }^{32} \mathrm{P}$. Au cours de ce test, pour chaque animal, $34 \times \mathrm{ro}^{9}$ spermatozoïdes ont été recueillis en 20 sauts consécutifs. Cette valeur, qui correspond bien aux réserves spermatiques de la queue de l'épididyme donnée par Almourst (tablea11 I2) représente environ $60 \mathrm{p}$. Ioo de la totalité des spermatozoïdes contenus dans l'épididyme. Puis ces animaux ont été collectés quotidiennement à partir du $45^{\mathrm{e}}$ jour. Les spermatozoïdes à $\mathrm{ADN}$ marqué sont arrivés dans l'éjaculat 49 jours après 1'injection. La vitesse de passage des spermatozoïdes dans l'épididyme semble donc avoir été légèrement accélérée mais cependant pas dans les proportions que l'on pouvait attendre après avoir épuisé la queue de l'épididyme de tous les spermatozoides qui s'y trouvaient stockés.

Dans une dernière expérience nous avons soumis les taureaux nos $499,706,706$ (2), $80 I_{(2)}$ à des " tests d'épuisement " tous les 2 jours à partir du $4 \mathrm{I}^{\mathrm{e}}$ jour. Les quantités de spermatozoïdes collectés allaient jusqu'à une moyenne de 14,4 . Io ${ }^{9}$ spermatozoïdes par jour, c'est-à-dire 2 fois la production spermagonétique quotidienne estimée par Almouist (I956). Dans ce cas, les spermatozoïdes à ADN marqué apparaissent chez un animal, le $47^{\mathrm{e}}$ jour et chez tous les autres, le $49^{\mathrm{e}}$ jour après l'injection de ${ }^{32} \mathrm{P}$, soit en moyenne 3 jours plus tôt que les chez animaux faiblement collectés.

Nous pouvons donc conclure que si le nombre moyen de spermatozoïdes collectés par iour ne dépasse pas la production spermatogénétique quotidienne, la fréquence des collectes n'infuence pas la vitesse de passage des spermazoïdes dans l'épididymequi est 11 jours environs, mais quand on dépasse la production spermatogénétique quotidienne, la durée du transit peut être raccourcie de 3 jours en moyenne. La fréquence des collectes a donc une infuence faible mais certaine sur la durée du transit épididymaire.

Les conclusions auxquelles nous arrivons ne correspondent pas à celles que KOEFED-JOHNSEN (I960) propose pour ses résultats. Cet auteur pense en effet que la fréquence des collectes n'influe pas sur la date d'apparition des spermatozoïdes marqués dans 1'éjaculat. Mais un examen attentif des résultats donnés par cet auteur (tableau I5) montre que même dans les cas où les fréquences des collectes sont élevées ( 2 à 3 éjaculats par jour) les quantités de spermatozoïdes collectés restent faibles et se situent toujours en deçà de la production spermatogénétique quotidienne sauf dans un seul cas. Dans ces limites, il y a effectivement peu de chances d'observer une accélération de la vitesse de passage des spermatozoïdes dans l'épididyme.

Remarquons que KOEFED-JoHnsen, chez les animaux faiblement collectés, obtient une apparition des spermatozoïdes marqués plus précoce que celle que nous observons. Cette différence est inexplicable, dans notre étude nous n'avons pris en 
TABLEAU I5

Apparition du phosphore radioactif dans l'ADN des spermatozoïdes ëjaculés après injection intra-musculaire de phosphate inorganique marqué à des Taureaux (KOEFED-JOHNSEN, I960).

\begin{tabular}{|c|c|c|c|c|}
\hline \multirow[b]{2}{*}{ No desTaureaux } & \multirow[b]{2}{*}{$\begin{array}{l}\text { Nombre de spermato- } \\
\text { zoüdeséjaculés }\left(\times 10^{9}\right) \\
\text { entre le } 30^{\mathrm{e}} \text { jour et } \\
\text { le jour d'alplparition } \\
\text { rle l'ADN marqué }\end{array}$} & \multirow{2}{*}{ 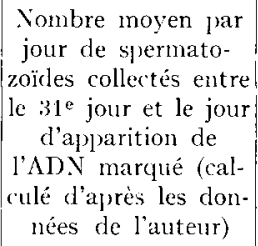 } & \multicolumn{2}{|c|}{ Intervalle (jours) entre l'injection et } \\
\hline & & & $\begin{array}{l}\text { La première appla- } \\
\text { rition du dap } \\
\text { dans l'ADN }\end{array}$ & $\begin{array}{l}\text { Le marquage } \\
\text { maximum du }{ }^{32} \mathrm{Y} \\
\text { de l'ADN (moyenne) }\end{array}$ \\
\hline $\mathrm{F}$ & 15,2 & 0.8 & is & - \\
\hline $18 \ldots$ & $2: 3,5$ & 1,2 & 5) & 69 \\
\hline F.. & 32,9 & $1, t i$ & 50 & $6 i t i$ \\
\hline $18 \ldots$ & 38,5 & 2,1 & 48 & (i) \\
\hline $\mathrm{Ph}$. & 50,2 & $2, i$ & 51 & $6 ; 3$ \\
\hline $\mathrm{F}$. & 45,1 & $\geq, 6$ & 47 & 55 \\
\hline $18 \ldots \ldots$ & $5: 3,7$ & $\because, 0$ & in & 52 \\
\hline Ph ...... & 167,7 & $x, x$ & 49 & 58 \\
\hline
\end{tabular}

considération que les valeurs statistiquement différentes du mouvement propre du compteurs après calcul du test " $t$ ". Évidemment lorsque les collectes ont eu lieu tous les 3 jours, l'apparition n'est connue qu'avec une précision de 2 jours, dans ce cas, les spermatozoïdes à $\mathrm{ADN}$ marqué ont pu apparaître dans l'éjaculat, en moyenne, le $5^{\mathrm{e}}$ jour après 1 'injection, si la quantité de spermatozoïdes collectés est infétieure à la production spermatogénétique quotidienne. Le même argument peut s'appliquer aux animaux fortement collectés et quel que soit le mode de raisonnement, l'écart reste de 2 jours au moins.

\section{III. - RECHERCHES SUR LA VARIATION DE LA DURÉE DE TRANSIT DE PARTICULES RADIOACTIVES}

Nos résultats différant de ceux obtenus par KOEFED-JOHNSEN, il était nécessaire de les vérifier par une autre méthode.

Des particules de charbon de sucre, de la taille des spermatozoïdes, sur lesquelles de l'or radioactif est adsorbé ont été injectées dans le rete testis puis détectées au compteur de Geiger-Muller au moment où elles arrivent dans l'éjaculat Ceci se produit le $8^{\mathrm{e}}$ et le $9^{\mathrm{e}}$ jour après l'injection, chez deux Taureaux ayant donné 5 à Io $\times \mathrm{ro}^{9}$ spermatozoïdes par jour au cours d'une collecte quotidienne et le $5^{\text {e jour chez un }}$ Taureau collecté 5 fois par jour et ayant donné I4 $\times$ Io ${ }^{9}$ spermatozoïdes par jour, c'est-à-dire 3 ou 4 jours plus tôt. Dans ce cas l'augmentation de la quantité de spermatozoïdes collectés a bien diminué la durée du passage des particules dans l'épididyme. Mais on constate que la durée de transit, donnée par cette méthode, ne correspond pas à celle obtenue avec les spermatozoïdes à ADN marqué. Nous avons vu en effet que dans le cas d'injections de particules, un certain nombre de facteurs pouvait modifier la durée de transit observée : volume du liquide injectée ou forme 
des particules. Néanmoins, dans cette étude, le volume de liquide injecté et les dimensions des particules étant toujours les mêmes on peut conclure que l'accélération du passage du sperme dans l'épididyme, que nous avons mis précédemment en évidence, est confirmée par cette expérience.

En conclusion nous pouvons dire que si la fréquence des collectes n'influence pas la date d'apparition des spermatozoïdes à ADN marqué dans la tête de l'épididyme, elle modifie de 2 à 3 jours la date leur arrivé dans l'éjaculat.

\section{B. - Variations de l’àge moyen des spermatozoïdes dans un éjaculat}

Jusqu'à maintenant, nous avons considéré uniquement la date d'apparition des spermatozoïdes à $\mathrm{ADN}$ marqué dans l'éjaculat. Ce moment correspond à l'arrivée des premiers spermatozoïdes parmi ceux issus des spermatocytes qui furent marqués, immédiatement après l'injection. Or nous avons vu que les spermatozoïdes provenant des spermatocytes marqués au stade préleptolène, sont libérés à la sortie du testicule pratiquement au même moment, l'écart ne dépassant pas une trentaine d'heures (Clermont, Leblond et Meissier, I959). On peut se demander si tous ces spermatozoïdes traversent le canal épididymaire à la même vitesse et, en particulier, si la fréquence des collectes n'exagère pas des différences pouvant exister dans la durée individuelle de passage des spermatozoïdes. Dans l'affirmative il y aurait une augmentation des écarts d'âge entre spermatozoïdes d'un même éjaculat, 1'âge d'un spermatozoïde étant par définition, le temps qui s'écoule depuis la formation du spermatocyte primaire jusqu'à l'arrivée du spermatozoïde issu de celui-ci, dans l'éjaculat.

KOEFED-JOHNSEN a essayé de calculer l'âge moyen des spermatozoïdes à partir de la courbe d'activité spécifique de l'AIJN, en recherchant l'âge moyen de tous les spermatozoïdes marqués après une injection de ${ }^{32} \mathrm{P}$. Il applique aux spermatozoïdes le raisonnement qui a permis à SHEMin et RITTENBERG (I946), OTTESEN (I954) de déterminer l'âge moyen d'une population de cellules sanguines. Ces auteurs, connaissant l'activité spécifique de l'ADN des leucocytes et l'activité spécifique du précurseur de l'ADN de ceux-ci, ont établi une équation différentielle qui, par intégration, donne 1'âge moyen de la population cellulaire. KOEFED-JOHNSEN, ne connaissant pas l'activité du précurseur immédiat de l'ADN des spermatozoïdes, suppose que l'activité spécifique du phosphore inorganique de l'urine en donne une approximation assez exacte, et il calcule que, chez le Lapin, l'âge moyen des spermatozoïdes éjaculés est de 65 jours, le maximum de l'activité spécifique de l'ADN étant à 60 jours.

Nous pensons qu'il n'est pas possible d'appliquer cette méthode. On ne connaît pas le précurseur immédiat de l'ADN et le choix de l'activité du phosphore de l'urine semble arbitraire, l'activité du phosphore du plasma sanguin en donnerait une approximation plus exacte. Mais si la radioactivité du phosphore de l'urine est encore appréciable au moment où l'ADN commence à être marqué, celle du plasma sanguin diminue beaucoup plus rapidement et est déjà faible 24 heures après l'injection (fig. 3). D'autre part un échantillon de leucocytes prélevés dans le sang ne peut pas se comparer à un éjaculat. En effet tous les leucocytes sont mélangés dans la circulation 
sanguine, quel que soit leur âge, alors que, dans l'appareil génital, les spermatozoïdes d'âge différent ne sont jamais que très partiellement mélangés.

Quand on considère un éjaculat obtenu quelques jours après l'apparition des spermatozoïdes marqués, la radioactivité spécifique de 1'ADN de cet éjaculat peut être due :

— soit à des spermatozoïdes marqués au même moment que ceux qui sont apparus dans le premier éjaculat radioactif mais qui ont traversé l'épididyme plus lentement :

- soit à des spermatozoïdes qui ont été marqués non plus au stade préleptotène mais antérieurement :

- soit enfin à des spermatozoïdes qui ont pu être marqués au stade préleptotène mais postérieurement à la date d'injection, par du ${ }^{32} \mathrm{P}$ provenant d'un précurseur mis à leur disposition par l'organisme.

Ne voulant pas déterminer l'âge moyen des spermatozoïdes mais ses variations en fonction de la fréquence des collectes, nous avons choisi un éjaculat particulier : celui correspondant à la radioactivité spécifique maximum de l'ADN. On peut penser en effet, que la majeure partie des spermatozoïdes de cet éjaculat, provient des spermatocytes primaires dans lesquels le ${ }^{32} \mathrm{P}$ s'est incorporé immédiatement après l'injection. On obtient ainsi une approximation de l'âge moyen des spermatozoïdes.

En partant de ce critère, et en appliquant deux fréquences de collectes différentes, si nous trouvons que les dates d'apparition des spermatozoïdes radioactifs dans 1'éjaculat diffèrent de $x_{1}$ jours et que la radioactivité maximum varie de $x_{2}$ jours, nous aurons une preuve que tous les spermatozoïdes n'ont pas traversé le canal épididymaire à la même vitesse que les premiers spermatozoïdes récoltés.

\section{Résultats}

Au cours de nos expériences nous avons done recherché, pour différentes fréquences de collectes, où se situe le maximum de l'activité spécifique de l'ADN des spermatozoïdes. Les résultats sont rapportés dans le tableau í 6 et la fig. II.

Compte tenu des précautions prises dans le choix de la dose injectée, la détermination de la courbe donnant l'activité spécifique de l'ADN des spermatozoïdes en fonction du temps n'est pas aisée car les comptages étant effectués plus de 2 mois après l'injection les activités mesurées sont faibles. Dans les cas douteux nous avons pris comme maximum la moyenne des jours où l'activité spécifique de l'ADN est supérieure ou égale à $95 \mathrm{p}$. Ioo de la radioactivité maximum.

D'après la figure I2 nous voyons que les activités spécifiques de 1'ADN des spermatozoïdes sont variables d'un animal à l'autre et que leur comparaison s'avère difficile. Pour pallier cet inconvénient, pour chacune des courbes de variation de cette activité, nous avons dû exprimer en pourcentage l'activité spécifique relative, par rapport à l'activité maximum dans chaque cas. On peut alors établir une courbe moyenne pour chaque lot d'animaux soumis à des fréquences de collectes différentes. Dans le premier lot sont groupés les animaux qui, collectés tous les 3 jours, ont donné entre $1 \mathrm{e} 4^{\mathrm{e}}$ et $1 \mathrm{e} 64^{\mathrm{e}}$ jour après l'injection, un nombre moyen de spermatozoïdes allant de $\mathrm{I}$ à $5 \times \mathrm{IO}^{9}$. Le detuxième lot est constitué par les animaux collectés quotidiennement ou tous les 2 jours et ayant donné entre 5 et ro $\times$ Io ${ }^{9}$ spermatozoïdes par jour (tableaux I7 et I8, figure I3). 


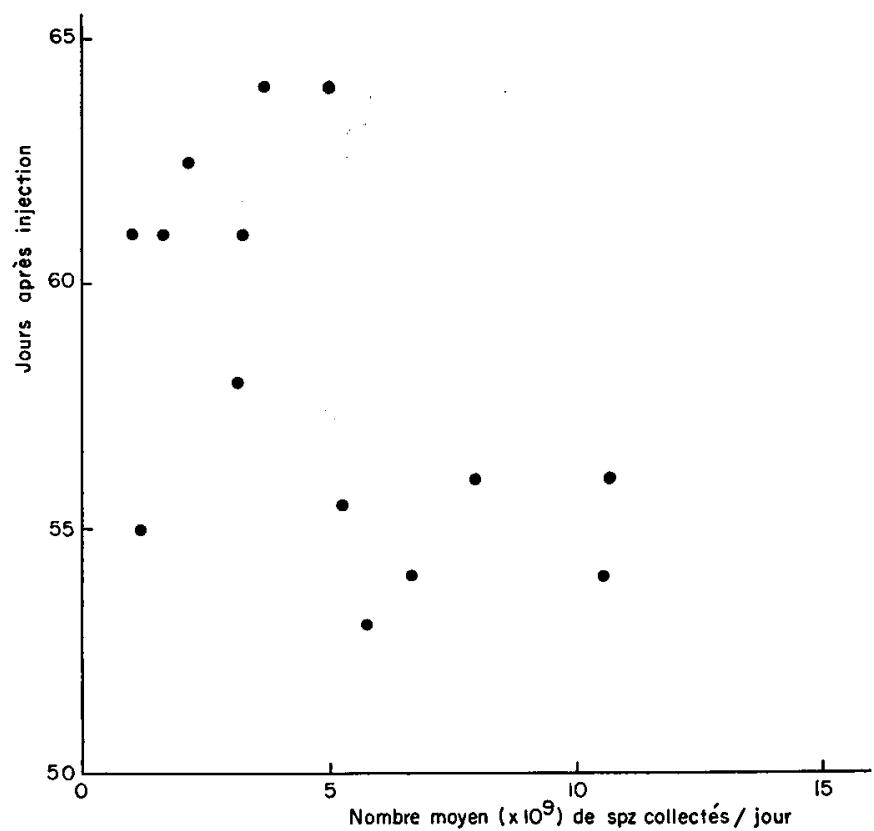

FIG. Ir. - Variation de la date d'activité spécifique de l'ADN en fonction de la fréquence des collectes.
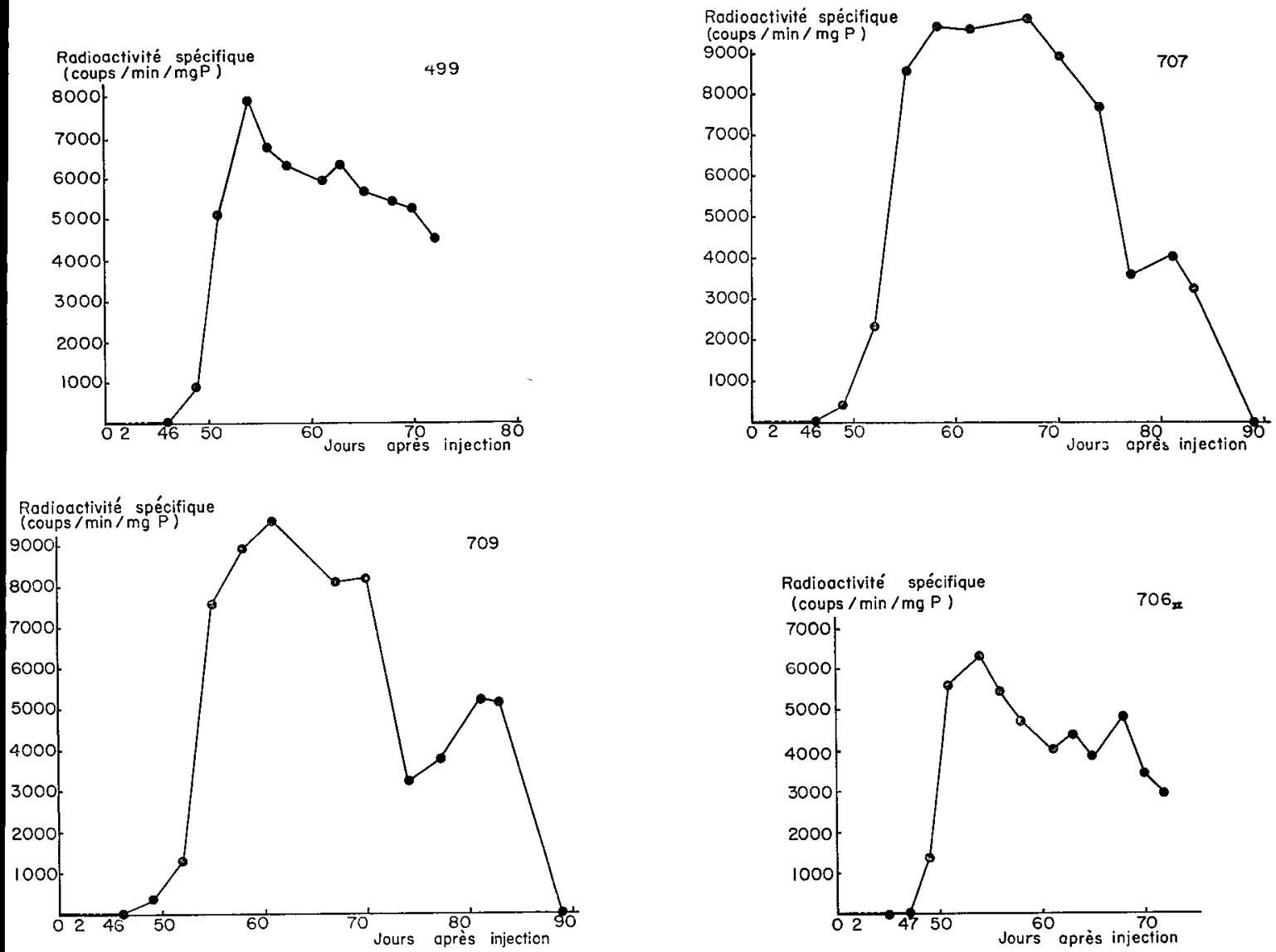

FIG. I2. - Variation de la radioactivité spécifique du phosphore de l'ADN dans les spermatozoides de quatre Taureaux 
TABLEAU I6

Influence du nombre de spermatozoïdes collectés sur la position du maximum d'activité spécifique de l'acide désoxyribonucléique de spermatozoïdes de l'éjaculat chez le Taureau

\begin{tabular}{|c|c|c|c|c|c|}
\hline No de l'animal & $\begin{array}{l}\text { Nombre moyen } \\
\left(\times 10^{9}\right) \text { desperma- } \\
\text { tozoïdes collectés } \\
\text { par jour entre le } \\
40^{\circ} \text { et le } 6^{\prime} \mathrm{e} \text { jour } \\
\text { après l'injection }\end{array}$ & $\begin{array}{l}\text { Intervalle entre } \\
\text { l'injection et la } \\
\text { première appari- } \\
\text { tion du } 32 \mathrm{P} \text { dans } \\
\text { l'ADN des sper- } \\
\text { matozoïdes } \\
\text { éjaculés (jours) }\end{array}$ & $\begin{array}{l}\text { Intervalle entre } \\
\text { l'injection et la } \\
\text { radioactivité ma- } \\
\text { ximum du } \mathbf{3 2} \mathrm{P} \\
\text { dans l'ADN des } \\
\text { spermatozoìdes } \\
\text { éjaculés (jours) }\end{array}$ & $\begin{array}{l}\text { Intervalle entre } \\
\text { l'apparition du } \\
\text { s2P dans l'ADN } \\
\text { et le maximum } \\
\text { de radioactivité } \\
\text { du }{ }^{32} \mathrm{P} \text { dans } \\
\text { l'ADNdessperma- } \\
\text { tozoïdes éjaculés }\end{array}$ & $\begin{array}{l}\text { Fréquence des } \\
\text { collectes }\end{array}$ \\
\hline $804 \ldots \ldots \ldots$ & 1,0 & 55 & 61 & 6 & Collecte tous les \\
\hline $809 \ldots \ldots \ldots$ & 1,1 & 52 & 55 & 3 & 3 jours depuis \\
\hline $709 \ldots \ldots \ldots$ & 1,7 & 52 & 61 & 9 & l'injection. \\
\hline $707 \ldots \ldots \ldots$ & 3,1 & 49 & 62,5 & 13,5 & \\
\hline $\begin{array}{l}35773 \ldots \ldots \ldots \\
4,4828 \ldots \ldots \ldots\end{array}$ & $\begin{array}{l}3,1 \\
3,2\end{array}$ & $\begin{array}{l}52 \\
50\end{array}$ & $\begin{array}{l}58 \\
61\end{array}$ & $\begin{array}{r}6 \\
11\end{array}$ & $\begin{array}{l}\text { Collecte tous les } \\
2 \text { jours à partir } \\
\text { du } 466^{\mathrm{e}} \text { jour après } \\
\text { l'injection. }\end{array}$ \\
\hline $804_{2} \ldots \ldots \ldots \ldots$ & 3,2 & 52 & 61 & 9 & Collecte tous les \\
\hline $709_{2} \ldots \ldots \ldots$ & 3,7 & 55 & 64 & 9 & 3 jours depuis \\
\hline $803 \ldots \ldots \ldots$ & 5,0 & 52 & 64 & 12 & $\begin{array}{l}\text { l'injection. } \\
\text { Épuisement le }\end{array}$ \\
\hline $\begin{array}{l}801 \ldots \ldots \ldots \ldots \\
805 \ldots \ldots \ldots \ldots\end{array}$ & $\begin{array}{l}5,2 \\
5,7\end{array}$ & $\begin{array}{l}49 \\
49\end{array}$ & $\begin{array}{l}55,5 \\
53\end{array}$ & $\begin{array}{l}6,5 \\
4\end{array}$ & $\begin{array}{l}\text { 1 e jour après } \\
\text { l'injection puis } \\
\text { collecte quoti- } \\
\text { dienne. }\end{array}$ \\
\hline $499_{2} \ldots \ldots \ldots$ & 6,6 & 49 & 54 & 5 & Épuisement tous \\
\hline $706 \ldots \ldots \ldots$ & 7,9 & 47 & 56 & 9 & les 2 jours à par- \\
\hline $706_{2} \ldots \ldots \ldots$ & 10,5 & 49 & 54 & 5 & tir du $41^{\mathrm{e}}$ jour \\
\hline $801_{2} \ldots \ldots \ldots \ldots$ & 10,6 & 49 & 56 & 7 & après l'injection \\
\hline
\end{tabular}

\section{TABLEAU I7}

Variation de l'activité spécifque de l'ADN des spermatozoïdes éjaculés chez des animaux faiblement collectés (exprimée en pourcentage de l'activité spócifique maximum)

\begin{tabular}{c|c|c}
\hline $\begin{array}{c}\text { Temps après l'injection } \\
\text { (jours) }\end{array}$ & Moyenne $\pm s_{m}$ & Nombre de données \\
\cline { 1 - 2 } 52 & $20,4 \pm 11,4$ & 7 \\
55 & $60,3 \pm 10,4$ & 7 \\
58 & $68,6 \pm 8,3$ & 9 \\
61 & $88,5 \pm 5,4$ & 7 \\
6. & $87,5 \pm 4,0$ & 7 \\
67 & $79,6 \pm 5,8$ & 7 \\
70 & $76,7 \pm 3,9$ & 7 \\
74 & $51,4 \pm 9,3$ & 4 \\
77 & $35,3 \pm 5,7$ & 4 \\
79 & $38,5 \pm 3,8$ & 3 \\
81 & $45,4 \pm 4,3$ & 4 \\
83 & $41,3 \pm 4,3$ & 4 \\
\hline
\end{tabular}




\section{TABLEAU I8}

Variation de l'activité spécifique de l'ADN des spermatozoïdes éjaculés chez des animaux fortement collectés (exprimée en pourcentage de l'activite' spécifique maximum)

\begin{tabular}{c|c|c}
\hline $\begin{array}{c}\text { Temps après l'injection } \\
\text { (jours) }\end{array}$ & Moyenne $\pm \mathrm{S}_{m}$ & Nombre de données \\
\hline 49 & $-1,5 \pm 7,1$ & 6 \\
51 & $63,0 \pm 8,1$ & 6 \\
54 & $88,4 \pm 5,0$ & 6 \\
56 & $88,5 \pm 5,9$ & 6 \\
58 & $77,7 \pm 1,3$ & 4 \\
61 & $73,6 \pm 4,6$ & 4 \\
63 & $56,7 \pm 5,2$ & 4 \\
72 & $55,7 \pm 4,0$ & 4 \\
\hline
\end{tabular}

Dans le premier lot on constate que la date d'apparition de la radioactivité de $1^{\prime} \mathrm{ADN}$ a lieu en moyenne le $5^{2} \mathrm{e}$ jour après 1 'injection, cette radioactivité augmente rapidement jusqu'à un maximum situé à 62,5 jours puis décroît lentement jusqu'au $84^{\mathrm{e}}$ jour après l'injection date à laquelle les activités observées ne sont plus significativement différentes du mouvement propre du compteur.

Dans le deuxième lot on constate que l'apparition des spermatozoïdes marqués

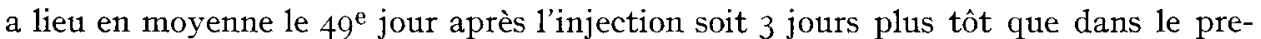
mier lot et que le maximum de la courbe de l'activité spécifique de l'ADN se situe 1e $55^{\mathrm{e}}$ jour, soit 7,5 jours plus tôt.

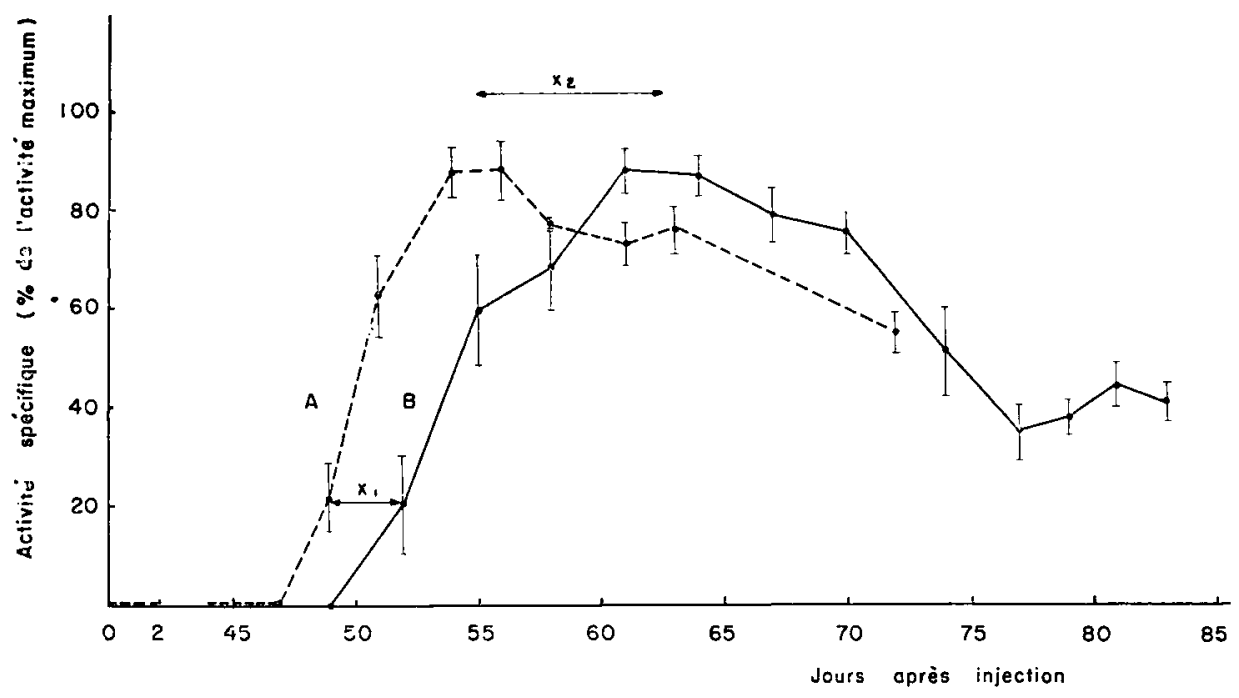

FIG. I3. - Variations de la radioactivité spécifique de l'ADN des spermatozoüdes éjaculés Courbe $\mathrm{A}$ chez des animaux fortement collectés - Courbe $\mathrm{B}$ chez des animaux faiblement collectés 
Nous avons voulu confirmer les données précédentes en recherchant l'effet de la fréquence des collectes sur le maximum de l'activité spécifique du plasma séminal après injection de ${ }^{32} \mathrm{P}$. Dans le cas d'animaux collectés tous les 3 jours et donnant I à $5 \times \mathrm{IO}^{9}$ spermatozoïdes par jour, le maximum de la radioactivité spécifique se situe en moyenne à I4,2 jours. Chez les animaux donnant de 5 à Io $\times$ I $0^{9}$ spermatozoïdes par jour, le maximum se situe en moyenne à 8,8 jours. Les résultats sont rassemblés dans le tableau I9 et les figures I4 et I5. On observe donc une différence de 5,4 jours résultats assez comparable à celui que nous avons trouvé en étudiant les variations de l'activité spécifique de l'ADN des spermatozoïdes.

\section{TABIEAU IO}

Influence du nombre des spermatozoïdes collectés sur l'intervalle entre l'injection et le maximum de radioactivité du ${ }^{32} \mathrm{P}$ dans le plasma séminal de Taureau

\begin{tabular}{|c|c|c|c|}
\hline Numéro de l'animal & $\begin{array}{l}\text { Nombre moyen }\left(\times 10^{9}\right) \text { par } \\
\text { jour des sjermatozoïdes } \\
\text { collectés jusqu'au } 16^{\mathbf{e}} \\
\text { jour suivant l'injection }\end{array}$ & $\begin{array}{l}\text { Intervalle entre l'injection } \\
\text { et le maximum de la } \\
\text { courbe (jours) }\end{array}$ & Fréquence des collectes \\
\hline 804 & 1,5 & 22 & \multirow{12}{*}{ Collecte tous les 3 jours } \\
\hline 809 & 1,8 & 13 & \\
\hline 707 & 2,0 & 13 & \\
\hline 709 & 2,2 & 13 & \\
\hline $709_{2}$ & 2,4 & 13 & \\
\hline $804_{2}$ & 2,5 & 13 & \\
\hline $809_{2}$ & 2,6 & 16 & \\
\hline $556^{2}$ & 2,8 & 11 & \\
\hline 803 & 2,9 & 16 & \\
\hline 701 & 3,2 & 15 & \\
\hline 703 & 3,8 & 15 & \\
\hline 702 & 4,0 & 11 & \\
\hline 33830 & 7,0 & 9,5 & \multirow{3}{*}{$\begin{array}{l}\text { Épuisement } \\
\text { tous les } 2 \text { jours }\end{array}$} \\
\hline $2668^{\prime} \mathrm{x}$ & 8,0 & 9 & \\
\hline $\left.\begin{array}{c}26684^{2} \\
162\end{array}\right\}$ & 9,0 & 8 & \\
\hline
\end{tabular}

KOEFED-JOHNSEN observe également au cours de ses expériences (tableau $\mathrm{I}_{4}$ ) une variation dans les dates des maxima de la courbe de l'activité spécifique de l'ADN en fonction du nombre des collectes, ce qui est en accord avec nos données.

Ainsi il est certain que la date du maximum de radioactivité spécifique de 1'ADN des spermatozoïdes subit un déplacement important en fonction de la fréquence des collectes.

La différence $x_{1}=3$ jours entre les dates d'apparition des premiers spermatozoïdes marqués dans les 2 lots d'animaux n'est pas égale à la différence $x_{2}=7,5$ jours entre les dates où le maximum d'activité est atteint. il en résulte que suivant la fréquence des collectes tous les spermatozoïdes ne traversent pas le canal épididymaire à la même vitesse et que l'âge des spermatozoïdes les plus jeunes n'a pas été influencé 


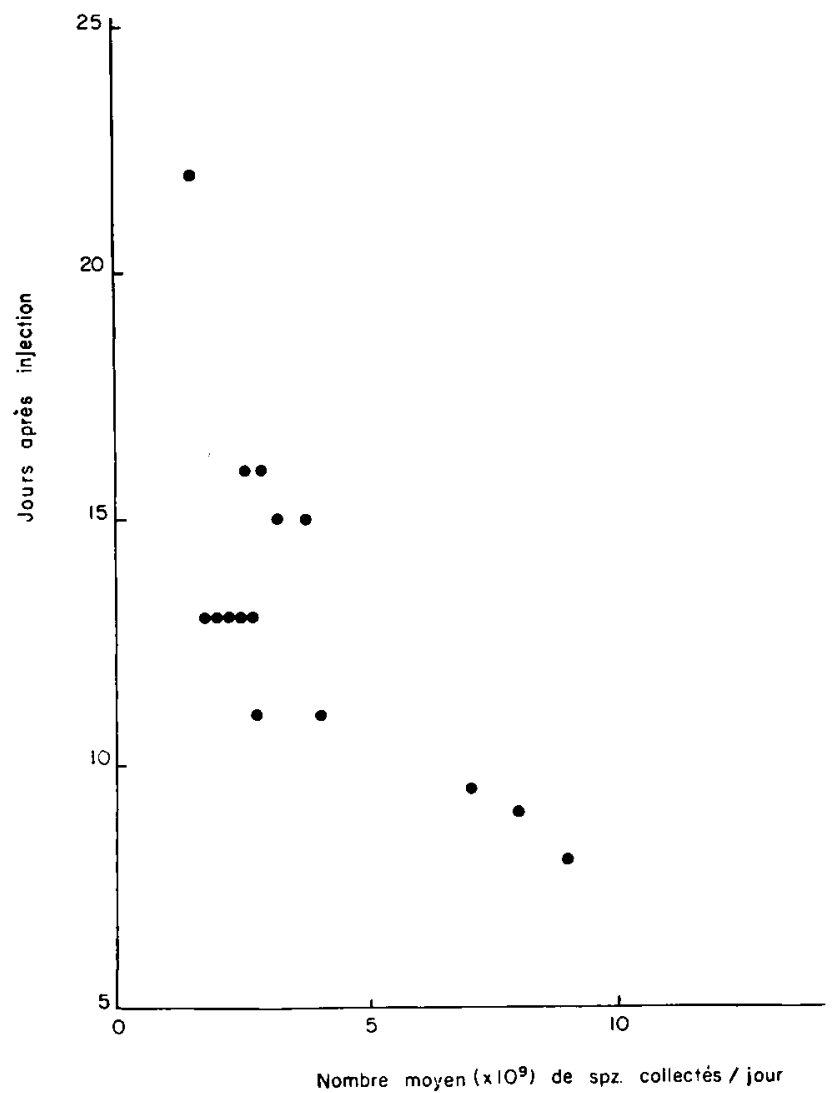

FIG. 14. - Variation de la date du maximum d'activité spécifique du plasma séminal en fonction de la fréquence dés collectes
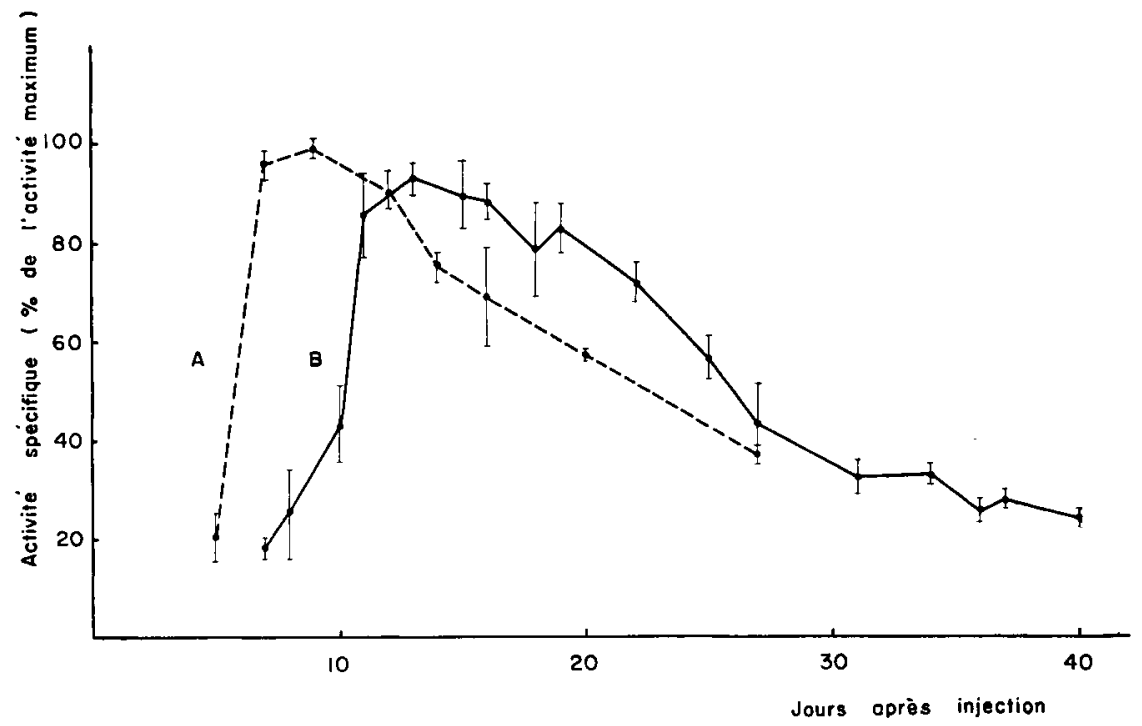

FIG. I5. - Variation de la radionctivité spécifique du plasma séminal : Courbe A chez des animaux fortement colleciés. Courbe $\mathrm{B}$ chez des animaux faiblement collectés

Annales de Biologic animale. - 1962. 
de la même façon que 1'âge moyen des spermatozoïdes par la fréquence des collectes.

Il y a donc un mélange des spermatozoïdes au cours de la traversée du canal épididymaire. Il est d'ailleurs d'observation courante qu'un éjaculat ne constitue pas une population homogène, certains spermatozoïdes étant très motiles d'autres moins et certains pas du tout. Ceci laisse penser que les spermatozoïdes d'un éjaculat n'ont pas tous le même âge.

Nous avons voulu voir comment s'opérait ce mélange des spermatozoïdes. A cet effet, 1'épididyme d'animaux injectés avec du ${ }^{32} \mathrm{P}$ est prélevé par castration, puis coupé en série. Par autoradiographie nous avons cherché à repérer à chaque niveau de l'épididyme les spermatozoïdes à ADN marqué. Cette méthode ne nous a pas donné de bons résultats car la radioactivité d'un seul spermatozoïde est trop faible pour impressionner l'émulsion autoradiographique. Aussi avons-nous utilisé des particules de charbon de sucre sur lesquelles de $1^{\prime 198} \mathrm{Au}$ était adsorbé. Après injection dans le rete testis nous avons constaté que :

- 48 heures après 1'injection, les particules sont groupées dans la partie distale de la tête de l'épididyme ; didyme ;

- 5 jours après l'injection les particules sont arrivées dans la queue de l'épi-

- et 6 jours après l'injection, elles sont dispersées dans toute la queue de l'épidyme et dans le canal déférent. Il semble donc que les particules une fois arrivées dans la queue de l'épididyme ne progressent pas toutes à la même vitesse.

Le phénomène est certainement identique pour les spermatozoïdes : certains sont déjà dans le canal déférent alors que d'autres, formés en même temps, ne sont encore que dans la partie proximale de la queue de l'épididyme. L'existence de ce mélange de spermatozoïdes permet de comprendre la présence de spermatozoïdes morts dans un éjaculat alors que d'autres sont très mobiles.

En conclusion, nous pouvons dire que dans le canal épididymaire, chez le Taureau, tous les spermatozö̈des n'avancent pas à la même vitesse, et qu'un éjaculat représente une population hétérogène de spermatozoïdes.

\section{DISCUSSION}

\section{A. - Variations DaNs la dURÉE DU TRANSit ÉPIDIDYMATRE SELON LES ESPÈCES}

La vitesse de passage des spermatozoïdes dans l'épididyme n'est pas la même selon les espèces. Les valeurs que nous avons indiquées dans la revue bibliographique variaient considérablement d'une espèce à une autre mais il était difficile de comparer entre eux des résultats provenant de l'utilisation de méthodes différentes. Aussi nous nous bornerons à comparer le Taureau au Bélier et au Verrat puisque la vitesse de passage des spermatozoïdes dans l'épididyme a été déterminées chez ces deux dernières espèces selon la même méthode (ORTAVANT, I956 ; Singh, I962). ('Tablea11 20.) 
TABLEAU 20

Temps de passage des spermatozoïdes dans l'épididyme quand les animaux sont régulièrement collectés

\begin{tabular}{|c|c|c|c|c|c|}
\hline Espèce & $\begin{array}{l}\text { Intervalle entre } \\
\text { l'injection et la } \\
\text { 1re apparition } \\
\text { du }{ }^{32} \mathrm{P} \text { dans } \\
\text { l'ADN des } \\
\text { spermatozoüdes } \\
\text { de la tête de } \\
\text { l'épididyme }\end{array}$ & $\begin{array}{l}\text { Intervalle entre } \\
\text { l'injection et la } \\
\text { 1re apparition } \\
\text { du }{ }^{2} \mathrm{P} \text { dans } \\
\text { l'ADN des } \\
\text { sperma tozoïdes } \\
\text { éjaculés }\end{array}$ & $\begin{array}{c}\text { Durée de } \\
\text { transit (jours) }\end{array}$ & $\begin{array}{l}\text { Nombre de } \\
\text { collectes par } \\
\text { semaine }\end{array}$ & Référence \\
\hline Taurcau... & 11 & $49-52$ & $8-11$ & $3-7$ & ORGEBIN (1961) \\
\hline Bélier ... & 30 & $42-45$ & $12-15$ & 7 & (ORTAVANT (1956) \\
\hline Verrat .... & 25 & 39 & $1 / t$ & 2 & SINGH $(1962)$ \\
\hline
\end{tabular}

On constate que si la durée de la spermatogenèse va en diminuant du Taureau au Bélier et au Verrat la durée du transit épididymaire semble varier en sens inverse dans des conditions expérimentales voisines.

ORTAVANT a rapporté (1956) que la fréquence des collectes influence le transit épididymaire chez le Bélier, en castrant des Béliers au repos sexuel, les spermatozoïdes radioactifs ne sont présents dans la partie distale de la quene de l'épididyme que le $5^{\mathrm{I}}$ jour après l'injection : la durée du transit épididymaire est alors de $\mathrm{I} 8$ à $2 \mathrm{r}$ jours. Nous avons vu que chez un Taureau collecté pour la $\mathrm{I}^{\mathrm{re}}$ fois le $5^{\mathrm{I}} \mathbf{e}$ jour après $1^{\prime}$ injection on trouve des spermatozoïdes radioactifs dès les premiers éjaculats. La vitesse de transfert des spermatozoïdes dans l'épididyme semble donc moins influencée chez le Taureau que le Bélier. Les modalités de passage des spermatozoïdes dans l'épididyme, chez ces deux espèces, pourraient donc être différentes. D'ailleurs, les réserves spermatiques du Bélier sont relativement plus élevées que celles du Taureau. Les réserves de la queue de l'épididyme du Bélier sont suffisantes pour une quarantaine d'éjaculations alors que celles du Taureau ne représentent que 7 à 8 éjaculats.

On constate également que la vitesse de passage dans l'épididyme est en rapport inverse avec la quantité de spermatozoïdes mis en réserve dans cet organe (tableau 2I) Chez le Bélier et le Verrat où les réserves spermatiques sont sensiblement les mêmes, la durée du transit épididymaire est peu différente.

\section{TABLEAU 2 I}

Nombre total de spermatozoïdes dans l'épididyme de Taureau de Bélier et de Verral (moyenne 上 erreur slandard)

\begin{tabular}{|c|c|c|c|}
\hline Espèce & $\begin{array}{l}\text { Nombre total cle } \\
\text { spermatozoïdes } \times 10^{9}\end{array}$ & Nombre d'animaux & Référence \\
\hline Taureau..................... & $\begin{array}{l}70,9 \pm 14,3 \\
51,3 \pm 5,0\end{array}$ & $\begin{array}{r}8 \\
15\end{array}$ & $\begin{array}{l}\text { Almovist }(1958) \\
\text { ORTAVANT }(1956)\end{array}$ \\
\hline Bélier $\ldots \ldots \ldots \ldots \ldots \ldots \ldots$ & $\begin{array}{l}162 \\
160,6 \pm 14,1\end{array}$ & $\begin{array}{l}13 \\
15\end{array}$ & $\begin{array}{l}\text { POLOVCEVA (1938) } \\
\text { ORTAVANT }(1956)\end{array}$ \\
\hline Verrat $\ldots \ldots \ldots \ldots \ldots \ldots \ldots$ & $\begin{array}{l}175-300 \\
142,9 \cdot 193 \\
190,8 \pm 8,3\end{array}$ & $\begin{array}{r}17 \\
8\end{array}$ & $\begin{array}{l}\text { NovoseljCev (1951) } \\
\text { KenNELLY (1960) } \\
\text { Singh }(1962)\end{array}$ \\
\hline
\end{tabular}




\section{B. - FRÉQUENCE DES COILECTES ÉT HÉTÉROGÉNÉITÉ DE L'ÉJACULAT}

Nous voyons en effet qu'en laissant un animal au repos sexuel ou en le collectant peu fréquemment, les spermatozoïdes obtenus dans un éjaculat sont très hétérogènes, la majorité d'entre eux commencent à subir des processus de vieillissement du fait de leur séjour prolongé dans l'épididyme. Ceci vient confirmer les observations de WiLLET et OHMS (I958), WALES et WhiTe (I959), de Groot (I96I) montrant que les spermatozoïdes du premier éjaculat sont moins résistants au choc thermique et moins mobiles que les spermatozoïdes du deuxième éjaculat, obtenu au cours d'une même collecte.

En augmentant la fréquence des collectes nos résultats montrent que les éjaculats obtenus sont plus homogènes, les écarts d'âge entre les spermatozoïdes étant moins importants. Le pouvoir fécondant de ces éjaculats devrait donc être meilleur que celui des éjaculats obtenus de Taureaux récoltés peu fréquemment. En effet Almouist, Hale et Amann (I958) ont montré que la fertilité de 3 Taureaux récoltés 6 fois par semaine pendant 8 à I4 mois n'était en rien diminuée. Le pourcentage de Vaches fécondées après une insémination était respectivement de 70,74 et 77 p. 100, 6 mois après le début de l'expérience ; le nombre de Vaches inséminées étaient de $28 \mathrm{I}$ pour le I $^{\text {er Taureau, } 286}$ pour le $2^{\mathrm{e}}$ et 656 pour le $3^{\mathrm{e}}$.

Cette expérience confirme nos résultats mais va à l'encontre de l'opinion généralement admise selon laquelle des spermatozoïdes immatures, et donc moins fécondants, apparaissent dans le sperme à la suite d'éjaculations répétées (LLOYD-JonEs et HAyES, I9I8; LEWIS, I9II ; LAGERLOF, I936). Cette expérience montre de plus que les Centres d'Insémination Artificielle auraient peut-être intérêt à utiliser les Taureaux reproducteurs plus souvent qu'ils ne le font généralement.

\section{C. - RÉSORPTION DES SPERMATOZOIDES}

Nous avons également été amené à tevoir l'importance des phénomènes de résorption à l'intérieur du canal épididymaire du Taureau. D'après le 'Tableau I6 on constate que chez 3 animaux $\left(499,80 \mathrm{I}_{(2)}\right.$ et $\left.80 \mathrm{I}_{(3)}\right)$ donnant entre le $4 \mathrm{I}^{\mathrm{e}}$ et le $49^{\mathrm{e}}$ jour après l'injection un nombre total de spermatozoïdes de $\mathbf{I} 8 \times \mathrm{IO}^{9}, 5^{6} \times \mathrm{ro}^{9}$ et I $5 \times$ IO $^{9}$, les premiers spermatozoïdes marqués arrivent à la même date dans l'éjaculat. Il y a donc une résorption des spermatozoïdes, non seulement quand les animaux sont au repos sexuel, mais aussi quand ils sont récoltés fréquemment et donnent par collecte presque l'équivalent de la production spermatogénétique journalière estimée par Almourst et HALE (I956). La résorption des spermatozoïdes dans l'épididyme a été signalée depuis fort longtemps mais chez le Taureau elle semble prendre une très grande importance. Elle doit être très rapide, car dans le sperme éjaculé, on trouve rarement des spermatozoïdes nécrosés ou en voie de dégénérescence. On ne peut manquer de rapprocher ces phénomènes de résorption de ceux qui se produisent dans les voies génitales femelles (Austin, 1956) et spécialement chez la Truie (du Mesnil, du Buisson et Dauzier, I957) où, en l'espace d'une heure, 80 p. Ioo spermatozoïdes présents dans l'utérus sont résorbés. Cette résorption des spermatozoïdes est réalisée vraisemblablement par digestion enzymatique mais il reste évidemment à le prouver par isolement des enzymes responsables et des produits de dégradation. 
Cette résorption a lieu à un niveau bien déterminé du canal déférent puisque après ligature de celui-ci ORTAVANT (non publié) a observé en amont de la ligature une accumulation de spermatozoïdes non mobiles mais intacts et ceci 6 mois après la vasectomie. Par contre ORTAVANT (I953) a observé que la population de spermatozoïdes provenant des ampoules déférentielles présentait une très grande proportion de spermatozoïdes morts, colorables électivement par l'éosine. Ce fait correspond à l'hypothèse de SIMEONE et Young (I930) situant à ce niveau la dégénérescence des spermatozoïdes. Mais au cours de la même expérience OrTAVANT a mis en évidence qu'un nombre élevé de spermatozoïdes de la partie proximale du corps de l'épididyme présente également une grande perméalibité à l'éosine. GLOVER (I960) au cours d'expériences de cryptorchidie expérimentale a confirmé cette observation en montrant que les spermatozoïdes du corps de l'épididyme sont moins résistants et présentent un fort pourcentage de spermatozoïdes morts ou décapités. Or d'après ces auteurs le pourcentage de spermatozoïdes morts baisse brusquement dès la partie distale du corps de l'épididyme. Il n'est donc pas exclu que dans la partie proximale du corps de l'épididyme les spermatozoïdes meurent et disparaissent, leur disparition étant extrêmement rapide.

On peut donc penser que la résorption des spermatozoïdes est un phénomène important chez le 'Taureau et qu'elle a lieu en grande partie dans les ampoules déférentielles mais peut-être aussi dans certains lieux privilégiés du canal épididymaire.

En conclusion, si l'augmentation de la fréquence des collectes diminue l'âge moyen des spermatozoïdes d'un éjaculat en vidant la queue de l'épididyme de ses réserves, l'action dece facteur sera plus faible sur la phase critique de la maturation épididymaire qui semble se situer dans le corps de l'épididyme. On conçoit ainsi qu'il persiste toujours une faible proportion de spermatozoïdes morts dans un éjaculat.

\section{HÉSUMÉ ET CONCLUSION}

La vitesse de passage des spermatozoïdes dans l'épididyme du Taureau a été déterminée au moyen du marquage de 1'ADN des spermatozoïdes par le ${ }^{32} \mathrm{P}$.

Les spermatozoïdes à $\mathrm{ADN}$ marqué apparaissent le $4 \mathrm{I}^{\mathrm{e}}$ jour après l'injection dans la partie proximale de la tête de l'épididyme quelle que soit la fréquence de collectes à laquelle ils sont soumis. Ces mêmes spermatozoïdes apparaissent en moyenne le $52^{\mathrm{e}}$ jour après l'injection dans l'éjaculat chez des animaux faiblement collectés ( 2 à 3 éjaculats par semaine). Dans ces conditions le temps de passage des spermatozoïdes dans l'épididyme est donc de i I jours environ.

Chez des animaux soumis à des "tests d'épuisement " tous les deux jours, les spermatozoïdes à ADN marqué apparaissent en moyenne le $49^{\mathbf{e}}$ jour après 1 'injection de ${ }^{32} \mathrm{P}$ dans l'éjaculat. Dans ce cas la durée de passage des spermatozoïdes dans l'épididyme est environ de 8 jours.

Selon la fréquence des collectes il est donc possible de faire varier de 3 jour le temps de passage des spermatozoïdes dans l'épididyme. Mais en fait ce temps de passage ainsi déterminé ne concerne que les spermatozoïdes qui parcourent le canal épididymaire le plus rapidement. Une étude portant sur l'ensemble des spermatozoïdes marqués montre que les variations de fréquence de collectes influent beaucoup 
plus sur le passage de l'ensemble des spermatozoïdes dans l'épididyme. La durée de ce passage peut varier en effet de 7,5 jours. Ceci est confirmé par les variations d'activité du plasma séminal en fonction des collectes.

En cas de collectes peu fréquentes il se produit dans l'épididyme un mélange de spermatozoïdes d'âge différent et l'éjaculat obtenu forme une population hétérogène. Il n'est donc possible de déterminer qu'une durée de transit moyenne, tous les spermatozoïdes n'avançant pas à la même vitesse dans l'épididyme.

Ces conclusions présentent une grande importance pour 1'utilisation des Taureaux dans les Centres d'Insémination Artificielle puisque 1'homogénéité des éjaculats dépend de la fréquence des collectes. Par ailleurs nos résultats montrent l'importance de la résorption des spermatozoïdes dans l'appareil génital de Taureau, l'intensité de celle-ci dépendant, elle aussi, de la fréquence des collectes.

Thèse soutenue le 16 décembre 1961

\title{
REMERCIEMENTS
}

Je tiens à remercier R. ORTAVAnT qui nous a suggéré ce sujet de recherches et qui tout au long de sa réalisation nous a formée aux méthodes expérimentales et nous a fait bénéficier de son expérience.

Ce travail n'a été possible que grâce au CNRS qui nous a acceptée comme stagiaire puis comme Attachée de recherches et grâce à l'INRA qui a mis à notre disposition les moyens très importants qui étaient indispensables.

\author{
SUMMARY \\ EXPERIMENTAL RESEARCH ON THE SPEED OF PASSAGE OF SPERMATOZOA \\ TIIROCGH TIE EPIDIDYMIS OF THE BULL
}

After leaving the testis spermatozoa undergo a process of physiological maturation in the epi. didymis where power of fecundation and motility is achieved.

In this study, we attempted to determine $: I$ ) the length of time that spermatozoa remain in the epididymis of the bull and 2) the variations of this time of transit according to the frequency of collection, with the use of isotopically labelled cells.

I. - In order to determine the speed of passage of spermatozoa in the epididymis, Io bulls were castrated at various times after the injection of ${ }^{32} \mathrm{P}$ and it was observed that, up to the 4oth day after the injection, no spermatozoa with labelled DNA are found in the epididymis. Labelled sperm begin to appear $4 \mathrm{I}$ days after the injection in the head of the epididymis (fig. 9).

In order to detect their arrival in the tail of the epididymis, the variations of the radioactivity of the spermatozoa in the ejaculate were simply followed, since these come from the ampulla of the vas deferens and from the distal part of the tail of the epididymis. It was observed that, in animals collected normally, 2 or 3 times per week, the spermatozoa with labelled DNA appear between the 49 th and the $55^{\text {th }}$ day after injection, with average time of detection on the 52 nd day (fig. I 3 , graph B).

It was concluded from this observation that spermatozoa take on the average I I days to pass through the epididymis, in animals lightly collected.

II. - Attempts were then made to find if it was possible to cause the length of time of the epididymal transit to vary, by changing the frequency of semen collection.

It was noted that, on the 4oth day after injection, there are no labelled spermatozoa in the head of the epididymis, whether the animals were frequently collected or not (table I5). On the other hand, on the 4Ist day after injection, labelled spermatozoa were consistently found. 'Therefore, the 
frequency of collection has no influence on the time of appearance of radioactive spermatozoa in the head of the epididymis. As a consequence, any change in the time of appearance of these spermatozoa in the ejaculate will come from a variation in the duration of the epididymal transit.

Experiments were then designed to determine if the appearance of the spermatozoa with labelled DNA in the ejaculate would be influenced by keeping the animals in sexual rest or by collecting ejaculate 2 or 3 times per week or by submitting the animals to exhaustive collections.

Two animals, in sexual rest since the day of the ${ }^{32} \mathrm{P}$ injection, were submitted to exhaustive collection on the 49 th day and on the 5 and day respectively. The specific radioactivity of the DNA, weak in the first ejaculates, increased continually up to the final ejaculates, indicating thereby that the spermatozoa with labelled DNA had already arrived in the tail of the epididymis on these two dates.

In animals collected every 2 or 3 days and giving, in the period between the 4Ist day after injection and the date of appearance of the first labelled spermatozoa, an average of 1.3 to $4.3 \times 10^{8}$ spermatozoa per day, the first spermatozoa with labelled DNA arrived the 52nd day after the injection in 7 out of 12 bulls.

It seemed then that the frequency of collection had no influence on the duration of passage of the spermatozoa in the epididymis.

If the average number of spermatozoa collected per day were increased up to values of 1.4 to I4.4 $\times 10^{9}$, it was possible to accelerate the passage of the radioactive spermatozoa through the epididymis. This occurred, on the average, at the 49 th day.

It may then be concluded that, if the average number of spermatozoa collected per day does not exceed $5 \times 10^{9}$, the differences in the frequency of collection has no influence on the speed of passage in the epididymis of the first radioactive spermatozoa which appear in the ejaculate. Its speed is about I I days; but when this limit is exceeded the duration of transit may be shortened by an average of 3 days. The frequency of collection has therefore an influence, weak, but certain, on the duration of epididymal transit.

The time of passage thus determined concerns only the spermatozoa which travel along the epididymal canal the most rapidly (that is, the first radioactive spermatozoa appearing in the ejaculate). A study bearing on the totality of the labeled spermatozoa which is represented by the maximum of the curve of specific activity of the DNA shows that the variations of frequency of collection has much more influence on the passage of the totality of the spermatozoa in the epididymis. The duration of the passage can vary, indeed, as much as 7.5 days (fig. I3). This is confirmed by the variations of activity of the seminal plasma, according to the frequency of collection (fig. I6).

III. - From all these preceeding results, the following conclusions can be made :

$I^{\circ}$ In the case of infrequent collection, a mixture of spermatozoa of differing ages takes place in the epididymis and an ejaculate forms, from the point of view of age and degree of maturity of the spermatozoa, a heterogeneous population.

$2^{\circ}$ Only an average duration of transit can be determined, since all the spermatozoa do not advance at the same speed in the epididymis.

$3^{\circ}$ The examination of table I4 shows that there is no difference in the date of appearance of radioactive spermatozoa in 3 bulls $\left(707-80 \mathrm{I}_{2}-80 \mathrm{I}_{3}\right)$ giving between the $4 \mathrm{Ist}$ and the 49 th day after injection a total number of spermatozoa of $16 \times 10^{\circ}, 61 \times 10^{9}, 115 \times 10^{9}$; in these three cases, the first labelled spermatozoa arrive at the same date in the ejaculate. Then there is a resorption of spermatozoa not only when animals are at the sexual rest but also when they are collected frequently. The resorption of spermatozoa in the genital apparatus of the bull seems extremely great and its intensity depends on the frequency of collection.

\section{RÉFÉRENCES BIBLIOGRAPHIQUES}

AIgNer A., I900. Uber das Epithel im Nebenhoder einiger Säugethiere und seine secretorische Thätigkeit. S. B. Akad. Wiss. Wien. Abt III, 109, 555-582.

ALleN R. J. L., I940. The estimation of Phosphorus. Biochem. J., 34, 858-865.

Allen J. M. et Slater J., 1957. A chemical and histochemical study of alkaline phosphatase and aliesterase in the epididymis of normal and castrate mice. Anat. Rec., 129, 255-273.

Allen J. M. et Slater J., 1958. A chemical and histochemical study of acid phosphatase in the epididymis of normal, castrate and hormone replaced castrate mice. Anat. Rec, 130, 73I-7+45.

Allen J. M. et SLATER J. J., I96r $a$. A cytochemical analysis of the lactic dehydrogenase-diphosphopyridine-nucleotide-diaphorase system in the epididymis of the mouse. J. Histochem. Cytochem., 9, $22 \mathrm{I}-233$.

Allen J. M., et Slater J. J., Ig6r $b$. A cytochemical study of Golgi associated thiamine pyrophosphatase in the epididymis of the mouse. J. Mistochem. Cytochem., 9, 418-423. 
Almovist J. O. et Hale L. B., 1956. An approach to the measurement of sexual behaviour and semen production of dairy bulls. Proc. IIIrd Int. Congr. Anim. Reprod., Cambridge.

Almouist J. O., Amann R. P. et O'denn W. 'T., 1958. Sperm reserves of dairy bulls as determined by depletion trials and post-slaughter sperm counts. J. Dairy Sci, 41, 733 (Abstract).

Almouist J. O., Hale E. B. et Amann R. P., I960. Sperm production at High collection frequencie with vary degrees of sexual preparation. J. Dairy Sci., 41, 733 (Abstract).

Amantea G. et Kryszkowsky K. N., Igzi. Ricerche fisiologiche sugli spermatozoi. Riv. Biol., 3, 569

ANdERson J., I945. The semen of animals and its use for artificial insemination. Imperial Bureau of Animal (ienetics. I Vol., I5 I pp., Edinburgh.

Austin C. R., 1957. Fate of spermatozoa in the uterus of the mouse and rat. J. Endocrin., 14, 335-342.

Bendicir A., Russell P. J. et Browx G. B., I953. On the heterogeneity of the deoxyribonucleic acids. J. Biol. Chem., 203, 305-3 I8.

Benctsson 1.. P., 1949. Spermaresorption Hos kaniner Ett preliminart meddelande. Kgl. Fysiogr. Sallsk. Lund Forhilg, $\mathbf{1 0}, \mathrm{I}-3$.

BENoIT J., I 925. Recherches anatomiques cytologiques et histophysiologiques sur les voies excrétrices du testicule chez les Mammifères. Thèse de Doctorat Strasbourg, 1-232.

BERRY R. E. et MAYER D. T., 1959. The isolation of some cullular constituents of bovine spermatozo.. Exp. cell. Res., 18, $398-401$.

Bisiop D. W. et Weinstock I., i948. Uptake of radioactive phosphorus by Bull spermatozoa. Anal. Rec., 101, 8r.

Bisirop D. W., I952. The metabolic machinery of sperm activity. Dans "Studies on testis and ovary, egg and sperm". E. T. Engle, 95, 122.

Blandat R. J. et Rumery R. E., ig6r. Fertilizing capacity of rat spermatozoa recovered from various segments of the epididymis. Anat. Rec., 139, 209 (Âstract).

Bonadonna T., I948. Nosioni di tecnica della fecondasione arificiale degli animali. Istituto Editor Cisalpino. Milano, 31 5-333.

Borenfreund E., FitT E. et Bendicir A., r96. Isolation and properties of Deoxyribonucleic acid from mammalian sperm. Nature London, 191, I 375-1 377 .

Brues A. M., Tracy M. M. et ConN W. E., I 944. Nucleic acids of rat liver and hepatoma: their metabolic turnover in relation to growth. J. Biol. Chem., 155, i6g-63.

Caspersson 'T., $1940 a$. Dic eiweiss Verteilungr in der Strukturen des Zeelkerus. Chromosoma, 1, 562-604.

Caspersson 'T., 1940 b. Nükleinsaüreketten und Genvermehrung. Chromosoma, 1, 605-619.

Cavazos L. F., I954. Iistochemical reactions in vertebrate testes. Thèse Iowa State College.

Clermont Y., Leblond C. P. et Meissier B., I959. Durée du cycle de l'épithélium séminal du rat. Arch Anat. micr. Morph. exp., $\mathbf{5 8}$ bis, $37-55$.

Clubs R. W., I95I. A study of the epididymal transport of India ink and related epithelial reactions. Thèse Deparlment anat., Uniw. Rochester, New York.

Covrrier R., 1920. Sur l'existence d'une sécrétion épididymaire chez la Chauve-Souris hibernante et sa signification. C. R. Soc. Biol. Paris, 83, 67-69.

Cox C. P'. et Melrose D. R., I953. The calibration of a photoelective absorptiometer for the rapid estimation of counts of spermatozoa in bull semen. J. agric. Sci., 43, 375-379.

Cross B. A., 1959. In Lloyd C. W. Recent progress in the Endocrinology of Reproduction, I67-177. Academic Press New York and London.

Dallam R. D. et Thomas I. E., 1953. Chemical studies on Mammalian sperm. Biochem. biophys. Acta., 11, $79-89$.

Dauzier L., Mesnil du Buisson F. (du), Gros D., Ortavant R., et Thibault C., i952. Utilisation d'une pâte soluble à l'eau froide ("Marsolub ") pour la lubrification des vagins artificiels et des speculums. Elevage et insémination, 11, I2-I3.

Dalzier L., Thibault C. et Wintenberger S., 1954. Conservation du sperme de Bélier après dilution et maintien de son pouvoir fécondant. Ann. Endocrin., 14, 341-350.

Davidson J. N. et Lestre I., i95o. Nucleic acids in relation to tissue growth : a Rewiew. Canc. Res., 10, $587-594$.

Davidson J. N., Frazer S. G. et Hutchison W. C., I95I. Phosphorus compounds in the cell. I Protein bound phosphorus fractions studied with the aid of radioactive phosphorus. Biochem J., 49, 3II-322.

DAvidsoN J. N. et SMellie R. M. S., 1952. Phosphorus compounds in the cell. 3 The incorporation of radioactive phosphorus into the ribonucleotide fraction of liver tissue. Biochem. J.52, 599-605.

Dawson R. M. C., ManN T. et White I. G., 1957. Glycerylphosphorylcholine and Phosphorylcholine in semen and their relation to Choline. Biochem. J., 65, 627-634.

Dawson R. M. C., I958a. The labelling of Ram semen in vivo with radioactive phosphate and (Carboxy $\mathrm{C}^{14}$ ) Stearic Acid. Biochem. J., 68, 512-519.

Dawson R. M. C., I958 b. Labelling of Bull semen with Phosphorus in vivo. Nature,London,181, Ior4-Ior 5.

DE Groot B., I96r. Agreing of Bull sperms at the end of the passage through the epididymis. J. Reprod. Fertil., 2, 107-1 16 . 
Diament M., Kainane L., et Levy J., 1952. Sur les esters hydrosolubles de la choline. La glycérylphosphoryl-choline. C. R. Acal. Sci, 235, 1058-1060.

Doniaci I. et Peic S. R., 1950. Autoradiograph technique. Brit. J. Radiol, 23, I84-I92.

Drasher M. L., I953. A criticism of the indiscriminate use of the Schmidt-Thannhauser method for the fractionation of nucleic acids in biological material. Science, 118, I8I-182.

Ernster L., ZetTerstrom R. et Lindierg O., 1950. A Method for the Determination of Tracer Phosphate in Biological Material Acta chem. scand., 4, 942-947.

lixner F., r9o4. Handbuch der Urologie. Wien, cité par Grant. Proc. Soc. Stud. Fertil., 10, 95-Ior.

FARRAGI HI., r952. Détection des éléments radioactifs par la technique photographique Autoradiographie. Comm. En. Alom. France, 27-33.

Findray J.et Levvy G. A., I960. Purification of B-N-Acetyl-glucosaminidase from the Pig Epididymis. Biochem. J., 7\%, $170-175$.

Foote R. H. et Koefed-Jonnsex I. H., 1959. The use of Adenine $8{ }^{14} \mathrm{C}$ for studying spermatogenesis in the rabbit. J. Anim. Sci., 18, 1553 .

Glover T. D., I960. Spermatozoa from the isolated cauda epididymis of rabbits and some effects ofartificial cryptorchidism. J. Reprod. Fertil., 1, 121-129.

Glucksmann A., Howari A. et Petc S. R., 1955. Incorporation of $\mathrm{S}^{35}$-DL-Mlethioline in mouse tissues as indicated by autoradiographs. J. Anal., London, $\mathbf{8 9}, 13^{-18 .}$

GRANT J. H., I958. The passage of Trypan blue through the epididymis and its uptake by this organ Pro, Soc. Stud. Fertil., 10, 95-ror.

Greex W. W., I940. The Chemistry and Cytology of the Sperm Membrane of Sheep. Anat. Rec., 76, $455^{-} 47 \mathrm{I}$.

GunN R. M. C., 1936. Fertility in Sheep : artificial production of seminal ejaculation and the characters of the spermatozoa contained therein. Bull. Counc. Sci. Indus, Res. Aust., no 94, I-I 16.

Habers E. et Netmani K., 1954. Grundlaggen der autoradiographischen Dorstellung der Nukleinsäuren in Gewebschnitten mit Ililfe von Radiophosphor. Ztschr. f. Naturforsch., 9, i 75-180.

IIAmmar J. A., 1897. Über secretionserscheinungen im Nebenhoden des IIundes. Arch. Anat. Physial. $L p z$, Suppl.. $1-42$.

HAMmond J. et ASDELL S. A., 1926. The vitality of the spermatozoa in the male and female reproductive tracts. Brit. J.exp. Biol., 4, 155-185.

Harcenco N., I939. Cercetari anatomica asupra cailor spermatica la Taur. Diss. Bucarest I930 cité par Ghetie V., Anat. Anz., 87, 369-374.

Heath H., Rimington C., Glover T., Mani T. et Leone E., i953. Studies using radioactive sulphur on ergothioneine formation in the pig. Biochem. J., 54, 606-6r I.

Henry A., igoo. Étude histologique de la fonction sécrétoire de l'épididyme chez les Vertébrés supérieurs. Arch. Anat. micr., 3, 229-292.

HokIN L. F., et IIOKIN M. R. I953. The incorporation of ${ }^{32} \mathrm{P}$ into the nucleotides of RNA in Pigeon pancreas slices. Biochem. biophys. Acta, 11, $59 \mathrm{I}-592$.

Howard A. et PELC J. R., I950. 32P Autoradiographs of Mouse testis. Preliminary observations of the timing of spermatogenic stages. Brit. J. Radiol., 23, $634-6+1$.

Hutchison W. C., Crosbie G. W., Mendes C. B., Mcindoe W. M., Childs M. et Davidson J. N., 1956. Protein-bound compounds of phosphorus and inositol. Biochem. biophys. Acta, 21, 44-57.

Johnson H. A. et Cronkite F. P., i959. The effect of Tritiated Thymidine on Mouse spermatogonia. Radialion Res., 11, 825-831.

Kaplan W. D. et Stsken J. E., 1960. Genetic and autoradiographic studies of Tritiated Thymidine in Testis of Drosophila melanogaster. Experientia, 16, 67-73.

KENNELLY J. J., I960. Spermatogenesis in boars. I. The testicular end epididymal spermatozoan reserves. II. Estimated potential daily production of spermatozoa. Thèse Cornell University.

Kirillov V.S. et Morozoy V.A., 1936. Durée de conservation de la vitalité des spermatozoïdes de Taureau dans les épididymes isolés du testicule (russe). Usp. zootekh, Nauk., 2, 19-22.

Kurne D. L. et Cimton E. E., ig. Lifespan of leucocytes in man. J. appl. Physiol., 5, 79-88.

Koefen-Johnsen H. H., I958. Investigations on sperm formation. Roy. Vet. Agric. Coll. Steril. Res. Inst, Ann. Rep., I8-33.

KoEFED-Johnsen H.H., I959. Influence of lijaculation Firequency on the time required for Sperm Formation and epididymal l'assage on the Bull. Nature, London, 185, 49-50.

Kyrle J. et Schopper K. I., I915. Über Regenerationsvorgänge im tierischem Nebenhoden. Wirchows Arch., 22, I-I9.

LAgerlof X., I936. Sterility in Bulls. Vet. Rec., 48, I I 59 .

LEBLOND C. P., 1950. Distribution of periodic acid-reactive carbohydrates in the adult rat. Amer. J. Anat. 86, $1-49$.

LEWIS L. L., I911. The vitality of reproductive cells. Bull. Okla. agric. Exp. Sta., 96, 3 .

Lilienield L., I894. Zur Chemie der Leucocyten. Hoppe-Seyl. Z., 18, 473.

Lison L. et PASTeELS J., ı949: Sur l'évolution quantitative de l'acide thymonucléique pendant la spermatogenese chez Talpa. C. R. Soc. Biol., 143, 1607-1608. 
Lloyd-Jones O. et HAYES F. A., 1918. The influence of excessif sexual activity of male rabbits. J.exp. Zool., 45, 463-497.

LODE A., 1891. Untersuchungen über die Zahlen und Regenerations verhlätnisse der Spermatozoiden bei Hund Mensch. Pflüg. Arch. ges. Physiol., 50, 278-292.

Lorentz F. W., Cavoulas M. et Carson J. D., i95o. Deposition of ${ }^{32} \mathrm{P}$ in Cock spermatozoa. Poult. Sci., 29, 769 (abstract).

Lundin M., 1958. Anterior pituitary gland and Lymphoid tissue growth. Acta endocr., Copenhagen, supl. 40.

McIndoe W. M. et Davidson J. N., 1952. The phosphorus compounds of the cell nucleus. Brit. J. Cancer., 6, 200-2I4.

MACMILLAN E. W. et IIARRISON R. G., i 955. The rate of passage of radioopaque medium along the ductus epididymis of the rat. Proc. Soc. Stud. Fertil., 7, $35^{\circ} 40$.

Macmillan E. W., I958. The mecanical influence of the vasa efferentia on the transport of radioopaque medium through the ductus epididymidis ot the rat. Proc. Soc. Stud. Ferit., 9, 67-7r.

Macmillan I.. W. et AukLAND J., i 960 . The transport of radioopaque medium through the initial segment of the rat epididymis. J. Reprod. Fertil., 1, I39-145.

Maneely R. B., 1959. Epididymal structure and function : a historical and critical review. Acta zool., Stockh., 40, I-21.

Mann T., 1954. The biochemistry of semen Methuen's monographs on biochemical subjects. Methuen London, I vol., $240 \mathrm{pP}$.

Mantegazza P., I866. Sullo sperma umano. cité par Manneely R. E., Acta zool., Stockh., 40, i-zi.

Manzina 1958. Accumulation du ${ }^{32}$ ' dans le sperme de Coq. Trud. Pushkiu. Nautsh. issled. Lab. Razved. Selchoz. Zhivoln, 8, 269-274.

Marko A. M. et BUTLER G. C., I95I. The isolation of sodium deoxyribonucleate with sodium dodecyl sulfate. J. biol. Chem., 190, $3,165-175$.

Martin P. et Scirauder W., I938. Lehrbuch der Anatomie des Haustizre. Stuttgart. Cité par Blom E., Cirristensen N. O. Skaud. Vert. Ticskz. 37, 1-49.

Mason K. E. et Shaver S. L., I952. Some functions of the caput epididymis. Ann. N. Y. Acad. Sci., 55, $585-593$.

Mauritzen C. M., Roy A. B. et Stedyan F., I952. The ribosenucleic acid content of isolated cell nuclei. Proc. roy'. Soc. B, 140, $18-3$ t.

Mesnil du Buisson F. (du) et Dauzier L., I955. Distribution et résorption du sperme dans le tractus génital de la truie : survie des spermatozoïdes. Ann. Endocr, Paris, 16, 4r 3-422.

Mictkiewski C., 1948. Sur les changements saisonniers dans l'épididyme de la taupe. Bull. Histol. Tech. micr., 25, 49-68.

Mirsky A. E. et Polisster A. W., ig42. Nucleoproteins of cell nuclei. Proc. Nat. Acad. S6., 28, 344-352.

Moore C. R., 1927. A qualitative indicator for the testis hormone. Proc. Soc. exp. Biol. N. Y., 24, $847-848$.

Moore C. R., I928. Sperm activity and testis hormone. J. exp. Zool., 50, 455.

Morgenstern S., I924. Zur Frage der Spermiophagie. Virchows Arch., 250, 648-66o.

MYers-WARD C. F., I998. Preliminary note on the structure and function of the epididymis and vas deferens in the higher mammalia. J. Anat., Lond., 32, $135^{-1} 40$.

Nassonov D., 1927. Die Tätigkeit des Golgi apparats in den Epithelzellen des Epididymis. Z. Zelltorsch.,

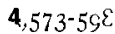

NemilofF A., 1926. Histo-physiologische Untersuchungen über den Nebenhoden. Z. ges. Anat., I, 79, I-43.

NicANDER I., 1957. On the regional histology and cytochemistry of the ductus epididymis in rabbit. Acta morphol. Neerlando-Scandin., 1, 99-1 18.

NiCANDER L., I958. Studies on the regional histology and cytochemistry of the ductus epididymis in stallions, rams and bulls. Acta morph. Neerlando-Scandin., 1, 337-362.

Novik I. E., 1956. Accumulation de ${ }^{32} \mathrm{P}$ dans le sperme de coq. C. R. Acad. Sci. U. R. S. S., 107, 597-599.

NovoseljeceV D. V., I95I. The quantity of spermatozoa in the boar's epididymides and principles governing it. (Russe). Sovet. Zootekh., 6, 76-83 in Anim. Breed. Abstr., $20{ }_{5} 8$.

OAKBerg E. F., I957. Gamma-ray sensitivity of spermatogonia of the mouse. J. exp. Zool. 134, 343-356.

OGur M. et Rosen G., 1950. The nucleic acids of plant tissues I. The extraction and estimation of desoxypentose nucleic acid and pentose nucleic acid. Arch. Biochem., 25, 262-276.

Orgerin M. C., I96r. Étude du transit épididymaire des spermatozoïdes de Taureau marqués à l'aide du 32P. Ann. Biol. anim. Bioch. Biophys., 1, 11 7-120.

Ortavant R., i953. Existence d'une phase critique dans la maturation épididymaire des spermatozoïdes de Bélier et de Taureau. C. R. Soc. Biol. Paris., 147, I552-1 555 .

Ortavant R., $1954 \mathrm{a}$. Contribution à l'étude de la durée du processus spermatogénétique du Bélier à l'aide du ${ }^{32}$ P. C. R. Soc. Biol. Paris., 148, 804.

ORtavant R., I954 $b$. Détermination de la vitesse de transfert des spermatozoïdes dans l'épididyme de Bélier à l'aide de ${ }^{32} \mathrm{p}$. C. R. Soc. Biol., 148, 866. 
Ortavant R., I956 a. Autoradiographie des cellules germinales du testicule de Bélier. Durée des phénomènes spermatogénétiques. Arch. Anat. micr. Morph. exp., 45, г-10.

Ortavant R., 1956 b. Etude sur la spermatogenèse des animaux domestiques à l'aide du phosphore-32. Cont. Int. util. pacifique énergie. atom., 12, 243-245.

Ortavant R., 1956 c. Données non publiées.

Ortavant R., 1958. Le cycle spermatogénétique chez le Bélier. Thèse Faculté des Sciences, Université de Paris.

Ottesen J., 1954. On the age of human white cells in peripheral blood. Acta physiol. scand., 32, 75-93.

Pelc S. R. et Howard A., I956. A difference between spermatogonia and somatic tissues of mice in the incorporation of $\left(8-{ }^{14} \mathrm{C}\right)$ adénine into deoxyribonucleic acid. Exp. Cell. Res., 11, I28-1 34 .

Phillips R. W., te Mc Kenzie, 1934. The thermoregulatory function and mechanism of the scrotum. Res. Bull. Mo. agric. Exp. Sta., 217.

PlaUt W. J., i954. DNA synthesis in the microsporocytes of Lilium IIenryi. Heredilas, Lund, 39, 438-444. Pollister A. W. et Mirsky A. E., 1946. The nucleoprotamine of trout sperm. J. gen. Physiol., 30, Ior.

Polovceva V. V., 1938. Vitesse de passage et temps de maturation des spermatozoïdes dans l'épididyme du Bélier. Dolk. Akad. Seljskokoz. Nauk., 15-16, 43-52.

Potter V. R. et libvejerm C. A., 1936. A modified method for the studie of tissue oxidations. J. Biol. Chem., 114, 495-504.

Redenz L., 1924. Versuch einer biologischen Morphologie des Nebenhodens. Arch.mikr. Anat.,103,593-628.

Regaud C., igor. Note sur les cellules glandulaires de l'épididyme du Rat. C. R. Soc. Biol., 53,6r6-6r8.

ReID B. L. et Cleland I. W., I 957. The structure and function of the epididymis. I. The histology of the rat epididymis. Aust. J. Zool., 5, 223-246.

REID B. I.., I959. The structure and function of the epididymis. II. The histogenesis of the rat epididymis. Aust. J. Zool., $\mathrm{r}, 22-38$.

Ristey P. L., 1958. The contractile behavior in vivo of the ductus epididymis and vasa efferentia of the rat. Anat. Rec. 130, 47I.

Rothschild Lord., I950. Counting spermatozoa. J. exp. Biol., 26, 388-390.

Russ C., 1950. Effects of Phosphorus-32 on the IHamster. Proc. Soc. exp. Biol. N. Y., 74, 729-731.

Salisbury G. W., De la Torre L., Birge W. J. et Loige J. R., i 960 . Effect of $5^{\circ} \mathrm{C}$ storage in yolkcitrate on feulgen positive material (DNA) of sperm heads. J. Dairy Sci., 43, 882.

Schaffer J., 1892. Über Drüsen im Epithel der Vasa efferentia Testis beim Menschen. Anat. Anz., 7, 7 II-7I8.

Schumt G. et Tilannhauser S. J., I945. A method for the determination of deoxyribonucleic acid, ribonucleic acid and phosphoproteins in animal tissues. J. biol. Chem., 161, 83-89.

Schineider W. C., r945. Phosphorus compounds in animal tissues. I. Extraction and estimation of deoxypentose nucleic acid and of pentose nucleic acid. J. biol. Chem., 161, 293-303.

Schneider W. C., I946. Phosphorus compounds in animal tissues. III. A comparison of methods for the estimation of nucleic acids. J. biol. Chem., 164, 747-75I.

Scirrader F. et Leuchtenberger C., 1950. A cytochemical analysis of the functional interrelations of various cell structures in Arvelius Albopunctatus (De Geer). Exp. Cell. Res., 1, 42I-45I.

SHAVER S. L., I $953 a$. X-irradiation injury and repair in the greminal epithelium of male rats. I. Injury and repair in adult rat. Amer. J. Anat., 92, $391-43^{2}$.

SHAVER S. L., I953 $b$. X-irradiation injury and repair in the germinal epithelium of male rats. II. Injury and repair in immature rats. Amer. J. Anat., 92, 433-450.

Shemin D. et Rittenberg D., i946. The life span of the human red blood cell. J. biol. Chem., 166,627-635.

Simeone F. A. et Young W. C., I9zo. A study of the function of the epididymis. IV. The fate of non ejaculated spermatozoa in the genital tract of the male guinea-pig. J.exp. Biol., 8, 16 $3^{-1} 75$.

Singi G., 1962. Durée de passage dans l'épididyme des spermatozoïdes de Verrat marqué au ${ }^{32} \mathrm{P}$. Ann. Biol. anim. Bioch. Biophys. (sous presse).

SingII G., 1962. Réserves spermatiques épididymaires chez le Verrat. Ann. Biol. anim. Bioch. Biophys. (sous presse).

Sirlin J. L. et EDwards R. G., 1955. The labelling of mouse sperm by adenine $8^{-14} \mathrm{C}$. Exp. Cell. Res. 9, 596-599.

SiRLIN J. L. et EDwards R. G., I958 $a$. The labelling of mammalian spermatozoa with radioactive tracers. J. exp. Zool., 137, 363-388.

SiRLiN J. L., I $95^{8}$ b. 'The labelling of mouse spermatozoa by adenine $8^{-14} \mathrm{C}$ and thymidine- ${ }^{3} \mathrm{H}$, Exp. Cell. Res., 15, $250-253$.

Stefano H. (Di) et Mazia D., I953. The role of the midpiece in the incorporation of ${ }^{32} \mathrm{P}$ into the ribonucleic acid of Arbacia Spermatozoa. Biol. Bull., 103, 299-300.

Stigler R., r9r8. Der Einfluss des Nebenhodens auf die Vitalität der Spermatozoen. Pflüg. Arch. ges. Physiol., 171, 273-282.

Sulkin N. M., I95I. Histochemical localization of ribonucleoproteins by alkaline hydrolysis. Proc. Soc. exp. Biol. N. Y., 78, 32-34. 
Summeritll W. R. et Olds D., r96r. Levels of deoxyribonucleic acid in bovine spermatozoa and their relationship to fertility. J. Dairy Sci., 44, 548-551.

Swick R. W., KoCh A. L. et HANidA D.'T., 1956. The Measurement of Nucleic acid Turnover in Rat Liver. Arch. Biochem. Biophys., 63, 226-242.

Swift II. H., I950. The desoxyribose nucleic acid content of animal nuclei. Physiol. Zool., 23, i69-198.

TAYLOR J. H., I953. Autoradiographic detection of incorporation of ${ }^{32} \mathrm{P}$ into chromosones during meiosis. and mitosis. Exp. Cell. Res., 4, 164-173.

Terril C. E., 1949. The artificial insemination of farm animals. Sheep and Goats. Enos J. Perry Editor. Rütgers University Press., I37-I59.

Toothill M. C. et Young W. C., I93I. The time consumed by spermatozoa in passing through the epididymis of the guinea-pig determined by india ink injections. Anal. Rec., 50, 95-107.

Tovrnade $\Lambda .$, 1913. Différence de motilité des spermatozoïdes prélevés dans les divers segments de l'épididyme. C. R. Soc. Biol., 74, 738-739.

VAN Der Stricit O., I893. La signification des cellules épithéliales de l'épididyme de Lacerta vivipara. C. R. Soc. Biol, , 5, 799 .

VAN WAGENEN $(\mathrm{i}, \mathrm{I})^{24} a$. Degeneration of germinal epithelium in the testis of the rat as a result of efferent duct ligation. Anat. Rec., 27, 189-Igo.

Van Wagenen G., $1924 b$. Changes in the testis of the rat following ligation of the ductuli efferenti. Anat. Rec., 29, 399 .

Von Ebner V., i888. Zur Spermatogenese bei den Sä̈gethieren. Arch. mikr. Anat., 31, 236-292.

Von LANZ T., I926. Über Bau und Funktion des Nebenhodens und geine Abhängigkeit von der Keimdrüse. Z. ges. Anat., I, 80, I 77-282.

Von Lan\% T., r924. Deobachtungen und Versuche am Neben hoden der Hausmaus. Z. Anat., 74, 76I-815.

Von Möllendorf W., ig20. Vitale Färbungen an tierischen Zellen. Ergebn. Physiol., 18, 141-306.

WAGenseil F., 1928, Experimentaluntersuchungen am Nebenhoden der Maus. Z. Zellforsch., 7, I41-176.

Wales R. G. et White I G., 1959. The susceptibility of spermatozoa to temperature shock. J. Endocrin., 19, 2 I I-220.

Warren S., Macmilian J. C., et Dixon F. J., i950. Effects of internal irradiation of mice with ${ }^{32} P$. II Gonads, Kidneys, adrenal glands digestive tract, spinal cord, lungs, liver. Radiology, 55, 557-570.

Wegelin C., r92I. Über Spermiophagie im menschlichen Nebenhoden. Beitr. path. Anat., 69, $281-293$.

Wilkins M. H. F. et Randale J. T., i 953 . Crystallinity in sperm heads : molecular structure of nucleoprotein in vivo. Biochem. Biophys. Acta., 10, 192.

Willet E. I. et IJUCKNER J. J., 195I. The determination of number of spermatozoa in bull scmen by measurement of light transmission. J. Anim. Sci., 10, 2 19-225.

WiLleTt E. L. et OHMS J. I., 1958. Influence of seminal plasma and maturity of bovine spermatozoa upon their freezability. J. Dairy Sci., 41, 90-95.

Young W. C., I927. The influence of high temperature on the guinea pig testis : histological changes and effects on reproduction. J.Exp. Zool., 49, 459-499.

Young W. C., I929 a. A study of the function of the epididymis I. Is the attainment of full spermatozoon maturity attribuable to some specific action of the epididymal secretion. $J$. Morph., 47, 479-495.

Young W. C., Ig29 b. A study of the function of the epididymis II. The importance of an aging process in sperm fot the length of the period during fertilizing capacity is retained by sperm isolated in the epididymis of the guinea pig. J. Morph., 48, 475 .

Young W. C., I93o. A study of the function of the epididymis. III. Functional changes undergone by spermatozoa during their passage through the epididymis and vas deferens in the guinea pig. J.exp. Biol., 8, I 5 I-I 63.

Young W. C., 1933. Die resorption in den Ductuli efferentes der Maus und ihre Bedeutung für das Problem der Unterbindung in Hoden-Nebenhoden system. Z. Kellforsch., 17, 729-759.

ZAJDELA F., 1952. Une nouvelle technique autohistoradiographique. J. Radiol. Electrol., 33, 549-551.

Zamenhof S., Shettles L. B. et Chargaff E., i95o. IIuman desoxypentose nucleic acid. Isolation of Desoxypentose Nucleic acid from human sperm. Nature, London, 165, 756.

ZixTle C. A. et O'Deli, R. A., I94I. Chemical studies of I3ull spermatozoa. Lipid, Sulfur, Cystine, Nitrogen, Phosphorus and Nucleid acid content of whole spermatozoa and of the parts obtained by physical means. J. Biol. Chem., 140, 899-957.

Le Direuteur-Gérant : M.-L. CAGNAC.

Imprimerie Bussıère à Saint-Amand (Cher), France. - 12-9-1962. Dépôt légal : $3^{\mathrm{e}}$ trimestre 1962. $\quad N^{\circ} d^{\prime}$ impression : 764 . 